\title{
A Revised Pseudo-Second Order Kinetic Model for Adsorption, Sensitive to Changes in Sorbate and Sorbent Concentrations
}

\author{
JAY BULLEN, Sarawud Saleesongsom, Dominik Weiss
}

Submitted date: 19/03/2020 - Posted date: 20/03/2020

Licence: CC BY-NC-ND 4.0

Citation information: BULLEN, JAY; Saleesongsom, Sarawud; Weiss, Dominik (2020): A Revised Pseudo-Second Order Kinetic Model for Adsorption, Sensitive to Changes in Sorbate and Sorbent Concentrations. ChemRxiv. Preprint. https://doi.org/10.26434/chemrxiv.12008799.v1

Much contemporary research considers the development of novel sorbents for the removal of toxic contaminants. Whilst these studies often include experimental adsorption kinetics, modelling is normally limited to application of the pseudo-second order (PSO) rate equation, which provides no sensitivity towards changes in experimental conditions and thus no predictive capability. We demonstrate a relatively simple modification of the PSO model, with the final form $d q t / d t=k^{\prime} C_{t}\left(1-\left(q_{t} / q_{e}\right)\right)^{\wedge} 2$ where $k^{\prime}=k_{2}{ }^{*}\left(q_{e}{ }^{* \wedge} 2\right) / C_{0}{ }^{*}$. We demonstrate that unlike the PSO model, this new rate equation provides first-order dependence upon initial sorbate concentration (observed experimentally as $\bar{x}=0.829 \pm 0.417$ ), whilst rate constant $k$ ' is significantly less sensitive to changes in $\mathrm{C}_{0}$ and $\mathrm{C}_{\mathrm{s}}$ than $\mathrm{PSO}$ rate constant $\mathrm{k}_{2}$. We demonstrate that this model improves predictive capacity towards changes in $\mathrm{C}_{0}$ and $\mathrm{C}_{\mathrm{s}}$, particularly when $\mathrm{q}_{\mathrm{e}}$ is calculated using the Langmuir or Freundlich adsorption isotherm. Finally, we explore how the new rate constant, $k$ ', responds to changes in sorbent morphology, identifying that particle radius is a better constraining parameter than surface area. In this new equation, the conditionality of the rate constant upon experimental conditions is significantly decreased, facilitating better comparison of new results with the literature.

File list (2)

A revised pseudo-second order kinetic model for adsorptio... (1.89 MiB) view on ChemRxiv • download file A revised pseudo-second order kinetic model for adsorptio... (1.34 MiB) view on ChemRxiv • download file 


\section{A revised pseudo-second order kinetic model for adsorption, sensitive to changes in sorbate and sorbent concentrations}

${ }^{1^{*}}$ Jay Bullen; ${ }^{1}$ Sarawud Saleesongsom; and ${ }^{1,2^{*}}$ Dominik J. Weiss

${ }^{1}$ Department of Earth Science and Engineering, Imperial College London, London SW7 2AZ, United Kingdom

${ }^{2}$ Civil and Environmental Engineering, Princeton University, United States of America

*Corresponding authors:

Email: j.bullen16@imperial.ac.uk; d.weiss@imperial.ac.uk 


\title{
Graphical Abstract
}

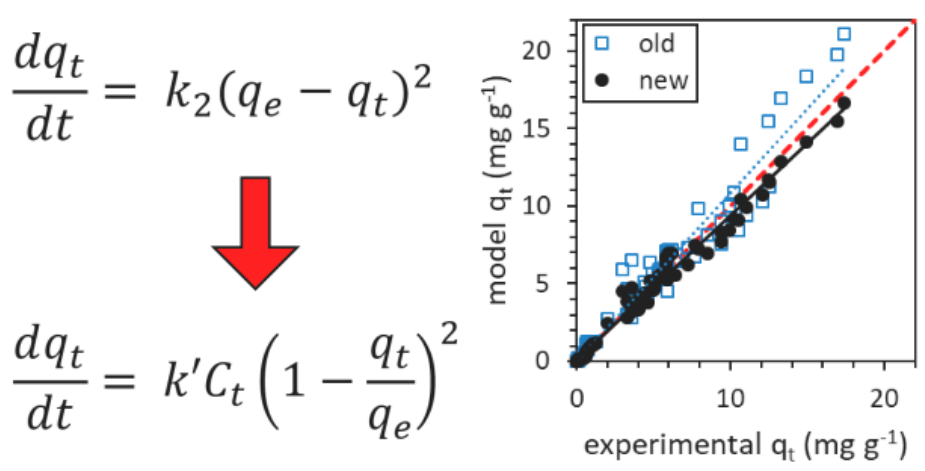

\section{Keywords}

Adsorption kinetics; kinetic model; Lagergren; Ho and McKay; intraparticle diffusion; particle size

\begin{abstract}
Much contemporary research considers the development of novel sorbents for the removal of toxic contaminants. Whilst these studies often include experimental adsorption kinetics, modelling is normally limited to application of the pseudo-second order (PSO) rate equation, which provides no sensitivity towards changes in experimental conditions and thus no predictive capability. We demonstrate a relatively simple modification of the PSO model, with the final form $d q t / d t=k^{\prime} C_{t}(1-$ $\left.\left(q_{t} / q_{e}\right)\right)^{\wedge} 2$ where $k^{\prime}=k_{2}{ }^{*}\left(q_{e}{ }^{* \wedge} 2\right) / C_{0}{ }^{*}$. We demonstrate that unlike the PSO model, this new rate equation provides first-order dependence upon initial sorbate concentration (observed experimentally as $\bar{x}=0.829 \pm 0.417$ ), whilst rate constant $k^{\prime}$ is significantly less sensitive to changes in $\mathrm{C}_{0}$ and $\mathrm{C}_{\mathrm{s}}$ than PSO rate constant $\mathrm{k}_{2}$. We demonstrate that this model improves predictive capacity towards changes in $\mathrm{C}_{0}$ and $\mathrm{C}_{\mathrm{s}}$, particularly when $\mathrm{q}_{\mathrm{e}}$ is calculated using the Langmuir or Freundlich adsorption isotherm. Finally, we explore how the new rate constant, $\mathrm{k}^{\prime}$, responds to changes in sorbent morphology, identifying that particle radius is a better constraining parameter than surface area. In this new equation, the conditionality of the rate constant upon experimental conditions is significantly decreased, facilitating better comparison of new results with the literature.
\end{abstract}




\section{Introduction}

There is a great wealth of recent literature concerning the development of novel sorbent materials for the remediation of contaminated water. This includes composite materials offering superior stability 1 , ease of separation from effluent ${ }^{23}$, or multifunctional capabilities such as photocatalytic activity ${ }^{4}$ 5. Understanding adsorption kinetics is important for identifying the minimum duration needed for batch treatments and estimating maximum flow rates for column or continuous-flow treatments ${ }^{6}$. Environments will be encountered with different concentrations of contaminants (with the initial concentration denoted as $\mathrm{C}_{0}$ ), where different amounts of sorbent (with sorbent concentration denoted as $C_{s}$ ) are required to achieve desired filter device life-times. Predicting the range of experimental conditions under which novel sorbents will be deployed is challenging, and laboratory experiments can only hope to capture the approximate environments in which new sorbents will operate. It is thus desirable to have an element of predictive capability towards understanding adsorption kinetics.

There are two main classes of kinetic adsorption models, differing in their mechanistic description: diffusion-controlled and adsorption-controlled. A summary of the major kinetic models in each category is given in Table 1. For diffusion-controlled models, external diffusion is rarely considered rate limiting ${ }^{7}$. Instead, adsorption rates are controlled by intraparticle diffusion, with a diffusivity parameter reflecting the rate at which sorbate diffuses through the porous spaces within sorbent particles ${ }^{7}$. This category includes the Crank model (1956) ${ }^{8}$ which approximates the sorbent as spherical particles and the concentration of sorbate at the surface is constant ${ }^{7}$. Adsorption kinetics can often be linearised using the Weber-Morris model $(1963){ }^{9}$, where $q_{t}$ is proportional to $t^{1 / 2} 10$.

Adsorption-controlled kinetic models consider formation of the surface complex to be the rate determining step. The original adsorption-controlled model was the Lagergren, or pseudo-first order model $(1898)^{11}$, with a reaction rate that is first order with respect to $\left(q_{e}-q_{t}\right)$, where $q_{e}$ is the concentration of sorbate adsorbed at equilibrium, and $q_{t}$ is the concentration of sorbate adsorbed at time $t^{10}$. The Elovich equation (1934) ${ }^{12}$ is another adsorption-control kinetic model, where the reaction rate decreases exponentially with increasing adsorption progress ${ }^{10}$.

At present, the pseudo-second order (PSO) rate equation, popularised by Ho and Mckay (1999) ${ }^{13}$, is probably the most popular model used to describe adsorption kinetics ${ }^{14}$, especially for new and novel sorbent materials. The PSO rate equation is the same as the earlier Lagergren model, save that the dependence of reaction rate upon $\left(q_{\mathrm{e}}-\mathrm{q}_{\mathrm{t}}\right)$ is second-order rather than first-order. The PSO rate equation takes the form:

$$
\frac{d q_{t}}{d t}=k_{2}\left(q_{e}-q_{t}\right)^{2}
$$

Equation 1

where $t$ is time (minutes), $\mathrm{q}_{\mathrm{t}}$ is the amount of sorbate adsorbed at time $\mathrm{t}\left(\mathrm{mg} \mathrm{g}^{-1}\right), \mathrm{k}_{2}$ is the pseudosecond order rate constant $\left(\mathrm{g} \mathrm{mg}^{-1} \mathrm{~min}^{-1}\right)$, and $\mathrm{q}_{\mathrm{e}}$ is the amount of sorbate adsorbed at equilibrium $\left(\mathrm{mg} \mathrm{g}^{-1}\right)^{13}$. The vital limitation of the PSO is that it does not explicitly include the variables $\mathrm{C}_{0}$ and $\mathrm{C}_{s}$ (the initial concentration of sorbate and sorbent, respectively) and therefore lacks sensitivity to changes in $C_{0}$ and $C_{s}$. The PSO therefore does not allow us to identify appropriate sorbent 
concentrations for water treatment design under different contaminant concentrations. Table 1 demonstrates that the lack of sensitivity towards $C_{t}$ and $C_{s}$ is common to most adsorption kinetic models - they are without predictive capacity, and their parameters are valid only for the particular experimental conditions under which they were calculated.

Furthermore, $\mathrm{k}_{2}$ is only valid for the experimental conditions under which it was determined, and so comparison of literature studies with different experimental values of $C_{0}$ and $C_{s}$ can lead to false conclusions ${ }^{15}$. The ability to normalise rate constants to $C_{0}$ and $C_{s}$ would thus be another major advantage, allowing improvements in sorbent engineering to be truly identified and validated.

The aim of this work was to develop a kinetic adsorption model that could be used to predict changes in adsorption kinetics as a function of sorbate and sorbent concentration. Furthermore, we explored how this model could provide normalised rate constants for better comparison between different sorbents. Our motivation towards both these aims was to help researchers consider the operating conditions under which their sorbents may be best used, e.g. comparative modelling of batch and continuous-flow systems ${ }^{6}$.

We used the PSO model as a starting point, due to it being well-known and ubiquitous, and capable of describing most kinetic data, despite doubts over whether adsorption or diffusion-controlled models are more mechanistically appropriate ${ }^{16}$. To achieve these aims, we (1) collected a wide range of literature where the influence of $C_{0}$ and $C_{s}$ on adsorption kinetics were investigated; (2) determined the relationship between $C_{0}$ and $C_{s}$ on adsorption kinetics within this data set; (3) built the observed $\mathrm{C}_{0}$ and $\mathrm{C}_{\mathrm{s}}$ dependence into a modified form of the PSO model; (4) verified that the rate constants of this new model are less conditional than PSO rate constant $\mathrm{k}_{2} ;(5)$ used the modified model to predict experimental data; (6) explored the influence of surface morphology on the remaining variance between rate constants in the literature. 
Table 1: A selection of kinetic models widely used to describe adsorption. The table illustrates that in most of these kinetic models $\frac{d q_{t}}{d t}$ is sensitive to neither changes in $C_{0}$ nor changes in $C_{s}$, and are thus limited in predictive capability. $C_{0}$ is the initial concentration of aqueous sorbate, $C_{t}$ is the concentration of aqueous sorbate at time $t, C_{e}$ is the concentration of aqueous sorbate at equilibrium, $q_{t}$ is the quantity of sorbate adsorbed at time $t\left(e . g . \mathrm{mg} \mathrm{g}^{-1}\right), q_{e}$ is the quantity of sorbate adsorbed at equilibrium ( $\left.\mathrm{mg} \mathrm{g}^{-1}\right), k$ is the rate constant, $a$ is the desorption constant, $\alpha$ is the initial adsorption rate, $D$ is molecular diffusion coefficient of the sorbate in solution, $r$ is the radial coordinate, $\rho$ is particle density, $\varepsilon_{r}$ is particle porosity, $N$ is the local concentration of sorbate in the adsorbed phase (presumably equivalent to $q_{t}$ ), $D_{s}$ is surface diffusivity (assumed constant), $\vartheta_{t}$ is surface coverage at time $t, \vartheta_{e}$ is surface coverage at equilibrium, $u_{e}$ is the relative sorbate uptake at equilibrium, with $u_{e}=$ $1-\frac{C_{e}}{C_{0}}, k_{a}$ is a rate constant for adsorption. $q_{e}{ }^{* 2}$ and $C_{0}{ }^{* 2}$ denote the values of $q_{e}$ and $C_{0}$ used to determine $k_{2}$ from a given experimental data set.

\begin{tabular}{|c|c|c|c|c|}
\hline Model & Equation & $\begin{array}{l}\text { Is the rate equation } \\
\text { sensitive to changes in } C_{t} \text { ? }\end{array}$ & $\begin{array}{c}\text { Is the rate equation } \\
\text { sensitive to changes in } \\
C_{s} \text { ? }\end{array}$ & Reference \\
\hline \multicolumn{5}{|c|}{ Intraparticle diffusion-controlled models } \\
\hline Crank model & $\frac{\partial C_{t}}{\partial t}=\frac{D}{T}\left(\frac{\partial^{2} C_{t}}{\partial r^{2}}+2 \frac{\partial C_{t}}{r \partial r}\right)-\frac{\rho}{\varepsilon_{r}} \frac{\partial N}{\partial t}$ & Yes & No & 17 \\
\hline $\begin{array}{l}\text { Simplified } \\
\text { Crank model }\end{array}$ & $\frac{\partial q_{t}}{\partial t}=\frac{D_{s}}{r^{2}} \frac{\partial}{\partial r}\left(r^{2} \frac{\partial q_{t}}{\partial r}\right)$ & $\begin{array}{c}\text { No } \\
\text { (model assumes constant } \\
\text { surface concentration of } \\
\text { sorbate) }\end{array}$ & No & 7 \\
\hline $\begin{array}{l}\text { Web and } \\
\text { Morris }\end{array}$ & $q_{t}=k t^{\frac{1}{2}}$ & No & No & 7 \\
\hline \multicolumn{5}{|c|}{ Adsorption-controlled models } \\
\hline $\begin{array}{l}\text { Pseudo-first } \\
\text { order }\end{array}$ & $\frac{d q_{t}}{d t}=k\left(q_{e}-q_{t}\right)$ & No & $\begin{array}{l}\text { No } \\
\text { (unless } \mathrm{q}_{\mathrm{e}} \text { is replaced } \\
\text { with a variable term) }\end{array}$ & 10 \\
\hline $\begin{array}{l}\text { Pseudo- } \\
\text { second order }\end{array}$ & $\frac{d q_{t}}{d t}=k\left(q_{e}-q_{t}\right)^{2}$ & No & $\begin{array}{l}\text { No } \\
\text { (unless } q_{\mathrm{e}} \text { is replaced } \\
\text { with a variable term) }\end{array}$ & 10 \\
\hline $\begin{array}{l}\text { Elovich } \\
\text { equation }\end{array}$ & $\frac{d q_{t}}{d t}=a e^{-\alpha q_{t}}$ & No & No & 10 \\
\hline $\begin{array}{l}\text { Second-order } \\
\text { rate equation } \\
\text { (aqueous } \\
\text { phase) }\end{array}$ & $\frac{d C_{t}}{d t}=-k_{2} C_{t}^{2}$ & $\begin{array}{c}\text { Yes } \\
\text { (second order) }\end{array}$ & No & 10 \\
\hline $\begin{array}{l}\text { Integrated } \\
\text { kinetic } \\
\text { Langmuir } \\
\text { model }\end{array}$ & $\begin{array}{c}\frac{d \theta_{t}}{d t}=k_{a} C_{0}\left[\left(1-\theta_{e} u_{e}\right)\left(1-\frac{q_{t}}{q_{e}}\right)\right. \\
\left.+\theta_{e} u_{e}\left(1-\frac{q_{t}}{q_{e}}\right)^{2}\right]\end{array}$ & $\begin{array}{c}\text { Yes } \\
\text { (but } C_{0} \text { only and not } C_{t} \text { ) }\end{array}$ & $\begin{array}{c}\text { Yes } \\
\left(\theta_{\mathrm{e}} \text { and } \mathrm{u}_{\mathrm{e}} \text { will change }\right. \\
\left.\text { with } \mathrm{C}_{\mathrm{s}}\right)\end{array}$ & 18 \\
\hline This work & $\begin{array}{r}\frac{d q}{d_{t}}=k^{\prime} C_{t}\left(1-\frac{q_{t}}{q_{e}}\right)^{2} \\
\text { where } \mathrm{k}^{\prime}=\frac{k_{2} q_{e^{* 2}}}{C_{0^{*}}}\end{array}$ & $\begin{array}{c}\text { Yes } \\
\left.\text { (1 } 1^{\text {st }} \text { order }\right)\end{array}$ & $\begin{array}{l}\text { Yes } \\
\text { ( } q_{\mathrm{e}} \text { is calculated at each } \\
\text { time interval using } \\
\text { adsorption isotherms) }\end{array}$ & This work \\
\hline
\end{tabular}




\section{Experimental}

\subsection{Data sets}

Literature sources that experimentally investigated the influence of $C_{0}, C_{s}$ or particle size upon adsorption kinetics were compiled (references are given in the Supplementary Information). Studies using oxyanions, metal cations and organic dyes as the sorbate were included, to ensure our findings would be general and non-sorbate-specific. Both mineral sorbents and organic sorbents (activated carbon and chitosan) were included, however zeolites and metal-organic frameworks (MOFs) were not since the sorption mechanism of sorbate trapping within cages might present inconsistent results. None of the literature sources found gave any mechanistic account or mathematical explanation for observed differences in adsorption kinetics due to varying $C_{0}, C_{s}$ or particle size. The majority of literature sources used the PSO equation to model adsorption kinetics.

In total 79 literature sources with around 200 kinetic experiments were collected. To investigate the influence of initial sorbate concentration, 11 literature sources with a combined 43 kinetic experiments were collected. For initial sorbent concentration, 11 literature sources with 43 experiments were collected. For particle size, 15 data sets from 6 literature sources, with a combined 47 experiments were collected. A data set was considered to be all kinetic experiments using the same sorbate-sorbent system within a single literature source.

\subsection{Calculation of initial rates}

To investigate the dependency of adsorption kinetics on $\mathrm{C}_{0}, \mathrm{C}_{\mathrm{s}}$ and particle radius, the method of initial rates was used ${ }^{19}$. Experimental kinetic data from the literature was tabulated and initial reaction rates were determined. Many data sets lacked good resolution for the initial stages of adsorption, e.g. in $\sim 30 \%$ of all experiments reaction progress had already exceeded $50 \%$ when the first data point after mixing sorbent with sorbate was collected. Calculating the initial rate (the rate of reaction at $t=0$ ) using the slope of $\mathrm{q}_{\mathrm{t}}$ versus time at the earliest data points would lead to a systematic under-calculation of the initial reaction rate, as early curvature in adsorption kinetics would be missed (Figure 1 ). This error would become more significant the later that initial adsorption data is collected. Determination of initial adsorption kinetics using the slope of $\mathrm{q}_{\mathrm{t}}$ versus $\mathrm{t}$ would also give a random error associated with calculating rates from two data points only.

To provide a better estimation of the initial rate, the PSO model was fit to each data set and the rate calculated at $t=0$. PSO parameters $\left(k_{2}\right.$ and $\left.q_{e}\right)$ were determined using the linearised form of the PSO rate equation, which is as follows:

$$
\frac{\mathrm{t}}{\mathrm{q}_{\mathrm{t}}}=\frac{1}{\mathrm{k}_{2} \mathrm{q}_{\mathrm{e}}^{2}}+\frac{\mathrm{t}}{\mathrm{q}_{\mathrm{e}}}
$$

Adsorption kinetic profiles were plotted as $\frac{t}{q_{t}}$ against $t$ and the linear regression obtained using the LINEST function in Excel. $q_{\mathrm{e}}$ was obtained via the relationship $q_{e}=\frac{1}{m}$ where $\mathrm{m}$ is the gradient of the 
linear regression, and $\mathrm{k}_{2}$ via $k_{2}=c \times q_{e}{ }^{2}$ where $\mathrm{c}$ is the $\mathrm{y}$-intercept. The initial rate of adsorption was calculated through simplifying Equation 1 as:

$$
\text { Initial rate }=\frac{d q_{t=0}}{d t}=k_{2} q_{e}{ }^{2}
$$

Parameters were normalised to the same units for ease of comparison: $\mathrm{k}_{2}-\mathrm{g} \mathrm{mg}^{-1} \mathrm{~min}^{-1} ; \mathrm{q}_{\mathrm{e}}-\mathrm{mg} \mathrm{g}^{-1}$; and initial rate $-\mathrm{mg} \mathrm{g}^{-1} \mathrm{~min}^{-1}$. The advantages in determining the initial rate of adsorption using the PSO model compared with the initial slope of $q_{t}$ versus time is demonstrated in Figure 1. In the example, the initial rate was three times greater when calculated using the PSO model compared with the initial slope (4.4 versus $1.3 \mathrm{mg} \mathrm{g}^{-1} \mathrm{~min}^{-1}$ ). In this experiment, the first data point collected after mixing gave a value of $\mathrm{q}_{\mathrm{t}}=4 \mathrm{mg} \mathrm{g}^{-1}$. Given that $\mathrm{q}_{\mathrm{e}}=5.4 \mathrm{mg} \mathrm{g}^{-1}$, adsorption progress had already reached $75 \%$ completion when the first data was collected, and it is therefore not surprising that the slope of $\mathrm{q}_{\mathrm{t}}$ versus time gives a significantly lower initial rate compared with the PSO model: the PSO includes curvature within its interpolation of early adsorption kinetics (interpolating between $t=0$ and 3 minutes). Not only are systematic errors reduced, but the PSO method also reduces the random error due to uncertainties in determination of sorbate concentrations, since most kinetic experiments gave at least 5 data points with which to fit the PSO parameters, rather than just two data points used in the initial slope method.

(a)

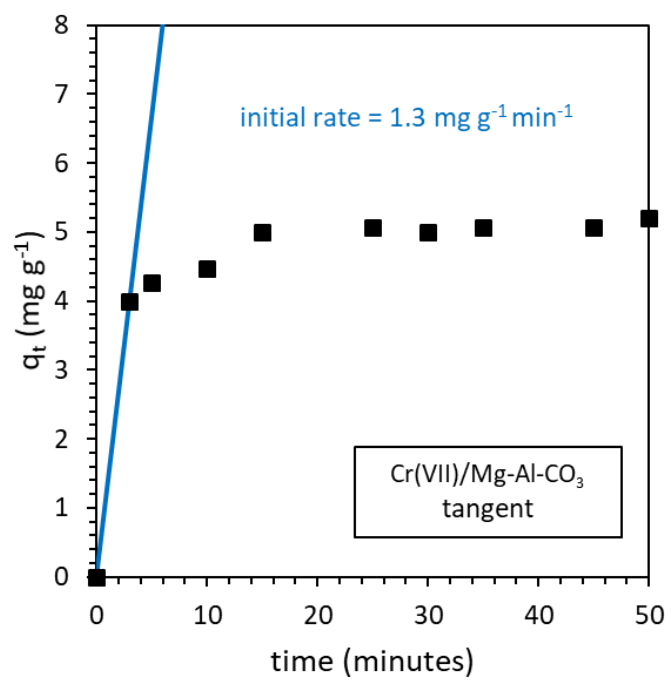

(b)

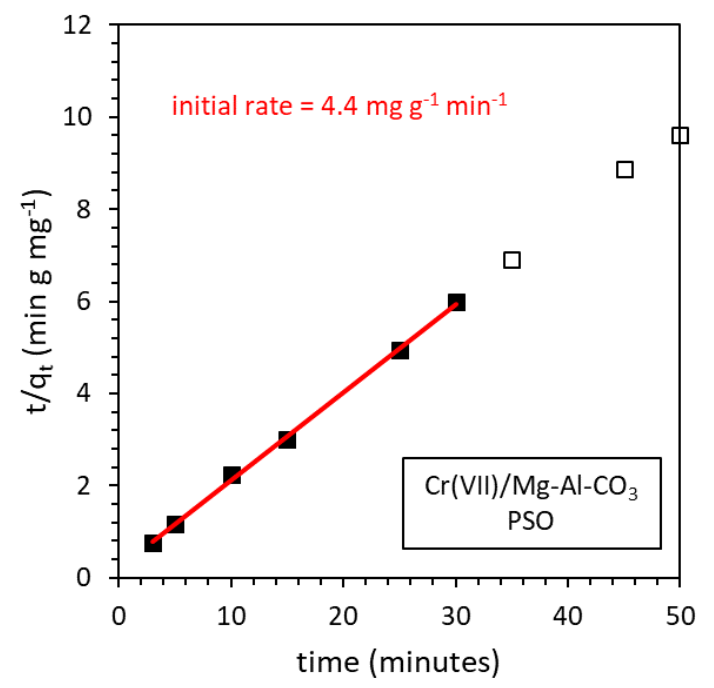

Figure 1: Illustration of how calculation of initial rates using the slope between the first two data points of $q_{t}$ as a function of $t$ gives a systematically lower result than when fitting the PSO model using the linearised plot of $t / q_{t}$ as a function of $t$. The data presented is from the $\mathrm{Cr}(\mathrm{VII}) / \mathrm{Mg}-\mathrm{Al}-\mathrm{CO}_{3}$ data set with $10 \mathrm{mg} \mathrm{L}^{-1}$ sorbate and $1.5 \mathrm{~g} \mathrm{~L}^{-1}$ sorbent ${ }^{20}$. The initial rate was calculated to be $8.5 \mathrm{mg} \mathrm{g}^{-1} \mathrm{~min}^{-1}$ when using the PSO method with only the first two data points.

\subsection{Determining the order of reaction}

The order of reaction with respect to $C_{0}, C_{s}$ or particle radius was determined by calculating the gradient of $\log$ (initial rate) versus $\log$ (independent variable) ${ }^{19}$, where each data point represents a single kinetic experiment within a given literature study where the influence of either $C_{0}$ or $C_{s}$ on adsorption kinetics was investigated. 


$$
\text { order of reaction }=\frac{\Delta \log (\text { initial rate })}{\Delta \log \left(C_{0}, C_{s} \text { or } r\right)}
$$

Equation 4

For each data set, the order of reaction with respect to the independent variable was calculated using the LINEST formula in Microsoft Excel. The error of each data set was calculated as the standard error of the slope. A generalised order of reaction was calculated as the average (mean, $\bar{x}$ ) and median ( $\tilde{x})$ order of reaction between all data sets collected, with errors reported as the standard deviation between all data sets. The dependencies of $k_{2}$ and $k^{\prime}$ upon $C_{0}, C_{s}$ and $r$ were determined using the same method, substituting initial rates for $\mathrm{k}_{2}$ or $\mathrm{k}^{\prime}$.

\subsection{Modelling}

As the modified rate equation was not easily linearised, this new model was simulated using Microsoft Excel. The quantity of sorbate adsorbed at the $\mathrm{n}^{\text {th }}$ data point was calculated using the following formula:

$$
q_{n}=q_{n-1}+\left(\left(t_{n}-t_{n-1}\right) \times\left(k^{\prime} C_{t(n-1)}\left(1-\frac{q_{n-1}}{q_{e}}\right)^{2}\right)\right)
$$

Equation 5

With the concentration of aqueous sorbate remaining, $C_{t}$, decreasing according to the following equation:

$$
C_{t(n)}=C_{t(n-1)}-C_{s} \times\left(q_{n}-q_{n-1}\right)
$$

Equation 6

The time interval between data points, $\left(t_{n}-t_{n-1}\right)$ or $\Delta \mathrm{t}$, was minimised until the magnitude of $\Delta \mathrm{t}$ had no significance on the observed kinetics. 


\section{Results and Discussion}

\subsection{Influence of $\mathrm{C}_{0}$ and $\mathrm{C}_{\mathrm{s}}$ upon adsorption rates}

We first aimed to establish the influence that initial sorbent concentration, $\mathrm{C}_{0}$, and sorbent concentration, $\mathrm{C}_{s}$, have on adsorption kinetics. We collected a range of experimental data, with oxyanions, metal cations and organic dyes represented as sorbates, as well as single component minerals, composite systems and activated carbon represented as sorbents. We calculated the initial rate of reaction (interpolated from the linearised PSO plot) and calculated the order of reaction with respect to $C_{0}$ and $C s$ as the gradient in the slope of $\log \left(\right.$ initial rate) as a function of $\log \left(C_{0}\right.$ or $\left.C_{s}\right)$. In total 11 data sets with a combined 43 kinetic experiments were collected to investigate the influence of $C_{0}$. For $C_{s}, 11$ data sets with a combined 43 kinetic experiments were collected.

The data compiled from the literature generally shows a linear relationship between initial sorbate concentration and initial rate (normalised to mass, $\mathrm{mg} \mathrm{g}^{-1} \mathrm{~min}^{-1}$ ). This is shown in Figure 2a where the average result for the gradient between $\log \left(\right.$ initial rate) and $\log \left(C_{0}\right)$ was $\bar{x}=0.829 \pm 0.417, \tilde{x}=0.801$. Despite large uncertainties, the average and median results were significantly closer to first-order than zero-order or second-order. This is intuitive for both diffusion and adsorption-controlled mechanisms, as twice as much sorbate should lead to twice as much sorbate flux from sorbent surface into pores, and collisions with the sorbent surface should be twice as frequent.

Similarly, a first order dependence of reaction rate on $C_{s}$ was observed in the compiled data sets. This is shown in Figure $2 \mathrm{~b}$ where the average gradient was $\bar{x}=1.18 \pm 0.61, \tilde{x}=1.15$. This is also intuitive for both diffusion and adsorption-controlled mechanisms, as when $C_{s}$ is doubled, the total surface area is doubled, and the overall flux of sorbate entering sorbent pores is doubled, whilst the rate of collisions between sorbate and sorbent surface is also doubled. When normalised to mass $\left(\mathrm{mg} \mathrm{g}^{-1} \mathrm{~min}^{-1}\right)$ the initial rate was zero-order with respect to $C_{s}$, as expected. Again, despite large statistical errors, the relationship between initial rate and $C_{s}$ was significantly closer to first-order (when rate is normalised to $\mathrm{mg} \mathrm{L}^{-1} \mathrm{~min}^{-1}$ ) than both zero-order and second-order. For both $\mathrm{C}_{0}$ and $\mathrm{C}_{\mathrm{s}}$, the median result was very close to the average, indicating that the analysis was not significantly skewed by any outlying data sets. 

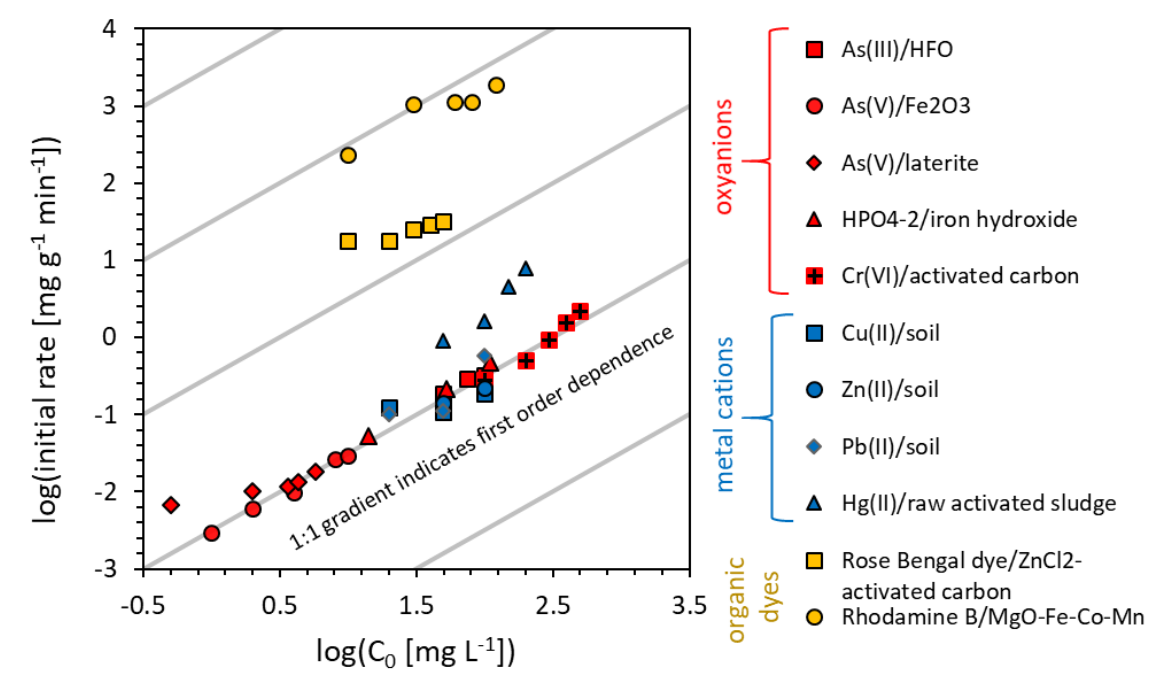

(a)
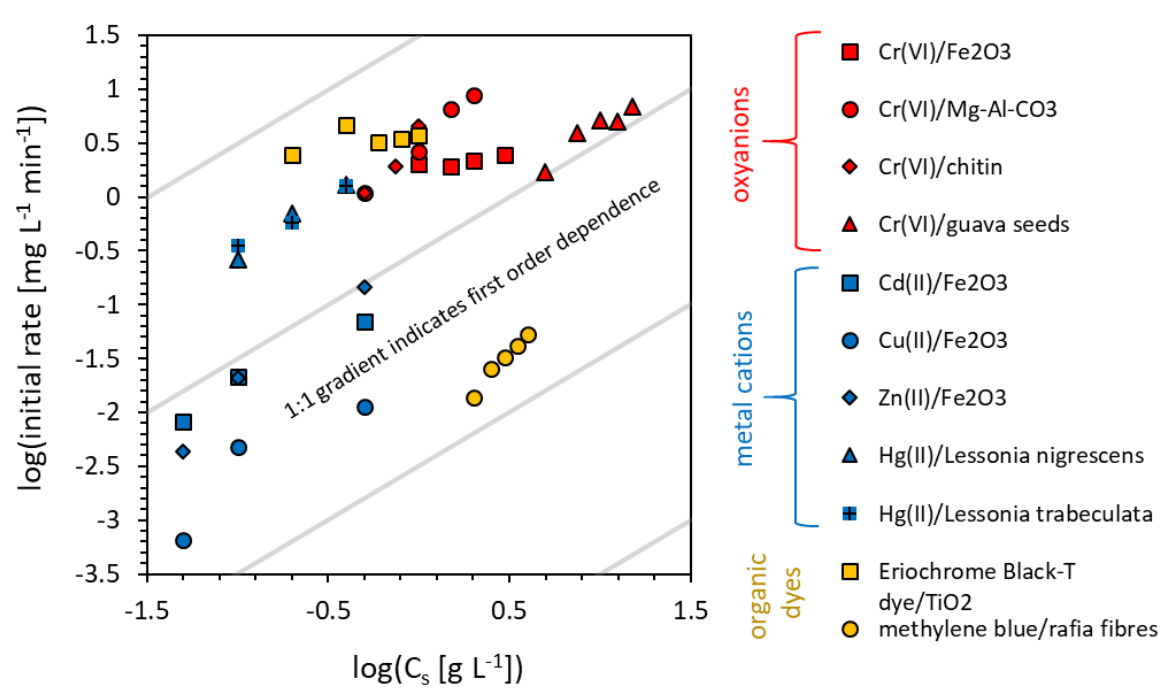

(b)

Figure 2: The initial rate of adsorption as a function of (a) initial sorbate concentration $\left(C_{0}\right)$ and $(b)$ initial sorbent concentration $\left(C_{s}\right)$. Each data point represents a single kinetic experiment - each experiment was fitted with the pseudosecond order model and the rate at time $t=0$ calculated as discussed in the experimental section. Kinetic experiments are grouped into data sets, where all conditions except for $(a) C_{0}$ or $(b) C_{s}$ were kept constant. The gradients of most data sets align with the 1:1 gradient (grey guidelines given for visual reference) indicating that the adsorption reaction is first order with respect to the independent variables $C_{0}$ and $C_{s}$.

\subsection{Conditionality of $\mathbf{k}_{2}$ and limitations to predictive capabilities of the PSO}

To predict the sensitivity of adsorption kinetics as a function of changes to $C_{0}$ and $C_{s}$, and to facilitate comparison of adsorption kinetics within the literature, it is necessary that the rate constant determined under one set of experimental conditions can used to model further experiments differing in $C_{0}$ and $C_{s}$. Having identified a first-order dependence of reaction rate on $C_{0}$ and $C_{s}$, we aimed to identify the influence that independent variables $C_{0}$ and $C_{s}$ have on $k_{2}$, using the same data sets. 
Whilst section 3.1 demonstrated that adsorption kinetics are approximately first order with respect to $\mathrm{C}_{0}$ (Figure 2a), the PSO rate constant, $\mathrm{k}_{2}$, is inversely proportional to $\mathrm{C}_{0}$, i.e. doubling initial sorbate concentration results in the rate constant $k_{2}$ decreasing by a factor of 2 (Figure 3a). The inverse relationship between $\mathrm{k}_{2}$ and $\mathrm{C}_{0}$ is explained by the second order dependence of PSO on the absolute concentration of available surface sites, $\left(\mathrm{q}_{\mathrm{e}}-\mathrm{q}_{\mathrm{t}}\right)$, and is demonstrated mathematically in the following discussion.

(a)
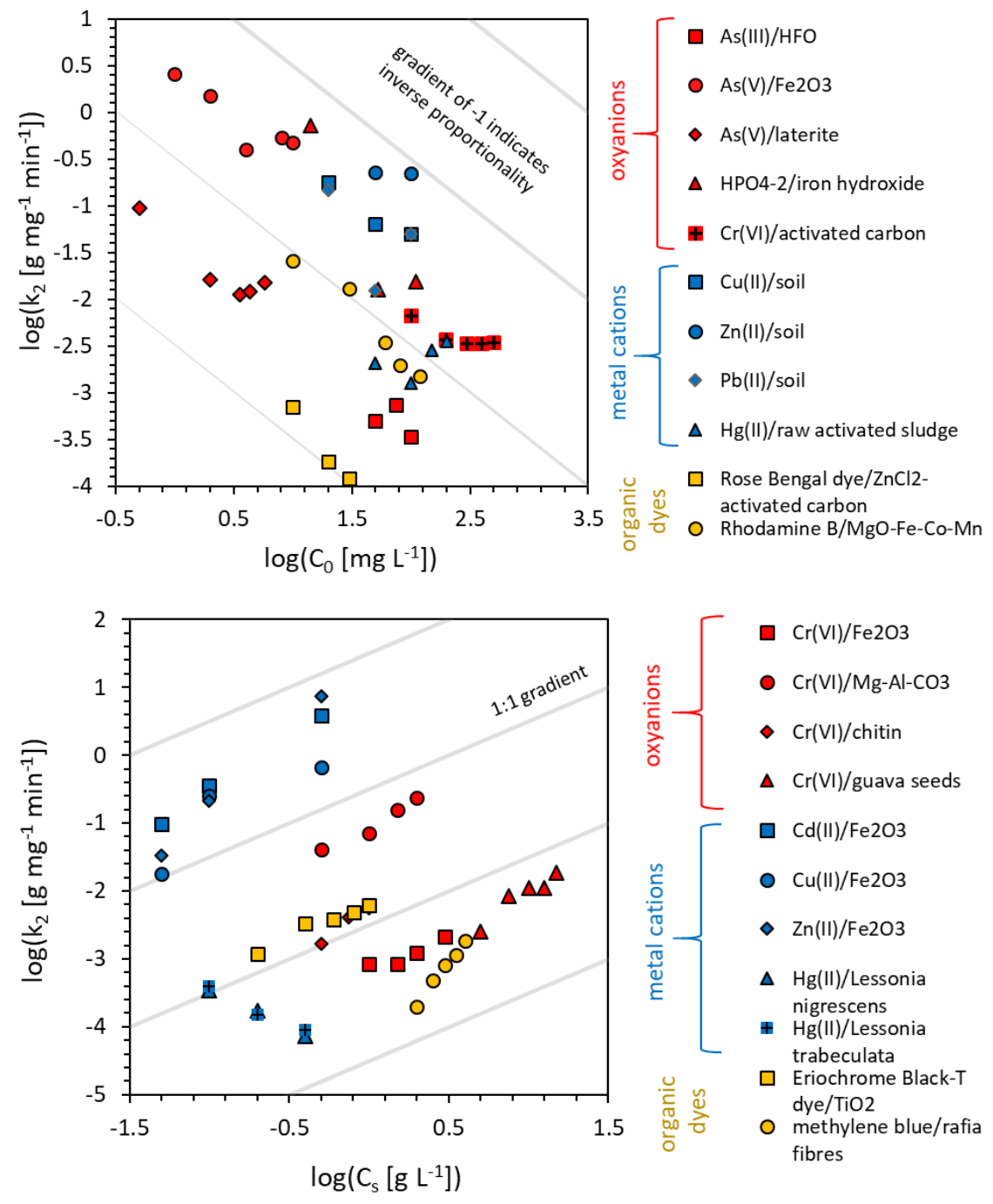

(b)

Figure 3: Pseudo-second order (PSO) rate constant $k_{2}$ as a function of (a) initial sorbate concentration ( $\left.C_{0}\right)$ and (b) initial sorbent concentration $\left(C_{s}\right)$. Grey lines indicate gradients and thus reaction orders of $(a)-1$ and $(b)+1$.

Many studies of adsorption kinetics operate under conditions where the sorbent remains unsaturated at equilibrium. This is natural as the authors wish to investigate the conditions under which their sorbent successfully removes contaminants. At low values of $C_{e}$, a linear relationship is observed between $\mathrm{C}_{\mathrm{e}}$ and $\mathrm{q}_{\mathrm{e}}$, known as Henry's adsorption isotherm ${ }^{21}$. If we approximate the adsorption isotherm as a linear relationship between $\mathrm{C}_{\mathrm{e}}$ and $\mathrm{q}_{\mathrm{e}}$, and let coefficient $a$ represent the factor increase in $C_{0}$ between experiments (1) and (2), we get the following:

$$
a=\frac{\text { reaction rate }(2)}{\text { reaction rate }(1)}=\frac{C_{0(2)}}{C_{0(1)}} \approx \frac{C_{e(2)}}{C_{e(1)}} \approx \frac{q_{e(2)}}{q_{e(1)}}
$$


where coefficient $a$ is equal not just to the quotient of $\mathrm{C}_{0(2)}$ and $\mathrm{C}_{0(1)}$, but also the quotient of reaction rates, given the first order dependence of reaction rate upon $\mathrm{C}_{0}$ observed in section 3.1. $\mathrm{q}_{\mathrm{e}(2)}$ can thus be substituted for the product of coefficient $a$ and the old $\mathrm{q}_{\mathrm{e}(1)}$ :

$$
q_{e(2)} \approx a q_{e(1)}
$$

Equation 8

Rearrangement of Equation 1 gives the following:

$$
k_{2}=\frac{\text { reaction rate }}{\left(q_{e}-q_{t}\right)^{2}}
$$

Equation 9

which at time $\mathrm{t}=0$ reduces to:

$$
k_{2}=\frac{\text { initial rate }}{q_{e}^{2}}
$$

Substitution of $\mathrm{q}_{\mathrm{e}(2)}$ with $\mathrm{aq}_{\mathrm{e}(1)}$ as per Equation 8 gives:

$$
k_{2(2)}=\frac{\text { initial rate }(2)}{q_{e(2)}{ }^{2}} \approx \frac{\text { initial rate }(2)}{\left(a q_{e(1)}\right)^{2}}
$$

Substituting initial rate (2) for the product of $a$ and initial rate (2) as per Equation 7 gives:

$$
k_{2(2)} \approx \frac{\text { initial rate }(2)}{\left(a q_{e(1)}\right)^{2}}=\frac{a \times \text { initial rate }(1)}{a^{2} q_{e(1)}{ }^{2}}=\frac{a \times k_{2(1)}}{a^{2}}=\frac{k_{2(1)}}{a}
$$

Equation 12

This mathematically demonstrates that $k_{2}$ is inversely proportional to $C_{0}$, to a first approximation, when the sorbent is unsaturated and adsorption can be represented by the linear adsorption isotherm. This was observed experimentally, as whilst the reaction rate only doubles with a doubling of $C_{0}$ (Figure $2 \mathrm{a}$ ), the PSO rate constant, $\mathrm{k}_{2}$, conditional to the value of $\mathrm{C}_{0}$ used, decreased by a factor of two. The final results for the order of reaction with respect to $C_{0}$ were $\bar{x}=-0.761 \pm 0.663, \tilde{x}=-0.765$, $\mathrm{N}=11$ data sets and 43 kinetic experiments. The standard deviation is large, nearly including $\mathrm{x}=0$ for a zero-order relationship between $\mathrm{k}_{2}$ and $\mathrm{C}_{0}$.

Most data sets showed first-order dependence of $k_{2}$ upon $C_{s}$ (Figure $3 b$ ). This can also be explained by considering adsorption isotherms and the term $\left(q_{\mathrm{e}}-\mathrm{q}_{\mathrm{t}}\right)^{2}$. If coefficient $b$ indicates the factor increase in $C_{s}$ between two experiments, then:

$$
b=\frac{C_{s(2)}}{C_{s(1)}}
$$


When the sorbent is saturated and $C_{e}>>\left(C_{s}{ }^{*} q_{e}\right)$, the adsorption isotherm approaches a plateau and increasing $C_{s}$ has limited effect on $\mathrm{q}_{\mathrm{e}}$.

$$
q_{e(2)} \approx q_{e(1)}
$$

Equation 14

Since a zero-order dependence of rate (when normalised to mass, $\mathrm{mg} \mathrm{g}^{-1} \mathrm{~min}^{-1}$ ) upon $\mathrm{C}_{\mathrm{s}}$ was identified in section 3.1, then:

$$
\text { initial rate }(2) \approx \text { initial rate }(1)
$$

Equation 15

From Equation 10, we obtain:

$$
k_{2(2)}=\frac{\text { initial rate }(2)}{q_{e(2)}{ }^{2}} \approx \frac{\text { initial rate }(1)}{q_{e(1)}{ }^{2}} \approx k_{2(1)}
$$

Equation 16

$C_{s}$ does not enter the equations, and thus $k_{2}$ is predicted to have zero order dependence upon $C_{s}$ at high values of $C_{e}$ where the adsorption isotherm reaches a plateau.

We can also consider the opposite case, being the low $\mathrm{C}_{\mathrm{e}}$ region of the adsorption isotherm. When $C_{e}<<\left(C_{s}{ }^{*} q_{e}\right)$ and the majority of sorbate is removed by adsorption at equilibrium regardless of sorbent concentration, and increasing $C_{s}$ causes a decrease in $q_{e}$ as limited sorbate is divided across a larger surface area. In this case:

$$
q_{e(2)} \approx \frac{q_{e(1)}}{b}
$$

If Equation 15 based upon our observations from section 3.1 is still valid, then:

$$
k_{2(2)}=\frac{\text { initial rate }(2)}{q_{e(2)}{ }^{2}} \approx \frac{\text { initial rate }(1)}{\left(\frac{q_{e(1)}}{b}\right)^{2}} \approx \frac{b^{2} \times \text { initial rate }(1)}{q_{e(1)}{ }^{2}} \approx b^{2} k_{2(1)}
$$

Equation 18

Which gives a second-order dependence of $k_{2}$ upon $C_{s}$.

It therefore follows that the low and upper bounds of $k_{2}$ dependence upon $C_{s}$ are zero and secondorder respectively. These bounds fit the majority of data sets, as shown in Figure $3 \mathrm{~b}$. The final results for the order of reaction with respect to $C_{0}$ were $\bar{x}=1.16 \pm 1.28, \tilde{x}=1.39, N=11$ data sets and 43 kinetic experiments. Zero, first and second-order dependencies between $k_{2}$ and $C_{s}$ are all included within the standard deviation. Out of 11 data sets, three showed a relationship between $\mathrm{k}_{2}$ and $\mathrm{C}_{s}$ outside of the predicted constraints: methylene blue/raffia fibres demonstrated a dependency of $3.1 \pm 0.2$, and the two $\mathrm{Hg}(\mathrm{II}) /$ biosorbent data sets gave a dependency of $-1.1 \pm 0.2$.

Having demonstrated the conditionality of PSO rate constant $k_{2}$ with respect to $C_{0}$ and $C_{s}$, we investigated the implications of this conditionality with regards to predictive adsorption kinetic 
modelling. For predictive modelling, a single rate constant should be able to model experiments differing in $C_{0}$ and $C_{s}$. We used a single value of $k_{2}$, being the average value of $k_{2}$ for all kinetic experiments within a given data set, to model experiments with different initial conditions $\left(C_{0}\right.$ and $\left.C_{s}\right)$. The unique value of $\mathrm{q}_{\mathrm{e}}$ determined for each kinetic experiment was kept for modelling. All parameters are tabulated in the supplementary information. Figure 4 shows that the resulting PSO model cannot accurately describe data sets differing in $\mathrm{C}_{0}$ or $\mathrm{C}_{s}$ when a fixed value for rate constant $\mathrm{k}_{2}$ is used. The implication is that (a) the PSO cannot be used to predict changes in adsorption kinetics as a function of $\mathrm{C}_{0}$ and $\mathrm{C}_{5}$, and (b) comparison of the PSO rate constant, $\mathrm{k}_{2}$, between different literature studies, is only valid if PSO parameters were determined under the same experimental conditions $\left(C_{0}\right.$ and $\left.C_{s}\right)$.

(a)

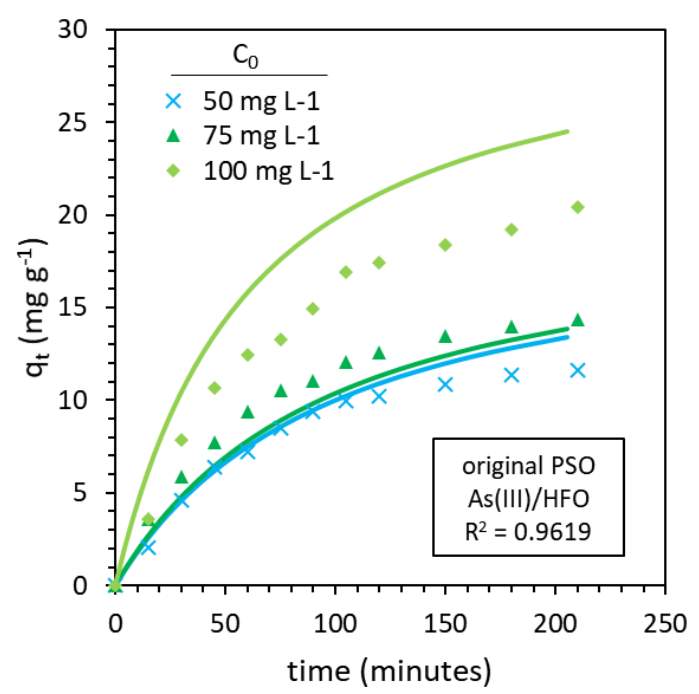

(c)

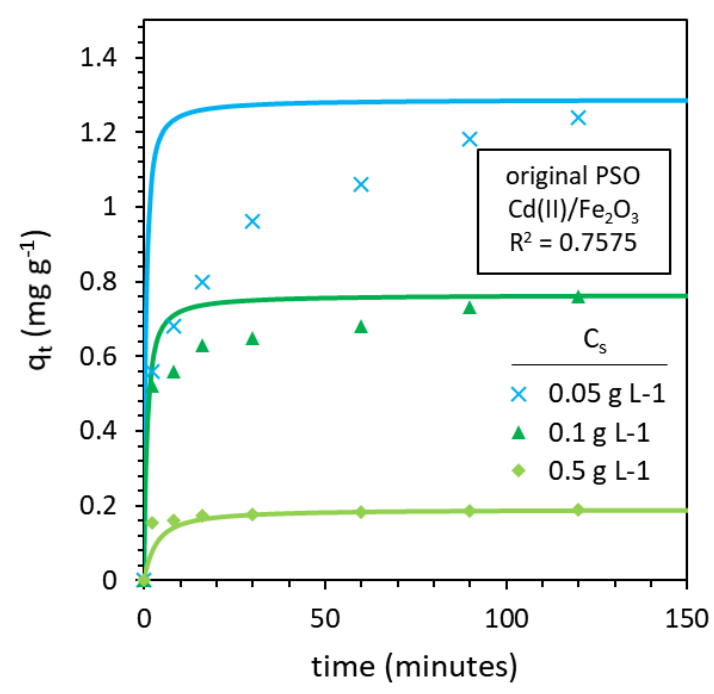

(b)

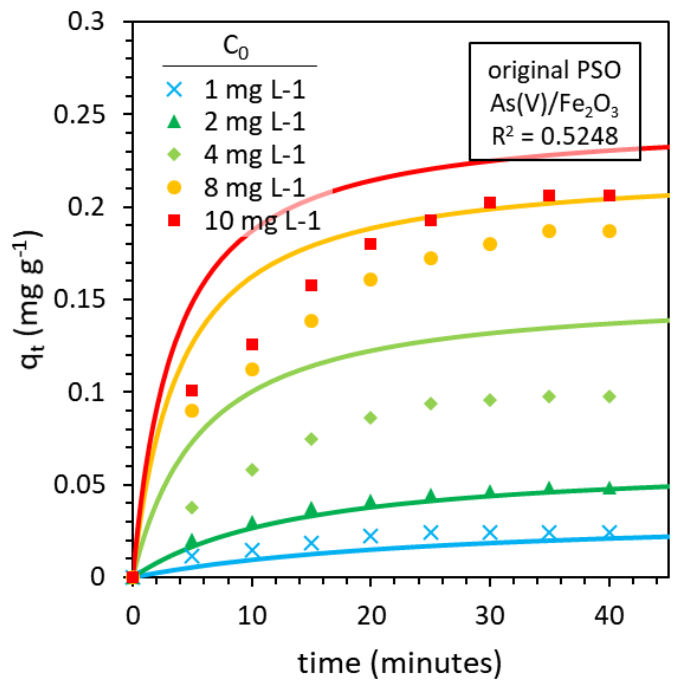

(d)

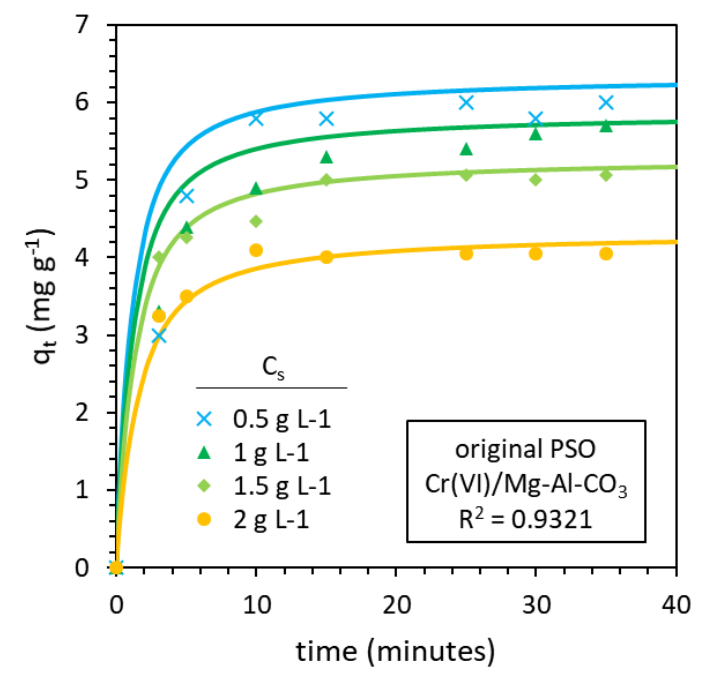

Figure 4: Demonstrating the lack of predictive capability in the PSO model due to the $C_{0}$ and $C_{5}$ conditionality of $k_{2}$. A selection of literature data sets were modelled using PSO kinetics with a single value of $k_{2}$, calculated as the average value of PSO rate constant, $k_{2}$, across all kinetic experiments within the given data set. (a) and (b) are data sets wherein $C_{0}$ is varied whilst (c) and (d) are data sets where $C_{s}$ is varied. Experimental data is from 22232420. 


\subsection{Development of a kinetic model sensitive to changes in $\mathrm{C}_{0}$ and $\mathrm{C}_{\mathrm{s}}$}

To provide sensitivity when predicting changes in adsorption kinetics due to changes in $C_{0}$ and $C_{s}$, we modified the PSO rate equation, giving a new pseudo-second order kinetic model, as follows. Firstly, to remove the inverse relationship between the rate constant upon $\mathrm{C}_{0}$ (Figure 3a), the right-hand side of the equation must be made proportional to $C_{0}$ (Figure 2a) and not proportional to $C_{0}{ }^{2}$, as the unmodified PSO equation approximates to through the term $\left(q_{\mathrm{e}}-\mathrm{q}_{\mathrm{t}}\right)^{2}$ (Equation 1). This problem is solved by replacing $\left(\mathrm{q}_{\mathrm{e}}-\mathrm{q}_{\mathrm{t}}\right)^{2}$, which provides second order dependence on the absolute amount of adsorption capacity remaining, with a new term providing second order dependence on the relative amount of adsorption capacity remaining. The term used herein is of the form $\left(1-\frac{q_{t}}{q_{e}}\right)^{2}$. This modification of Equation 1 gives the following:

$$
\frac{d q_{t}}{d_{t}}=k^{\prime}\left(1-\frac{q_{t}}{q_{e}}\right)^{2}
$$

Equation 19

where $\mathrm{k}^{\prime}=\mathrm{k}_{2} \mathrm{q}_{\mathrm{e}} *^{2}$. Here, $\mathrm{q}_{\mathrm{e}}{ }^{*}$ denotes the equilibrium concentration of adsorbed sorbate in the particular kinetic experiment used to calculate $\mathrm{k}_{2}$. At time $\mathrm{t}=0$, this new term, $\left(1-\frac{q_{t}}{q_{e}}\right)^{2}$, always returns a value of 1 , independent of the sorbate concentration.

The first order dependence of rate upon the sorbate concentration can then be explicitly defined, giving the final equation:

$$
\frac{d q_{t}}{d t}=k^{\prime} C_{t}\left(1-\frac{q_{t}}{q_{e}}\right)^{2}
$$

where $\mathrm{k}^{\prime}=\frac{\mathrm{k}_{2} \mathrm{q}_{\mathrm{e}} * 2}{\mathrm{C}_{0} *}$ with $\mathrm{C}_{0}{ }^{*}$ denoting the initial sorbate concentration in the kinetic experiment used to calculate $k_{2}$. Modification of the equation to this form, with second order dependence on the relative concentration of unused adsorption capacity rather than the absolute concentration, results in no change to adsorption kinetics when simulated under the same experimental conditions.

Figure $2 \mathrm{~b}$ demonstrated a first-order dependence of initial rate upon $\mathrm{C}_{\mathrm{s}}$ when normalised to volume $\left(\mathrm{mg} \mathrm{L}^{-1} \mathrm{~min}^{-1}\right)$ and zero order when normalised to sorbent mass $\left(\mathrm{mg} \mathrm{g}^{-1} \mathrm{~min}^{-1}\right)$. The current modified equation is dependent on the relative availability of adsorption capacity rather than the absolute availability. Any changes in $\mathrm{q}_{\mathrm{e}}$ due to varying $\mathrm{C}_{\mathrm{s}}$ do not affect the term $\left(1-\frac{\mathrm{q}_{\mathrm{t}}}{\mathrm{q}_{\mathrm{e}}}\right)^{2}$ at $\mathrm{t}=0$, as it continues to reduce to unity. Therefore, when the rate equation is normalised to $\mathrm{mg} \mathrm{g}^{-1} \mathrm{~min}^{-1}$ (i.e. $\frac{d q_{t}}{d t}$ rather than $\frac{d C_{t}}{d t}$ ) no modification of the rate equation for $C_{s}$ is required. Our modified rate equation, Equation 20 , is similar to the adsorption-only form of the kinetic Langmuir model $(\mathrm{kLm})$, which at high surface coverage is first order with respect to $\mathrm{C}_{\mathrm{t}}$ and second order to $\left(1-\frac{q_{t}}{q_{e}}\right) 2518$. 


\subsection{Confirming that $\mathbf{k}^{\prime}$ is less conditional than $\mathbf{k}_{2}$}

A predictive adsorption kinetic model, sensitive to changes in $C_{0}$ and $C_{s}$, requires a rate constant that is unaffected by either independent variable. Since the ideal rate constant is therefore entirely unaffected by changes to $C_{0}$ and $C_{s}$, the slope of $\log$ (initial rate) as a function of $\log \left(C_{0}\right) \operatorname{or} \log \left(C_{s}\right)$ should return a gradient of zero, indicating zero-order dependence. We calculated the dependency of $k^{\prime}$ upon $\mathrm{C}_{0}$ and $\mathrm{C}_{\mathrm{s}}$ identically as for $\mathrm{k}_{2}$ in section 3.2. We then validated whether $\mathrm{k}^{\prime}$ is less conditional than $\mathrm{k}_{2}$ by identifying whether $\Delta \log \left(k^{\prime}\right) / \Delta \log \left(C_{0}\right.$ or $\left.C_{s}\right)$ or $\Delta \log \left(k_{2}\right) / \Delta \log \left(C_{0}\right.$ or $\left.C_{s}\right)$ returns the gradient closes to zero.

The visual comparison of $k_{2}$ and $k^{\prime}$ dependencies upon $C_{0}$ and $C_{s}$ is given in Figure $5 . k_{2}$ displayed an inverse dependence on $C_{0}$ with $\bar{x}=-0.761 \pm 0.663, \tilde{x}=-0.765$, and an approximately first-order dependence on $C_{s}$ with $\bar{x}=1.16 \pm 1.28, \tilde{x}=1.39$. The new rate constant $k^{\prime}$ was significantly closer to zeroorder dependency than any other relationship with regards to both $C_{0}$ and $C_{s}$. For $C_{0}$ the results were $\bar{x}=-0.28 \pm 0.53, \tilde{x}=-0.38$ for $C_{0}$ dependency, and $\bar{x}=0.04 \pm 0.61, \tilde{x}=-0.02$ for $C_{s}$ dependency. The standard deviation values of $\mathrm{k}^{\prime}$ were also smaller than for $\mathrm{k}_{2}$, indicating that the relationships between independent variables and rate constants were most consistent across data sets for $\mathrm{k}^{\prime}$ than $\mathrm{k}_{2}$. These results suggest that the new rate constant $\mathrm{k}^{\prime}$ is less conditional than $\mathrm{k}_{2}$, and that the dependency of adsorption kinetics upon $C_{0}$ and $C_{s}$ has been captured by the new rate equation, at least in part, if not fully.

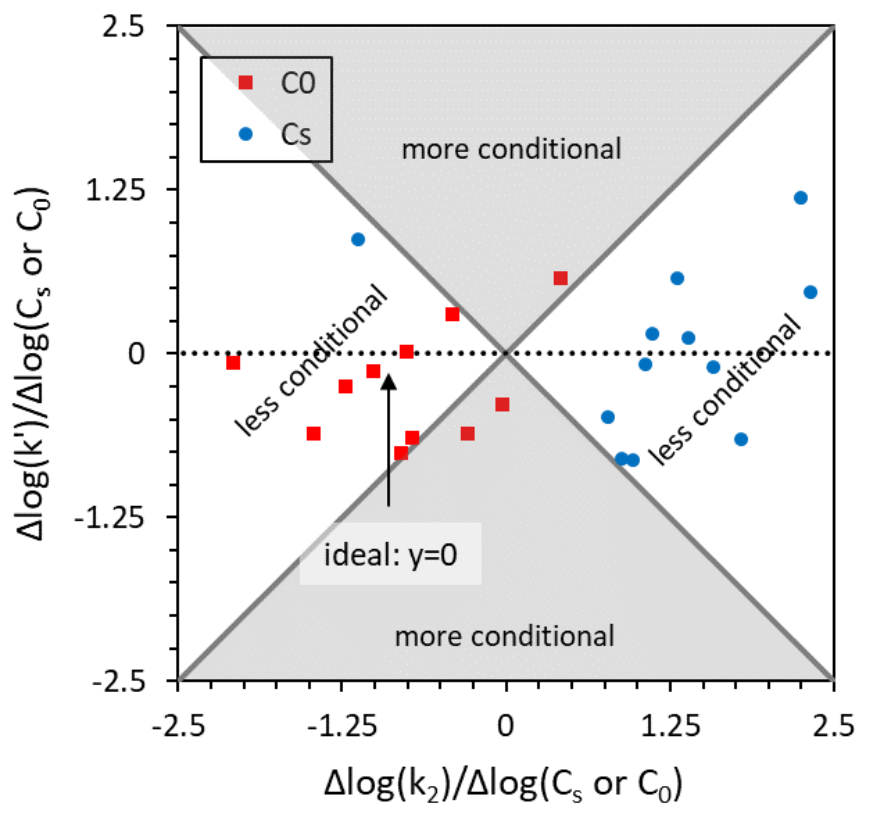

Figure 5: Mathematical demonstration of reduced sensitivity to $C_{0}$ and $C_{s}$ in the new rate constant $k^{\prime}$ compared with $k_{2}$. Where the rate constant is not influenced by changes in $C_{0}$ and $C_{s}$, a gradient of the $\log \left(\right.$ rate constant) versus either $\log \left(C_{0}\right) \operatorname{or} \log \left(C_{s}\right)$ will return a value of zero (indicating that the rate constant does not change). A value of +1 indicates a first order relationship, -1 indicates an inverse relationship and so on. The white shaded area of the plot indicates experimental data sets where $k^{\prime}$ was less sensitive to changes in $C_{0}$ and $C_{s}$ than $k_{2}$. The grey shaded area indicates data sets where $k^{\prime}$ varied more with changes in $C_{0}$ and $C_{s}$ than $k_{2}$.

\subsection{Use of adsorption isotherms for modelling adsorption kinetics}

The PSO model traditionally uses a unique, fixed value of $\mathrm{q}_{\mathrm{e}}$ to model each adsorption kinetic experiment. However, $\mathrm{q}_{\mathrm{e}}$ is sensitive to both $\mathrm{C}_{0}$ and $\mathrm{C}_{\mathrm{s}}$, and so the single value of $\mathrm{q}_{\mathrm{e}}$ obtained under 
one set of experimental conditions cannot be used to predict adsorption kinetics once $C_{0}$ and $C_{s}$ are changed. To provide appropriate sensitivity, the modified kinetic model must therefore have a $\mathrm{q}_{\mathrm{e}}$ term that is sensitive to sorbate concentration. This can be achieved by replacing $\mathrm{q}_{\mathrm{e}}$ with adsorption isotherms such as the Langmuir or Freundlich models ${ }^{21}$. Using adsorption isotherms, $q_{e}$ can either be set as the concentration of adsorbed sorbate at equilibrium (as per convention), or $\mathrm{q}_{\mathrm{e}}$ can be recalculated at each point in time, giving an out-of-equilibrium value of $\mathrm{q}_{\mathrm{e}}$ which decreases throughout the kinetic experiment as adsorption progress increases. In this second case, the term $\mathrm{C}_{\mathrm{e}}$ within the adsorption isotherm would be replaced with $C_{t}$. Huang et al. previously demonstrated that this second case actually gives better account of the true driving force of the reaction during the initial stages of adsorption ${ }^{26}$. Recalculating ' $\mathrm{qe}_{\mathrm{e}}$ ' using $\mathrm{C}_{\mathrm{t}}$ in this way is also more appropriate when modelling column systems, where $\mathrm{C}_{\mathrm{t}}<<\mathrm{C}_{\mathrm{e}}$ for the majority of the experiment. Langmuir and Freundlich adsorption isotherm data from the literature was incorporated into the modified rate equation (Equation 19), and a selection of data sets were then modelled using this approach, presented in section 3.6.

\subsection{Validating improvements in the modified equation}

In order to validate our modified model, we used Equation 19 to model the same selection of data sets previously modelled using the PSO model with an average value of $\mathrm{k}_{2}$ (Figure 4). A single value of $k^{\prime}$ was used to model all kinetic experiments within each data set, taken as the average value of $k^{\prime}$ across the data set. All parameters are tabulated in the supplementary information. The results are given in Figure 6 and in all cases the goodness of fit (represented by $R^{2}$ ) was improved compared with when predicting adsorption kinetics using the PSO model with a value of $k_{2}$ taken as the average between all kinetic experiments within the data set. The results were $R^{2}=0.9735$ vs. 0.9619 for $\mathrm{As}(\mathrm{III}) / \mathrm{HFO}$ (with $\mathrm{C}_{0}$ varied), $\mathrm{R}^{2}=0.8225$ vs. 0.5248 for $\mathrm{As}(\mathrm{V}) / \mathrm{Fe}_{2} \mathrm{O}_{3}\left(\mathrm{C}_{0}\right.$ varied), $\mathrm{R}^{2}=0.8833$ vs. 0.7575 for $\mathrm{Cd} / \mathrm{Fe}_{2} \mathrm{O}_{3}\left(\mathrm{C}_{\mathrm{s}}\right.$ varied) and $\mathrm{R}^{2}=0.9751$ vs. 0.9321 for $\mathrm{Cr}(\mathrm{VI}) / \mathrm{Mg}-\mathrm{Al}-\mathrm{CO}_{3}\left(\mathrm{C}_{\mathrm{s}}\right.$ varied). This is especially significant given that in section 3.2 a unique value of $\mathrm{q}_{\mathrm{e}}$ determined by experimental fitting was used for the PSO model, whilst for the modified kinetic model, $\mathrm{q}_{\mathrm{e}}$ was calculated using a single adsorption isotherm (Langmuir or Freundlich) for all kinetic experiments within the data set. The modified model thus not only provided a better fit than the unmodified pseudo-second order model, but provided a better fit whilst using fewer fitting parameters. 
(a)

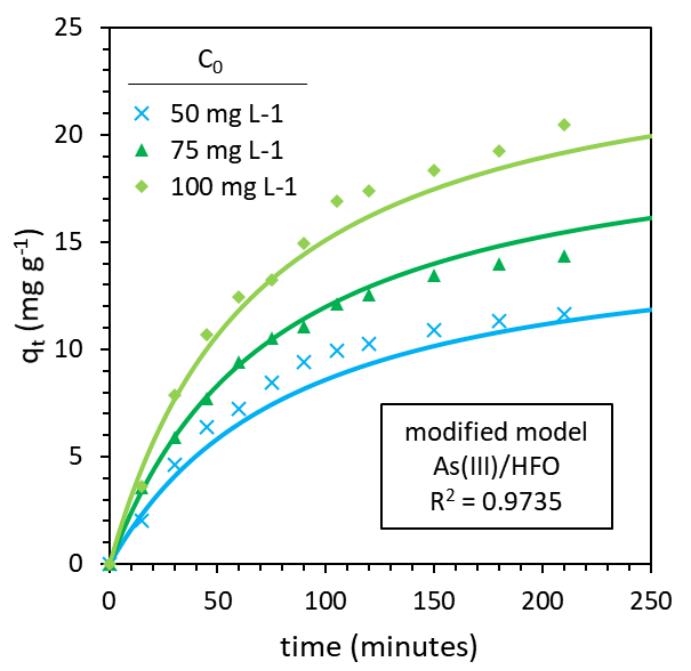

(c)

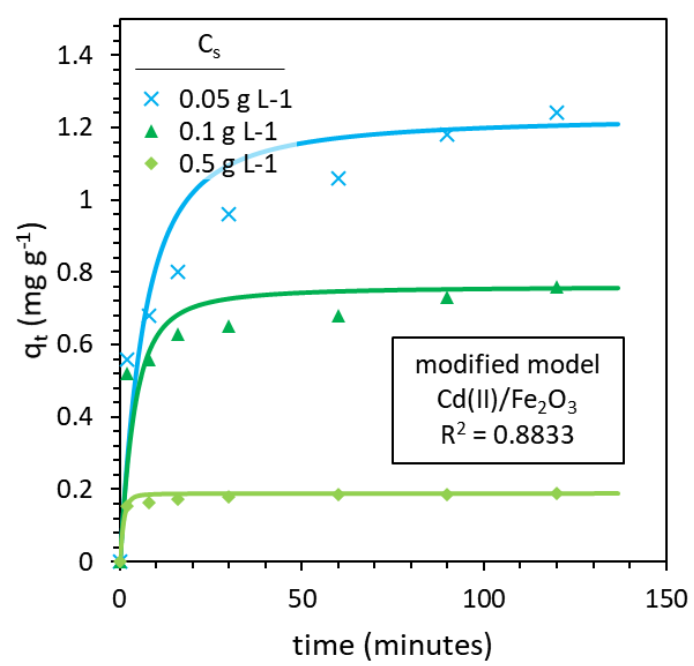

(b)

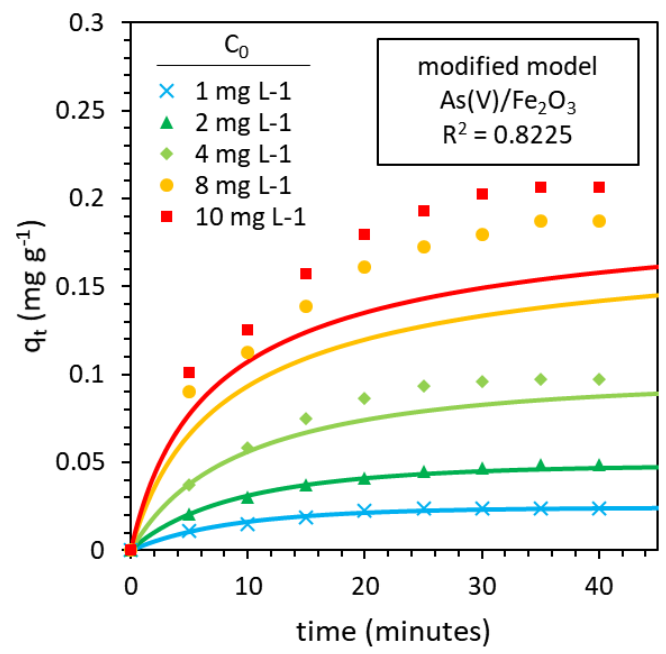

(d)

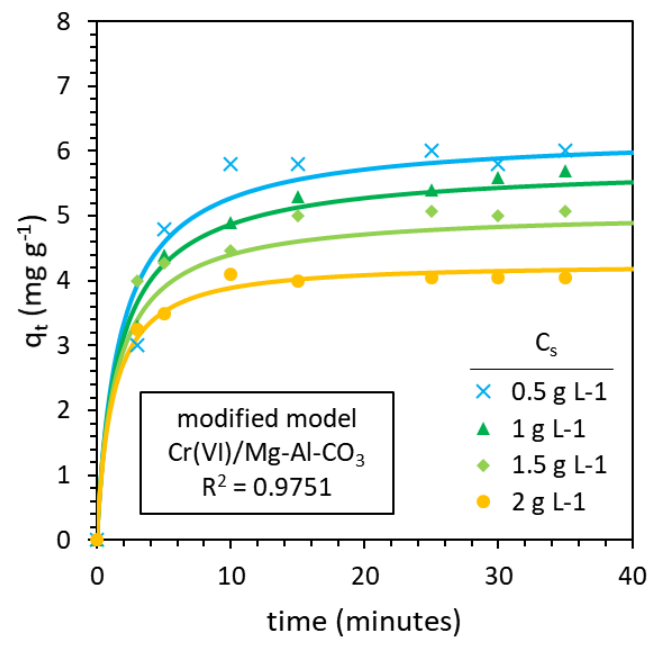

Figure 6: Modelling adsorption kinetics using the modified model. For each data set a single value of rate constant $k^{\prime}$ was used (chosen as the average value of $k^{\prime}$ between all kinetic experiments within the given data set) and $q_{e}$ was determined for all points in time, within all kinetic experiments using the same adsorption isotherm parameters. The single kinetic model was used to model experiments differing in $C_{0}$ ( $a$ and $b$ ) and $C_{s}$ ( $c$ and $d$ ). The Freundlich adsorption isotherm was used for all experiments in (a) and (d), and the Langmuir adsorption isotherm for all experiments in (c) and (d). Experimental data is from 22232420

The $\mathrm{q}_{\mathrm{t}}$ values predicted by the PSO and modified models were cross-calibrated against the values of $q_{t}$ observed experimentally (Figure 7). Using the unmodified PSO with a single value of $k_{2}$ but unique experimentally-fitted values of $q_{e}$ gave a cross-calibration slope of $1.0770 \pm 0.0186\left(R^{2}=0.9638\right)$, i.e. an error of $7.7 \%$ and uncertainty of $1.7 \%$ (Figure $7 \mathrm{a}$ ). The cross-calibration between experiment and model was improved when using the modified kinetic model, with a slope of $0.9598 \pm 0.0061\left(R^{2}=\right.$ 0.9949 ) - an error of $4.0 \%$ and an uncertainty of $0.6 \%$, both lower than in the unmodified PSO model. In the logarithmic form (Figure $7 \mathrm{~b}$ ) the cross-calibration slope of the modified model versus experiment was closer to unity with a gradient of $1.0117 \pm 0.0063$ and $R^{2}=0.9957$, indicating that the linear regression in the previous panel (Figure 7a) is skewed by the few data points at high $\mathrm{q}_{\mathrm{t}}$ values. Again, there is a better goodness of fit in the modified model compared with the original PSO (slope $=1.0104 \pm 0.0106$ and $R^{2}=0.9880$ ). The modified rate equation presented in this work therefore goes some way towards providing sensitivity towards changes in $\mathrm{C}_{0}$ and $\mathrm{C}_{\mathrm{s}}$. 
(a)

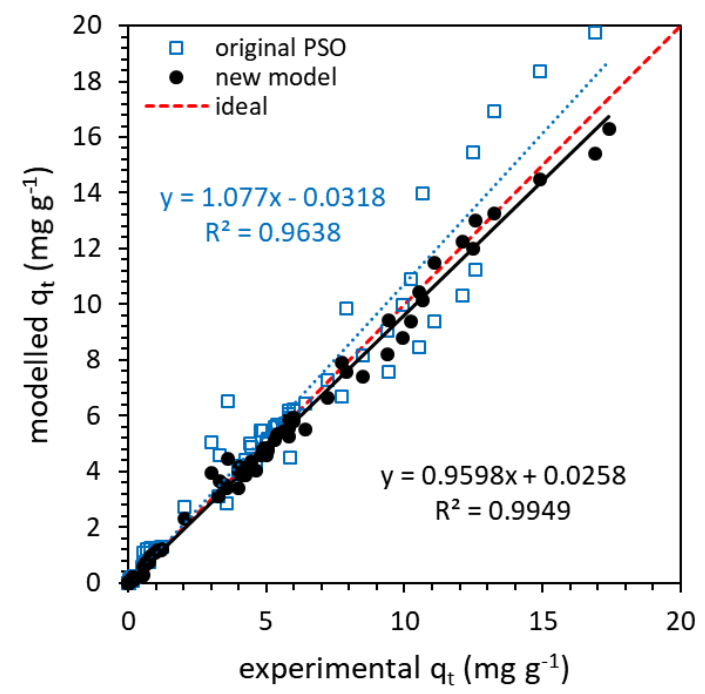

(b)

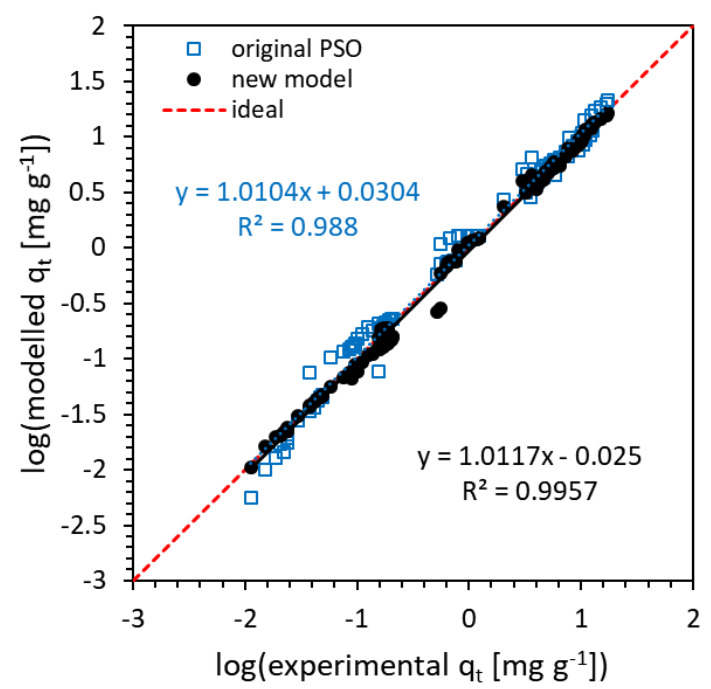

Figure 7: Calibration curves between the experimentally observed $q_{t}$ and $q_{t}$ predicted by the original PSO and modified kinetic models in (a) absolute form and (b) logarithmic form. Again, a single averaged value of $k^{\prime}$ was used to model all kinetic experiments in a single data set. $N=132$ data points were included in the calibration plots. Shown are data points for the original PSO model (blue open squares) and the modified model (black filled circles) along with their linear regressions (blue dotted and black solid lines respectively). The red dashed line indicates the one-to-one slope for a perfect model.

Using the original PSO model, two unique parameters $\left(\mathrm{k}_{2}\right.$ and $\left.\mathrm{q}_{\mathrm{e}}\right)$ were required for each kinetic experiment within each data set, and no predictive capability was offered. In the modified model, one kinetic parameter, rate constant $\mathrm{k}^{\prime}$, along with two adsorption isotherm parameters $\left(\mathrm{K}_{\mathrm{L}}\right.$ and $\mathrm{q}_{\max }$ for Langmuir or $\mathrm{K}_{\mathrm{F}}$ and $\mathrm{n}$ for Freundlich), can be used to model multiple kinetic experiments, offering some (though clearly imperfect) predictive capability.

\subsection{Influence of sorbent morphology on rate constant $\mathbf{k}^{\prime}$}

Whilst rate constants were successfully normalised to differences in experimental conditions $C_{0}$ and $\mathrm{C}_{\mathrm{s}}$ by converting the PSO model with rate constant $\mathrm{k}_{2}$ to the modified rate equation with rate constant $\mathrm{k}^{\prime}$, values of $\mathrm{k}^{\prime}$ calculated for given sorbate-sorbent combinations still showed significant variation across the literature (Supplementary Information). One important factor not yet discussed is sorbent morphology, i.e. particle size, porosity and surface area, which all vary depending on the preparation of the given sorbent sample. We thus investigated whether sorbent morphology accounts for the remaining variance in rate constants.

\subsubsection{Surface area}

The influence of surface area on the initial rate of reaction could not be probed as fully as the influence of $C_{0}$ and $C_{s}$ was in section 3.1, due to a lack of literature investigating the effects of surface area on adsorption kinetics. However, an example of the influence of surface area on initial kinetics is given in Figure 8. Instead, different literature sources with the same sorbate-sorbent combinations were compared on the basis of surface area. 


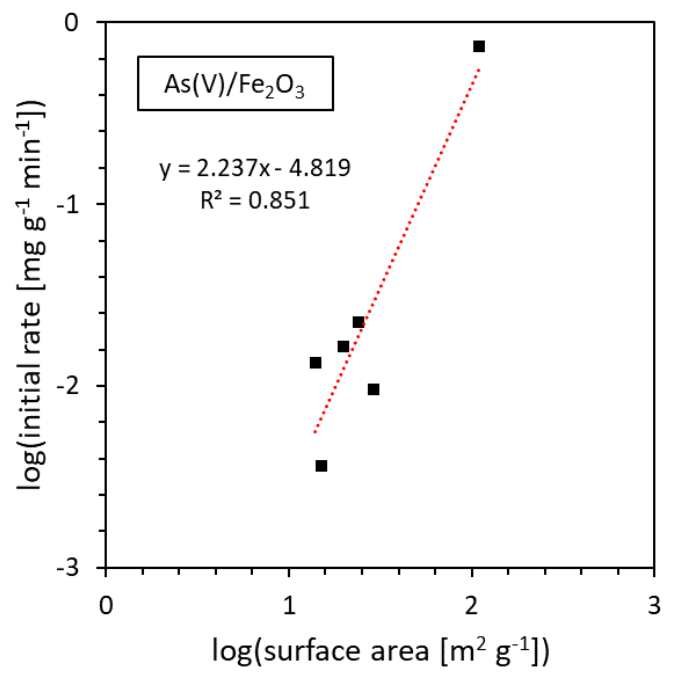

Figure 8: Example of the influence of surface area on initial kinetics. Experimental data from Di et al. ${ }^{27}$.

A correlation between increasing surface area and $\mathrm{k}^{\prime}$ was identified from a comparison of the compiled literature data (Figure 9). For arsenic oxyanions with mineral sorbents this correlation was weak: the average gradient of $\log \left(k^{\prime}\right)$ as a function of $\log \left(\right.$ surface area) was just $0.404 \pm 0.472\left(R^{2}=0.287\right.$ only, $N=5$ sorbate-sorbent combinations). The correlation was more significant when considering all arsenic oxyanion-sorbent combinations as a single data set, giving a gradient of $0.564 \pm 0.192\left(R^{2}=0.291, N=23\right.$ data sets). Whilst the upper bound of $\log \left(\mathrm{k}^{\prime}\right)$ values increased with increasing surface area, the lower bound changed little, and this generated the large uncertainty in the gradient and the source for low $R^{2}$ values.

Similar results were found for activated carbon/chitosan data sets: whilst the upper bound of $\log \left(\mathrm{k}^{\prime}\right)$ increased with surface area, the lower bound changed little. The average gradient was $0.150 \pm 0.167$ $\left(R^{2}=0.043, N=4\right.$ sorbate-sorbent combinations), whilst the combination of all data into a single data set gave a gradient of $0.197 \pm 0.535\left(\mathrm{R}^{2}=0.292, \mathrm{~N}=20\right)$. The fluoride $/ \mathrm{Al}_{2} \mathrm{O}_{3}$ and methylene blue $/ \mathrm{TiO}_{2}$ systems showed the strongest correlations. For fluoride $/ \mathrm{Al}_{2} \mathrm{O}_{3}$ the gradient was $4.36 \pm 2.49\left(\mathrm{R}^{2}=0.435\right.$, $\mathrm{N}=6)$, and for methylene blue/ $\mathrm{TiO}_{2}$ the gradient was $0.97 \pm 0.81\left(\mathrm{R}^{2}=0.419, \mathrm{~N}=3\right)$.

High surface areas can be achieved both by reducing particle radius and by introducing greater porosity. The poor goodness of fit in the linear regression might be due to a convolution of particle radius and porosity effects within the measured surface area, meaning that surface area is an inappropriate choice for constraining variables. It is also worth noting that the PSO rate constant $k_{2}$ tended to decrease with increasing surface area (Supplementary Information). This is explained by the term $\left(\mathrm{q}_{\mathrm{e}}-\mathrm{q}_{\mathrm{t}}\right)^{2}$ within the PSO rate equation and the fact that $\mathrm{q}_{\mathrm{e}}\left(\mathrm{mg} \mathrm{g}^{-1}\right)$ is roughly proportional to surface area. 
(a)

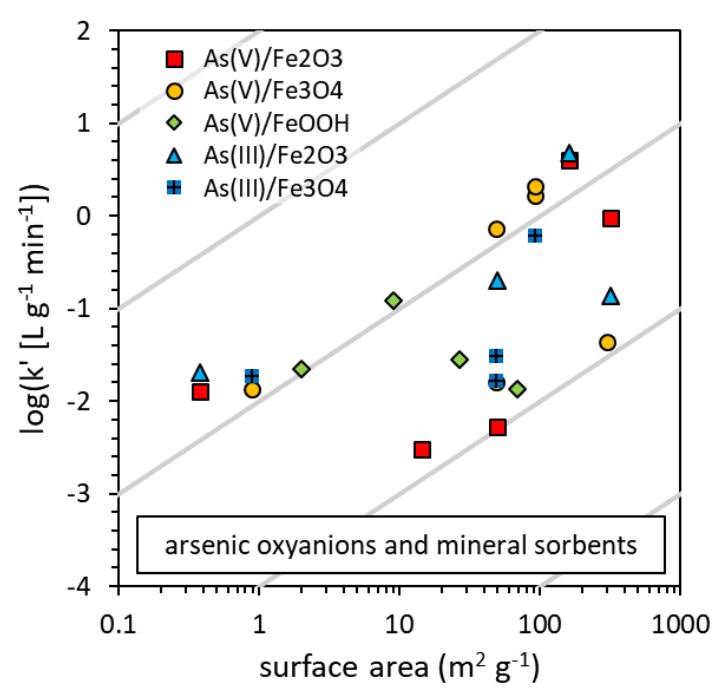

(c)

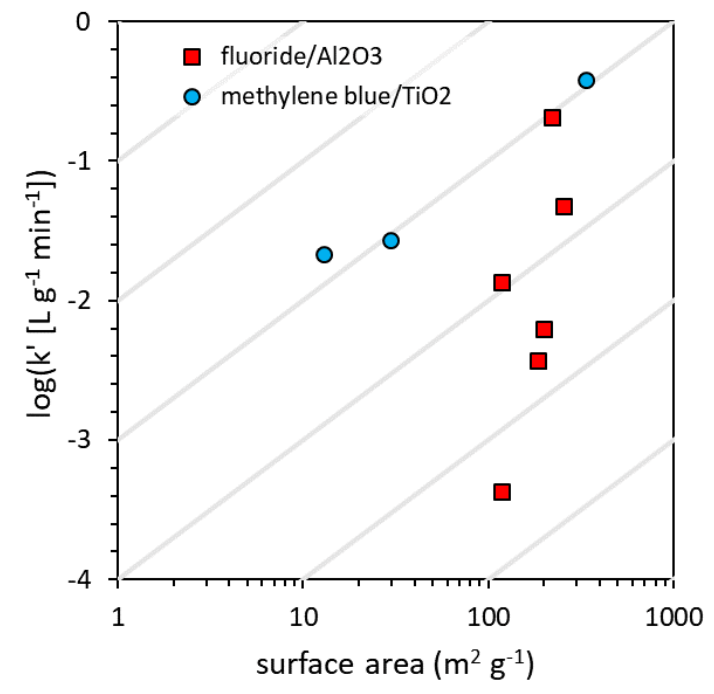

(b)

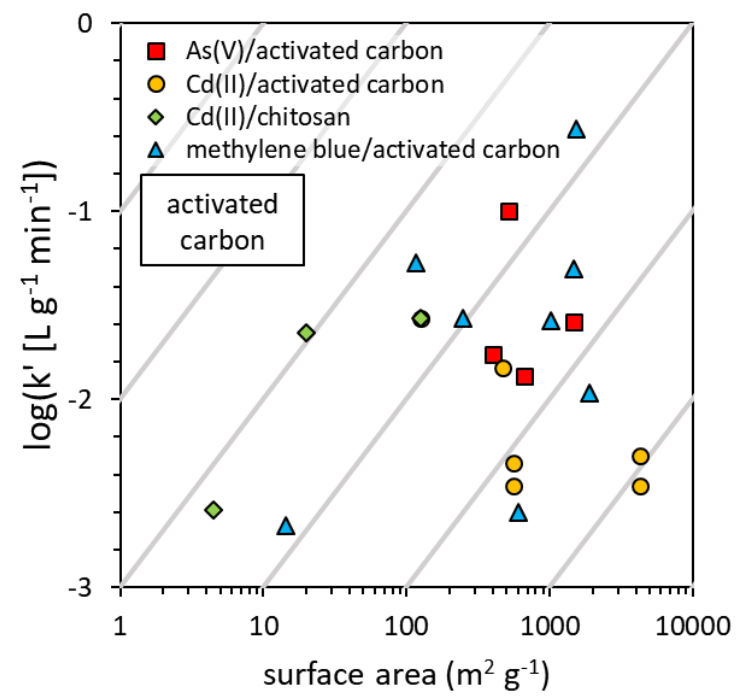

Figure 9: Greater values of rate constant $k^{\prime}$ were obtained with increasing surface area, demonstrated for (a) arsenic oxyanion and mineral sorbent systems, (b) activated carbon and chitosan systems, and (c) fluoride $/ \mathrm{Al}_{2} \mathrm{O}_{3}$ and methylene blue/TiO . Each data point within a given data set refers to a separate study, so despite sharing a chemical formula, the sorbents within a data set may differ in sorbent morphology. Grey lines indicate the 1:1 gradient between log( $\left.k^{\prime}\right)$ and log(surface area).

\subsubsection{Particle size}

In the intraparticle diffusion model, adsorption kinetics are controlled by the rate at which sorbate diffuses within sorbent pores ${ }^{28}$. One form of the intraparticle diffusion kinetic model is as follows:

$$
\frac{\delta q_{t}}{\delta t}=\frac{D}{r^{2}} \frac{\delta}{\delta r}\left(r^{2} \frac{\delta q_{t}}{\delta r}\right)
$$

Equation 21

where $D$ is the effective diffusivity of the sorbate, and $r$ is the radius of spherical sorbent particles ${ }^{29}$. In the intraparticle diffusion model the rate of adsorption is thus proportional to the inverse of $r^{2}$. 
The influence of particle size on adsorption kinetics has been investigated more thoroughly in the literature than the influence of surface area, so an analysis of initial rates was performed, with the dependence of initial rate, $\mathrm{k}^{\prime}$ and $\mathrm{k}_{2}$ upon particle radius illustrated in Figure 10 ( $\mathrm{N}=14$ data sets with 37 kinetic experiments). Due to the wide variety of techniques used to report particle size, values of $r$ have a large degree of uncertainty: the literature reported particle size as the size fractionation achieved through mesh sieving (either upper bounds, lower bounds, or both); the particle size distribution of sorbent suspensions determined by dynamic light scattering (itself strongly dependent on $\mathrm{pH}$ ); and from SEM and TEM images.

(a)

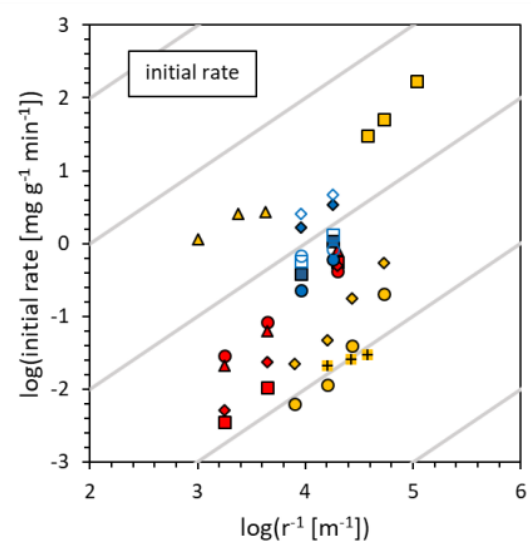

(b)

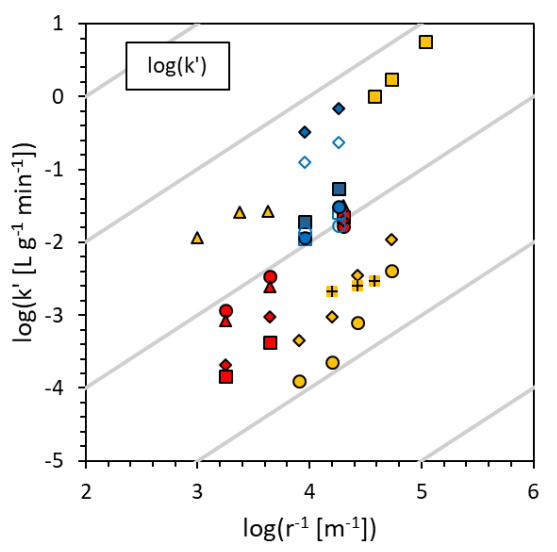

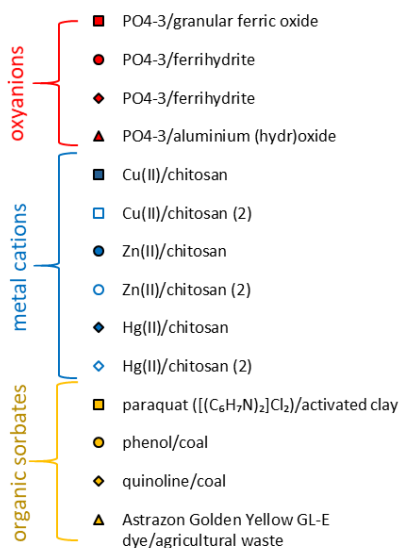

Figure 10: The relationship between (a) the initial rate and (b) $k^{\prime}$ and particle radius. Each data set is sourced from a separate study, i.e. all data points within a given data set uses the same sorbent, with the same morphology. Grey lines are a visual reference for the 1:1 gradient. The relationship between particle radius and $k_{2}$ is presented in the Supplementary Information.

$\log \left(\right.$ initial rate) as a function of $\log \left(\frac{1}{r}\right)$ gave an average gradient of $1.25 \pm 0.57(\tilde{x}=1.31)$. For $\log \left(k_{2}\right)$ the gradient was only $0.982 \pm 0.891(\tilde{x}=1.08)$. The new rate constant, as $\log \left(k^{\prime}\right)$, gave a gradient of $1.12 \pm 0.63$ $(\tilde{x}=1.15)$, lying between those of $\log \left(\right.$ initial rate) and $\log \left(k_{2}\right)$. This again suggests that the modified model gives a better description of kinetic sensitivities to experimental conditions, in this case, particle size. With a gradient of $1.25 \pm 0.57$, the dependence of initial rate upon particle radius was thus determined to be closer to first-order than second-order, in contradiction to the $\left(\frac{1}{r^{2}}\right)$ dependency of rate given by the intraparticle diffusion model (Equation 21).

Having determined the empirical relationship between initial rate, $\mathrm{k}^{\prime}$ and particle radius using the method of initial rates, we then investigated whether adsorption kinetic data reported in the literature using the same sorbate-sorbent concentrations could be rationalised on the basis of particle radius. The relationship between particle radius and $\log \left(\mathrm{k}^{\prime}\right)$ was weaker when incorporating multiple literature sources into a single sorbate-sorbent data set, compared with when using a single literature source where the influence of particle radius was explicitly investigated (Figure 11).

As discussed, using a single literature source for each sorbate-sorbent combination, an average gradient of $1.25 \pm 0.57$ was obtained (median=1.31, N=14 data sets ad 37 kinetic experiments), indicating a first-order, or greater than first-order, dependence of $k^{\prime}$ upon $1 / r$. However, when comparing the same sorbate-sorbent combinations but between different literature sources, the dependency was only $0.405 \pm 0.341(\tilde{x}=0.353, N=12$ data sets and 64 sources) indicating a relationship that is weaker than first-order (Figure 11a-d). In the first case, literature studies investigating the influence of particle size upon adsorption kinetics primarily achieved a range of sorbent particle sizes 
by size fractionation (sieving) which often maintained surface area and porosity ${ }^{30}$. In the second case where sorbate-sorbent combinations are compared between different literature sources, despite having the same chemical formula, sorbents were synthesised under different experimental conditions and the surface morphology and porosity cannot be assumed constant. Combining all data points, when not categorised into sets of the same sorbate-sorbent combination, a gradient of $0.329 \pm 0.095$ ( $N=12$ data sets and 64 sources) was obtained, not dissimilar to the gradient obtained when data was catalogued into same sorbate/sorbent combination sets.

With each sorbate-sorbent combination considered as a separate data set, the average order of reaction was $0.404 \pm 0.472$ with respect to surface area, and $0.405 \pm 0.341$ with respect to $1 / \mathrm{r}$. Combining all data points (with different sorbate-sorbent combinations) into a single data set gave an average order of reaction of $0.564 \pm 0.192$ with respect to surface area, and $0.329 \pm 0.095$ with respect to $1 / r$. In both cases the uncertainties in the linear regression between $\log \left(k^{\prime}\right)$ and $\log \left(r^{-1}\right)$ were smaller than the regression between $\log \left(\mathrm{k}^{\prime}\right)$ and $\log ($ surface area) both on an absolute and relative basis. Particle radius is thus a better constraining parameter for adsorption kinetics than surface area, and whilst rate constant $\mathrm{k}^{\prime}$ could not be normalised across literature data into a single unifying value on the basis of particle radius alone (Figure 11a-d), particle size is clearly an important factor in any discussion or cross-comparison of adsorption kinetics and normalised rate constants such as $\mathrm{k}^{\prime}$. 
(a)

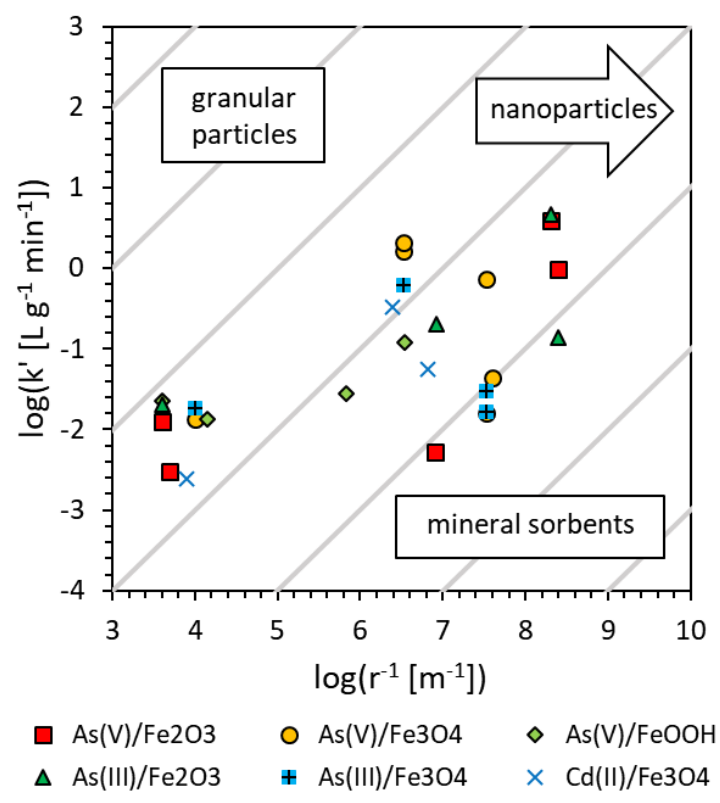

(c)

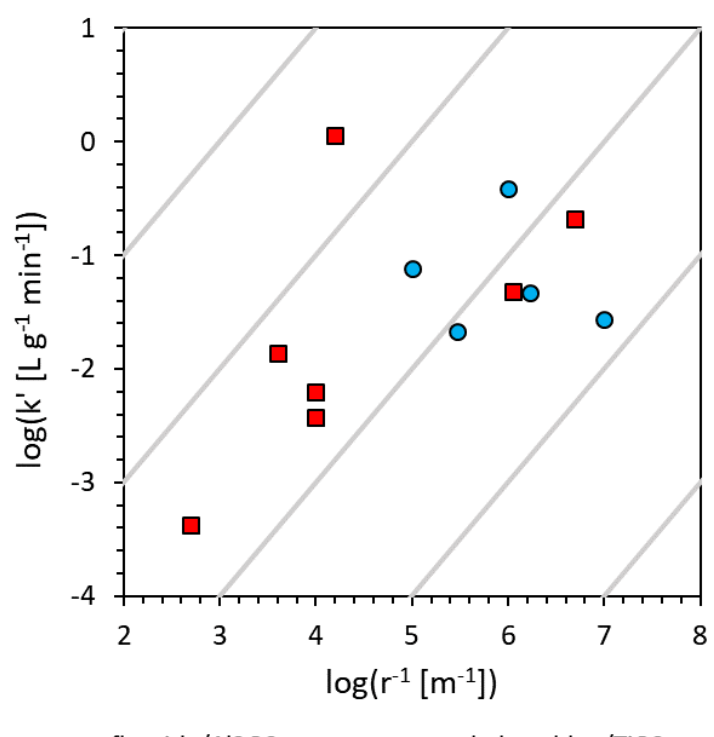

(b)

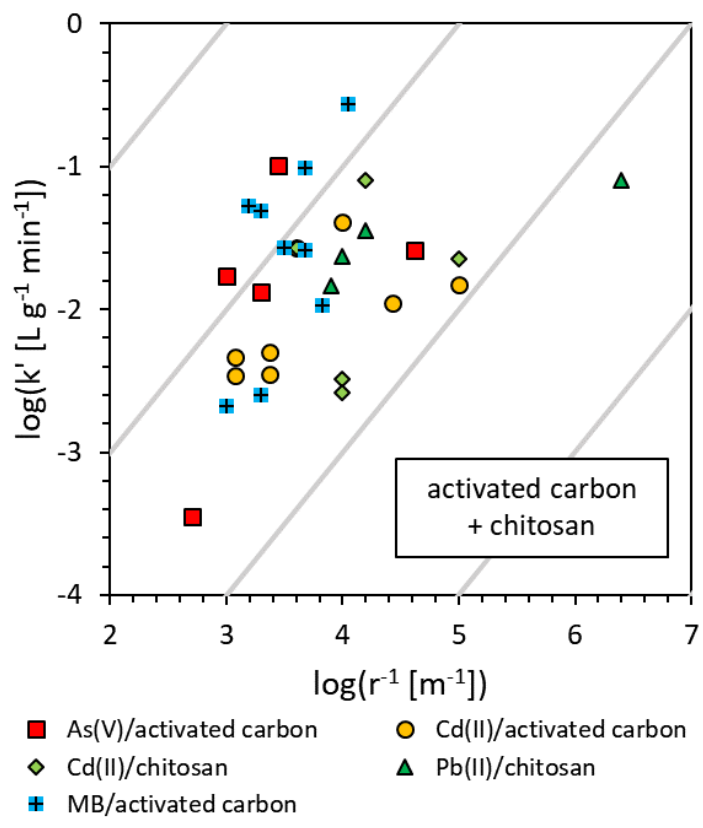

(d)

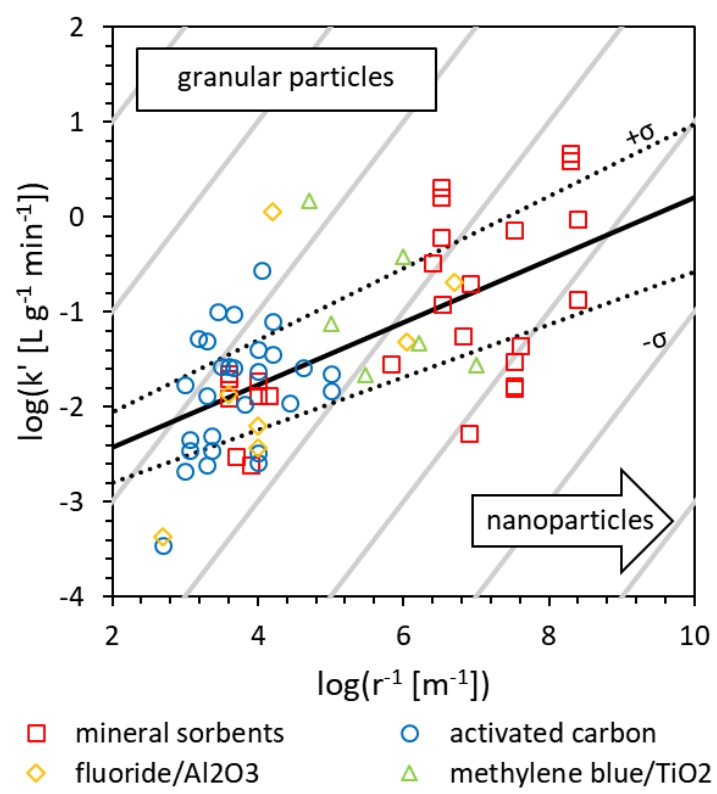

Figure 11: The relationship between $k^{\prime}$ and particle radius for (a) arsenic oxyanions/mineral sorbents, (b) activated carbon and chitosan sorbents, and (c) $\mathrm{F} / \mathrm{Al}_{2} \mathrm{O}_{3}$ and methylene blue/TiO ${ }_{2}$ systems. Each data point within a given data set is a separate study within the literature, i.e. despite sharing a chemical formula, data points within the set may differ in morphology. The solid and dashed black lines in figure (d) presents the average gradient of all data points combined into a single data set (0.329 \pm 0.051$)$. 


\section{Conclusions}

This work demonstrates that the PSO kinetic model can be made sensitive towards changes in initial sorbate concentration and sorbent concentration through modification into the form $\frac{d q_{t}}{d_{t}}=k^{\prime} C_{t}(1-$ $\left.\frac{q_{t}}{q_{e}}\right)^{2}$ where $\mathrm{k}^{\prime}=\frac{k_{2} q_{e} * 2}{C_{0} *}$. This model provides a better fit to experimental data varying in $\mathrm{C}_{0}$ and $\mathrm{C}_{\mathrm{s}}$ than the unmodified PSO with fewer fitting parameters, and therefore provides a limited amount of predictive capability. The new rate equation is similar to an adsorption-only form of the kinetic Langmuir model $(\mathrm{kLm})$, which at high surface coverage is first order with respect to $C_{t}$ and second order to $\left(1-\frac{q_{t}}{q_{e}}{ }^{25}{ }^{18}\right.$, however with fewer parameters it is simpler, and may be more useful for the non-expert. Furthermore, normalising conditional rate constants $\mathrm{k}_{2}$ to our new $\mathrm{k}^{\prime}$ is recommended to remove some of the error that arises when comparing literature adsorption kinetics data where experimental conditions are different ${ }^{15}$. Finally, we explored the influence of sorbent morphology upon rate constant $\mathrm{k}^{\prime}$ and demonstrated that particle size is a better constraining parameter than surface area. Particle radius was, however, insufficient to fully account for the variance remaining between experimentally determined values of rate constant, $\mathrm{k}^{\prime}$. This study indicates that the modified kinetic model and its rate constant are better equipped for comparing new sorbents with literature data than the original pseudo-second order model and $k_{2}$, with $k^{\prime}$ being easily calculated from PSO parameters through the expression $\mathrm{k}^{\prime}=\frac{k_{2} q_{e^{* 2}}}{C_{0}{ }^{*}}$.

\section{Acknowledgements}

The authors acknowledge support from the Engineering Physical Sciences Research Council (EPSRC) [grant number EP/N509486/1]. 


\section{References}

(1) Boddu, V. M.; Abburi, K.; Randolph, A. J.; Smith, E. D.; Boddu, V. M.; Abburi, K.; Randolph, A. J.; Edgar, D. Removal of Copper (II) and Nickel (II) lons from Aqueous Solutions by a Composite Chitosan Biosorbent. 2008, 6395 (li). https://doi.org/10.1080/01496390801940762.

(2) Linghu, W.; Yang, H.; Sun, Y.; Sheng, G.; Huang, Y. One-Pot Synthesis of LDH/GO Composites as Highly Effective Adsorbents for Decontamination of U(VI). ACS Sustain. Chem. Eng. 2017, 5 (6), 5608-5616. https://doi.org/10.1021/acssuschemeng.7b01303.

(3) Deng, L.; Shi, Z.; Peng, X. Adsorption of $\mathrm{Cr}(\mathrm{VI})$ onto a Magnetic CoFe2O4/MgAl-LDH Composite and Mechanism Study. RSC Adv. 2015, 49791-49801. https://doi.org/10.1039/c5ra06178d.

(4) D’Arcy, M.; Weiss, D.; Bluck, M.; Vilar, R. Adsorption Kinetics, Capacity and Mechanism of Arsenate and Phosphate on a Bifunctional TiO2-Fe2O3 Bi-Composite. J. Colloid Interface Sci. 2011, 364 (1), 205-212. https://doi.org/10.1016/j.jcis.2011.08.023.

(5) Chi, S.; Ji, C.; Sun, S.; Jiang, H.; Qu, R.; Sun, C. Magnetically Separated Meso-g-C3N4/Fe3O4: Bifuctional Composites for Removal of Arsenite by Simultaneous Visible-Light Catalysis and Adsorption. Ind. Eng. Chem. Res. 2016, 55 (46), 12060-12067. https://doi.org/10.1021/acs.iecr.6b02178.

(6) Dichiara, A. B.; Weinstein, S. J.; Rogers, R. E. On the Choice of Batch or Fixed Bed Adsorption Processes for Wastewater Treatment. Ind. Eng. Chem. Res. 2015, 54 (34), 8579-8586. https://doi.org/10.1021/acs.iecr.5b02350.

(7) Largitte, L.; Pasquier, R. A Review of the Kinetics Adsorption Models and Their Application to the Adsorption of Lead by an Activated Carbon. Chem. Eng. Res. Des. 2016, 109, 495-504. https://doi.org/10.1016/j.cherd.2016.02.006.

(8) Crank, J. Mathematics of Diffusion; Oxford at the Clarendon Press, 1956.

(9) Weber, W. Kinetics of Adsorption on Carbon from Solution. J. Sanit. Eng. Div. 1963.

(10) Qiu, H.; Lv, L.; Pan, B. C.; Zhang, Q. J.; Zhang, W. M.; Zhang, Q. X. Critical Review in Adsorption Kinetic Models. J. Zhejiang Univ. Sci. A 2009, 10 (5), 716-724. https://doi.org/10.1631/jzus.A0820524.

(11) Lagergren, S. Zur Theorie Der Sogenannten Adsorption Gelöster Stoffe. K. Sven. Vetenskapsakademiens. Handl. 1898, 24 (4), 1-39.

(12) Zeldowitsch, J. Über Den Mechanismus Der Katalytischen Oxydation von CO an MnO2. Acta Physicochim. U.R.S.S. 1934, No. 1, 364-449.

(13) Ho, Y. S.; McKay, G. Pseudo-Second Order Model for Sorption Processes. Process Biochem. 1999, 34 (5), 451-465. https://doi.org/10.1016/S0032-9592(98)00112-5.

(14) Simonin, J. P. On the Comparison of Pseudo-First Order and Pseudo-Second Order Rate Laws in the Modeling of Adsorption Kinetics. Chem. Eng. J. 2016, 300, 254-263. https://doi.org/10.1016/j.cej.2016.04.079.

(15) Wang, Z.; Giammar, D. E. Tackling Deficiencies in the Presentation and Interpretation of Adsorption Results for New Materials. Environ. Sci. Technol. 2019, 53 (10), 5543-5544. https://doi.org/10.1021/acs.est.9b02449.

(16) Plazinski, W.; Dziuba, J.; Rudzinski, W. Modeling of Sorption Kinetics: The Pseudo-Second Order Equation and the Sorbate Intraparticle Diffusivity. Adsorption 2013, 19 (5), 1055-1064. https://doi.org/10.1007/s10450-013-9529-0.

(17) Plazinski, W.; Rudzinski, W. Kinetics of Adsorption at Solid/Solution Interfaces Controlled by Intraparticle Diffusion: A Theoretical Analysis. J. Phys. Chem. C 2009, 113 (28), 12495-12501. https://doi.org/10.1021/jp902914z.

(18) Marczewski, A. W. Analysis of Kinetic Langmuir Model. Part I: Integrated Kinetic Langmuir Equation (IKL): 
A New Complete Analytical Solution of the Langmuir Rate Equation. Langmuir 2010, 26 (19), 1522915238. https://doi.org/10.1021/la1010049.

(19) Kirby, M. E.; Bullen, J. C.; Hanif, M. D.; Heiba, H. F.; Liu, F.; Northover, G. H. R.; Resongles, E.; Weiss, D. J. Determining the Effect of $\mathrm{PH}$ on Iron Oxidation Kinetics in Aquatic Environments: Exploring a Fundamental Chemical Reaction to Grasp the Significant Ecosystem Implications of Iron Bioavailability. J. Chem. Educ. 2019. https://doi.org/10.1021/acs.jchemed.8b01036.

(20) Lazaridis, N. K.; Pandi, T. A.; Matis, K. A. Chromium(VI) Removal from Aqueous Solutions by Mg-Al-CO3 Hydrotalcite: Sorption-Desorption Kinetic and Equilibrium Studies. Ind. Eng. Chem. Res. 2004, 43 (9), 2209-2215. https://doi.org/10.1021/ie030735n.

(21) Ayawei, N.; Ebelegi, A. N.; Wankasi, D. Modelling and Interpretation of Adsorption Isotherms. J. Chem. 2017, 2017. https://doi.org/10.1155/2017/3039817.

(22) Manna, B. R.; Dey, S.; Debnath, S.; Ghosh, U. C. Removal of Arsenic from Groundwater Using Crystalline Hydrous Ferric Oxide (CHFO). Water Qual. Res. J. Canada 2003, 38 (1), 193-210. https://doi.org/10.2166/wqrj.2003.013.

(23) Singh, D. B.; Prasad, G.; Rupainwar, D. C. Adsorption Technique for the Treatment of As(V)-Rich Effluents. Colloids Surfaces A Physicochem. Eng. Asp. 1996, 111 (1-2), 49-56. https://doi.org/10.1016/09277757(95)03468-4.

(24) Shipley, H. J.; Engates, K. E.; Grover, V. A. Removal of Pb(II), Cd(II), Cu(II), and Zn(II) by Hematite Nanoparticles: Effect of Sorbent Concentration, PH, Temperature, and Exhaustion. Environ. Sci. Pollut. Res. 2013, 20 (3), 1727-1736. https://doi.org/10.1007/s11356-012-0984-z.

(25) Azizian, S. Kinetic Models of Sorption: A Theoretical Analysis. J. Colloid Interface Sci. 2004, 276 (1), 4752. https://doi.org/10.1016/j.jcis.2004.03.048.

(26) Huang, Y.; Farooq, M. U.; Lai, S.; Feng, X.; Sampranpiboon, P.; Wang, X.; Huang, W. Model Fitting of Sorption Kinetics Data: Misapplications Overlooked and Their Rectifications. AlChE J. 2018, 64 (5), 17931805. https://doi.org/10.1002/aic.16051.

(27) Di, E.; Goo, H.; Liu, Y.; Cheng, Z. Arsenate Retention Mechanisms on Hematite with Different Morphologies Evaluated Using AFM , TEM Measurements and Vibrational Spectroscopy ScienceDirect Arsenate Retention Mechanisms on Hematite with Different Morphologies Evaluated Using AFM , TEM Measure. Geochim. Cosmochim. Acta 2018, 237 (July), 155-170. https://doi.org/10.1016/j.gca.2018.06.027.

(28) Simonin, J.; Boute, J. Intraparticle Diffusion-Adsorption Model to Describe Liquid / Solid Adsorption Kinetics. Rev. Mex. Ing. Quim. 2016, 15 (1), 161-173.

(29) Cooney, D. O.; Adesanya, B. A.; Hines, A. L. Effect of Particle Size Distribution on Adsorption Kinetics in Stirred Batch Systems. Chem. Eng. Sci. 1983, 38 (9), 1535-1541. https://doi.org/10.1007/978-1-44198074-8_10.

(30) Tsai, W. T.; Lai, C. W.; Hsien, K. J. Effect of Particle Size of Activated Clay on the Adsorption of Paraquat from Aqueous Solution. J. Colloid Interface Sci. 2003, 263 (1), 29-34. https://doi.org/10.1016/S00219797(03)00213-3. 
A revised pseudo-second order kinetic model for adsorptio... (1.89 MiB) view on ChemRxiv • download file 


\section{A revised pseudo-second order kinetic model for adsorption, sensitive to changes in sorbate and sorbent concentrations}

\section{Supplementary Information}

${ }^{1 *}$ Jay Bullen; ${ }^{1}$ Sarawud Saleesongsom; and ${ }^{1,2^{*}}$ Dominik J. Weiss

${ }^{1}$ Department of Earth Science and Engineering, Imperial College London, London SW7 2AZ, United Kingdom ${ }^{2}$ Civil and Environmental Engineering, Princeton University, United States of America

*Corresponding authors:

Email: j.bullen16@imperial.ac.uk; d.weiss@imperial.ac.uk

\section{Table of Contents}

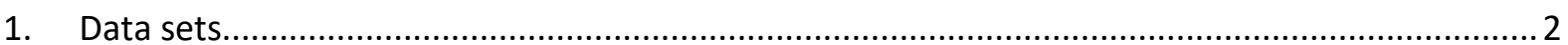

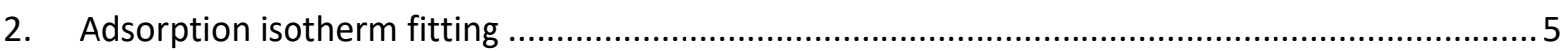

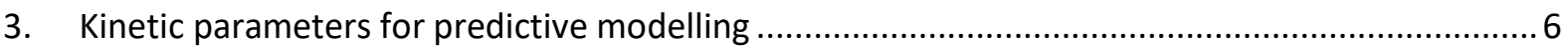

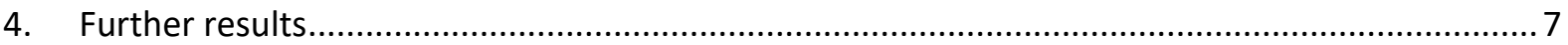

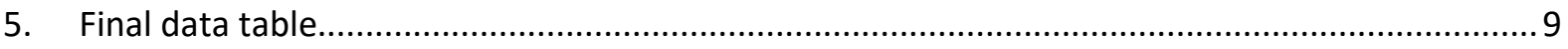

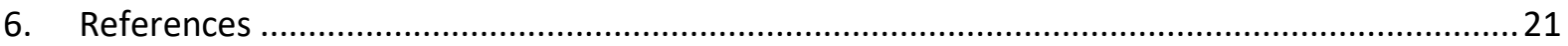




\section{Data sets}

Table 1: Data sets collected, and the experimental conditions varied across each set. $C_{0}$ is the initial sorbate concentrations ( $\left.m g L^{-1}\right), C_{s}$ is the sorbent concentration $\left(g L^{-1}\right)$ and $r$ is particle radius ( $\mathrm{nm}, \mu \mathrm{m}$ or $\mathrm{mm}$ ).

\begin{tabular}{|c|c|c|c|}
\hline Sorbate & Sorbent & Factor varied & Reference \\
\hline $\mathrm{As}(\mathrm{V})$ & $\mathrm{Fe}_{2} \mathrm{O}_{3}$ & $\begin{array}{c}\text { Initial sorbate } \\
\text { concentration, } C_{0}\end{array}$ & 1 \\
\hline $\mathrm{As}(\mathrm{V})$ & Laterite & $\mathrm{C}_{0}$ & 2 \\
\hline $\mathrm{As}(\mathrm{III})$ & Hydrous ferric oxide & $\mathrm{C}_{0}$ & 3 \\
\hline $\mathrm{HPO}_{4}{ }^{2-}$ & Iron hydroxide & $C_{0}$ & 4 \\
\hline $\mathrm{Cr}(\mathrm{VI})$ & Activated carbon & $\mathrm{C}_{0}$ & 5 \\
\hline $\mathrm{Cu}(\mathrm{II})$ & Soil & $\mathrm{C}_{0}$ & 6 \\
\hline $\mathrm{Zn}(\mathrm{II})$ & Soil & $\mathrm{C}_{0}$ & 6 \\
\hline $\mathrm{Pb}(\mathrm{II})$ & Soil & $\mathrm{C}_{0}$ & 6 \\
\hline $\mathrm{Hg}(\mathrm{II})$ & Raw activated sludge & $\mathrm{C}_{0}$ & 7 \\
\hline Rose Bengal dye & $\mathrm{ZnCl} 2$-activated carbon & $\mathrm{C}_{0}$ & 8 \\
\hline Rhodamine B & MgO-Fe-Co-Mn & $\mathrm{C}_{0}$ & 9 \\
\hline $\mathrm{Cr}(\mathrm{VI})$ & $\mathrm{Fe}_{2} \mathrm{O}_{3}$ & sorbent concentration, $C_{s}$ & 10 \\
\hline $\mathrm{Cr}(\mathrm{VI})$ & $\mathrm{Mg}-\mathrm{Al}-\mathrm{CO}_{3}$ & $\mathrm{C}_{\mathrm{s}}$ & 11 \\
\hline $\mathrm{Cr}(\mathrm{VI})$ & Chitin & $\mathrm{C}_{\mathrm{s}}$ & 12 \\
\hline $\mathrm{PO}_{4}^{3-}$ & $\begin{array}{l}\text { Peat/amorphous iron(III) } \\
\text { hydroxide }\end{array}$ & $\mathrm{C}_{\mathrm{s}}$ & 13 \\
\hline $\mathrm{Cr}(\mathrm{VI})$ & Guava seeds & $\mathrm{C}_{\mathrm{s}}$ & 14 \\
\hline $\mathrm{Cd}(\mathrm{II})$ & $\mathrm{Fe}_{2} \mathrm{O}_{3}$ & $\mathrm{C}_{s}$ & 15 \\
\hline $\mathrm{Cu}(\mathrm{II})$ & $\mathrm{Fe}_{2} \mathrm{O}_{3}$ & $\mathrm{C}_{\mathrm{s}}$ & 15 \\
\hline $\mathrm{Zn}(\mathrm{II})$ & $\mathrm{Fe}_{2} \mathrm{O}_{3}$ & $\mathrm{C}_{s}$ & 15 \\
\hline $\mathrm{Hg}(\mathrm{II})$ & Lessonia nigrescens (kelp) & $\mathrm{C}_{\mathrm{s}}$ & 16 \\
\hline $\mathrm{Hg}(\mathrm{II})$ & Lessonia trabeculata (kelp) & $\mathrm{C}_{\mathrm{s}}$ & 16 \\
\hline Eriochrome Black-T dye & $\mathrm{TiO}_{2}$ & $\mathrm{C}_{\mathrm{s}}$ & 17 \\
\hline Methylene blue & Rafia fibres & $\mathrm{C}_{\mathrm{s}}$ & 18 \\
\hline $\mathrm{PO}_{4}^{-3}$ & Granular ferric oxide & particle size, $r$ & 19 \\
\hline $\mathrm{PO}_{4}^{-3}$ & Ferrihydrite & r & 19 \\
\hline $\mathrm{PO}_{4}^{-3}$ & Ferrihydrite & $r$ & 19 \\
\hline $\mathrm{PO}_{4}^{-3}$ & Aluminium (hydr)oxide & $r$ & 19 \\
\hline $\mathrm{Cu}(\mathrm{II})$ & Chitosan & $r$ & 20 \\
\hline
\end{tabular}




\begin{tabular}{|c|c|c|c|}
\hline Sorbate & Sorbent & Factor varied & Reference \\
\hline $\mathrm{Zn}(\mathrm{II})$ & Chitosan & r & 20 \\
\hline $\mathrm{Hg}(\mathrm{II})$ & Chitosan & $r$ & 20 \\
\hline paraquat, $\left[\left(\mathrm{C}_{6} \mathrm{H}_{7} \mathrm{~N}\right)_{2}\right] \mathrm{Cl}_{2}$ & Activated clay & $r$ & 21 \\
\hline phenol & Coal & $r$ & 22 \\
\hline $\begin{array}{c}\text { Omega Chrome Red ME } \\
\text { dye }\end{array}$ & Fly ash & $r$ & 23 \\
\hline $\begin{array}{c}\text { Astrazon Golden Yellow GL- } \\
\text { E dye }\end{array}$ & Agricultural waste & $r$ & 24 \\
\hline $\mathrm{As}(\mathrm{V})$ & $\mathrm{Fe}_{2} \mathrm{O}_{3}$ & - & 1 \\
\hline $\mathrm{As}(\mathrm{V})$ & $\mathrm{Fe}_{2} \mathrm{O}_{3}$ & - & 25 \\
\hline $\operatorname{As}(\mathrm{V})$ & $\mathrm{Fe}_{2} \mathrm{O}_{3}$ & - & 26 \\
\hline $\mathrm{As}(\mathrm{V})$ & $\mathrm{Fe}_{2} \mathrm{O}_{3}$ & - & 27 \\
\hline As(V) & $\mathrm{Fe}_{2} \mathrm{O}_{3}$ & - & 28 \\
\hline $\mathrm{As}(\mathrm{V})$ & $\mathrm{Fe}_{2} \mathrm{O}_{3}$ & - & 29 \\
\hline $\mathrm{As}(\mathrm{V})$ & $\mathrm{Fe}_{3} \mathrm{O}_{4}$ & - & 27 \\
\hline $\operatorname{As}(\mathrm{V})$ & $\mathrm{Fe}_{3} \mathrm{O}_{4}$ & - & 30 \\
\hline $\mathrm{As}(\mathrm{V})$ & $\mathrm{Fe}_{3} \mathrm{O}_{4}$ & - & 31 \\
\hline $\operatorname{As}(\mathrm{V})$ & $\mathrm{Fe}_{3} \mathrm{O}_{4}$ & - & 32 \\
\hline $\mathrm{As}(\mathrm{V})$ & $\mathrm{Fe}_{3} \mathrm{O}_{4}$ & - & 33 \\
\hline $\operatorname{As}(\mathrm{V})$ & $\mathrm{Fe}_{3} \mathrm{O}_{4}$ & - & 30 \\
\hline $\operatorname{As}(\mathrm{V})$ & $\mathrm{FeOOH}$ & - & 34 \\
\hline $\mathrm{As}(\mathrm{V})$ & $\mathrm{FeOOH}$ & - & 27 \\
\hline $\operatorname{As}(\mathrm{V})$ & $\mathrm{FeOOH}$ & - & 35 \\
\hline $\mathrm{As}(\mathrm{V})$ & $\mathrm{FeOOH}$ & - & 36 \\
\hline $\operatorname{As}(\mathrm{V})$ & $\mathrm{FeOOH}$ & - & 37 \\
\hline $\mathrm{As}(\mathrm{III})$ & $\mathrm{Fe}_{2} \mathrm{O}_{3}$ & - & 26 \\
\hline $\mathrm{As}(\mathrm{III})$ & $\mathrm{Fe}_{2} \mathrm{O}_{3}$ & - & 27 \\
\hline $\mathrm{As}(\mathrm{III})$ & $\mathrm{Fe}_{2} \mathrm{O}_{3}$ & - & 28 \\
\hline $\mathrm{As}(\mathrm{III})$ & $\mathrm{Fe}_{2} \mathrm{O}_{3}$ & - & 29 \\
\hline $\mathrm{As}(\mathrm{III})$ & $\mathrm{Fe}_{3} \mathrm{O}_{4}$ & - & 27 \\
\hline $\mathrm{As}(\mathrm{III})$ & $\mathrm{Fe}_{3} \mathrm{O}_{4}$ & - & 30 \\
\hline $\mathrm{As}(\mathrm{III})$ & $\mathrm{Fe}_{3} \mathrm{O}_{4}$ & - & 32 \\
\hline $\mathrm{As}(\mathrm{V})$ & Activated carbon & - & 38 \\
\hline
\end{tabular}




\begin{tabular}{|c|c|c|c|}
\hline Sorbate & Sorbent & Factor varied & Reference \\
\hline $\operatorname{As}(\mathrm{V})$ & Activated carbon & - & 39 \\
\hline $\mathrm{As}(\mathrm{V})$ & Activated carbon & - & 40 \\
\hline $\mathrm{As}(\mathrm{V})$ & Activated carbon & - & 41 \\
\hline $\mathrm{As}(\mathrm{V})$ & Activated carbon & - & 42 \\
\hline $\mathrm{Cd}(\mathrm{II})$ & Activated carbon & - & 43 \\
\hline $\mathrm{Cd}(\mathrm{II})$ & Activated carbon & - & 44 \\
\hline $\mathrm{Cd}(\mathrm{II})$ & Activated carbon & - & 45 \\
\hline $\mathrm{Cd}(\mathrm{II})$ & Activated carbon & - & 46 \\
\hline $\mathrm{Cd}(\mathrm{II})$ & Activated carbon & - & 47 \\
\hline $\mathrm{Cd}(\mathrm{II})$ & Activated carbon & - & 48 \\
\hline Methylene blue & Activated carbon & - & 49 \\
\hline Methylene blue & Activated carbon & - & 50 \\
\hline Methylene blue & Activated carbon & - & 51 \\
\hline Methylene blue & Activated carbon & - & 52 \\
\hline Methylene blue & Activated carbon & - & 53 \\
\hline Methylene blue & Activated carbon & - & 54 \\
\hline Methylene blue & Activated carbon & - & 55 \\
\hline Methylene blue & Activated carbon & - & 56 \\
\hline Methylene blue & Activated carbon & - & 57 \\
\hline Methylene blue & Activated carbon & - & 58 \\
\hline $\mathrm{Cd}(\mathrm{II})$ & Chitosan & - & 59 \\
\hline $\mathrm{Cd}(\mathrm{II})$ & Chitosan & - & 60 \\
\hline $\mathrm{Cd}(\mathrm{II})$ & Chitosan & - & 61 \\
\hline $\mathrm{Cd}(\mathrm{II})$ & Chitosan & - & 62 \\
\hline $\mathrm{Cd}(\mathrm{II})$ & Chitosan & - & 63 \\
\hline $\mathrm{Cd}(\mathrm{II})$ & Chitosan & - & 64 \\
\hline Methylene blue & $\mathrm{TiO}_{2}$ & - & 65 \\
\hline Methylene blue & $\mathrm{TiO}_{2}$ & - & 66 \\
\hline Methylene blue & $\mathrm{TiO}_{2}$ & - & 67 \\
\hline Methylene blue & $\mathrm{TiO}_{2}$ & - & 68 \\
\hline Methylene blue & $\mathrm{TiO}_{2}$ & - & 69 \\
\hline Methylene blue & $\mathrm{TiO}_{2}$ & - & 70 \\
\hline
\end{tabular}




\begin{tabular}{|c|c|c|c|}
\hline Sorbate & Sorbent & Factor varied & Reference \\
\hline Methylene blue & $\mathrm{TiO}_{2}$ & - & 71 \\
\hline Methylene blue & $\mathrm{TiO}_{2}$ & - & 73 \\
\hline Fluoride & $\mathrm{Al}_{2} \mathrm{O}_{3}$ & - & 74 \\
\hline Fluoride & $\mathrm{Al}_{2} \mathrm{O}_{3}$ & - & 76 \\
\hline Fluoride & $\mathrm{Al}_{2} \mathrm{O}_{3}$ & - & 77 \\
\hline Fluoride & $\mathrm{Al}_{2} \mathrm{O}_{3}$ & - & 78 \\
\hline Fluoride & $\mathrm{Al}_{2} \mathrm{O}_{3}$ & - & 79 \\
\hline Fluoride & $\mathrm{Al}_{2} \mathrm{O}_{3}$ & - & 79 \\
\hline Fluoride & $\mathrm{Al}_{2} \mathrm{O}_{3}$ & & 7 \\
\hline
\end{tabular}

\section{Adsorption isotherm fitting}

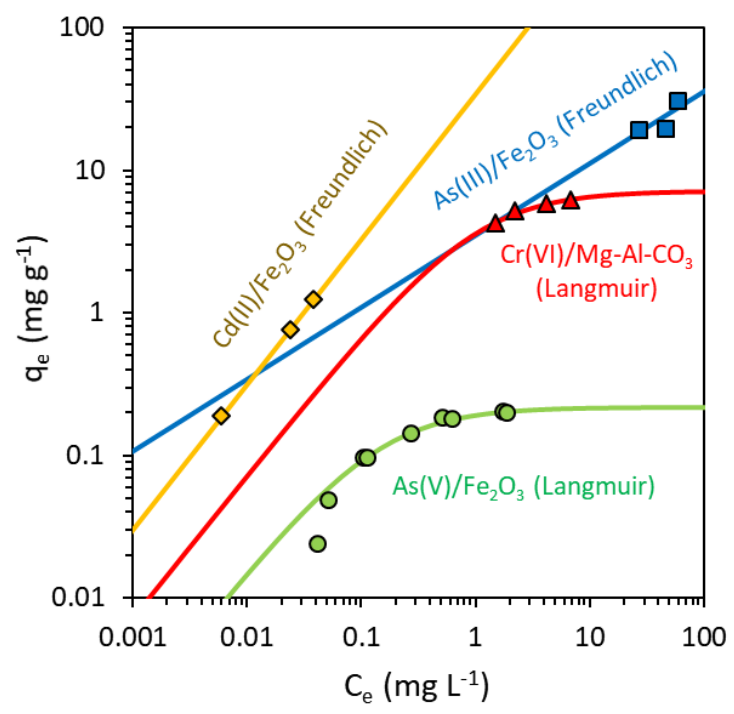

Figure 1: Adsorption isotherms were fit using experimental data and then used to recalculate $q_{e}$ at each point in time when modelling kinetic experiments using our modified form of the pseudo-second order rate equation. 
3. Kinetic parameters for predictive modelling

Table 2: Parameters used to model selected data sets using the PSO model and the modified model, using a single rate constant to model experimental data where $C_{0}$ and $C_{s}$ are varied.

\begin{tabular}{|c|c|c|c|c|c|c|c|c|c|c|c|}
\hline \multirow{3}{*}{ system } & \multirow{3}{*}{$\begin{array}{c}\mathrm{C}_{0} \\
\left(\mathrm{mg} \mathrm{L}^{-1}\right)\end{array}$} & \multirow{3}{*}{$\begin{array}{c}\mathrm{C}_{\mathrm{s}} \\
\left(\mathrm{g} \mathrm{L}^{-1}\right)\end{array}$} & \multicolumn{3}{|c|}{ PSO model } & \multicolumn{6}{|c|}{ modified model } \\
\hline & & & \multirow{2}{*}{$\begin{array}{c}\mathrm{k}_{2} \\
\left(\mathrm{~g} \mathrm{mg}^{-1}\right. \\
\left.\mathrm{min}^{-1}\right)\end{array}$} & \multirow{2}{*}{$\begin{array}{c}\mathrm{qe}_{\mathrm{e}} \\
\left(\mathrm{mg} \mathrm{g}^{-1}\right)\end{array}$} & \multirow{2}{*}{$R^{2}$} & \multirow{2}{*}{$\begin{array}{c}k^{\prime} \\
\left(\mathrm{Lg}^{-1} \min ^{-1}\right)\end{array}$} & \multicolumn{2}{|c|}{ Langmuir parameters } & \multicolumn{2}{|c|}{ Freundlich parameters } & \multirow{2}{*}{$\mathrm{R}^{2}$} \\
\hline & & & & & & & $\begin{array}{c}\mathrm{KL} \\
\left(\mathrm{L} \mathrm{mg}^{-1}\right)\end{array}$ & $\begin{array}{c}Q_{\max } \\
\left(\mathrm{mg} \mathrm{L}^{-1}\right)\end{array}$ & $\begin{array}{c}\mathrm{K}_{\mathrm{F}} \\
\left(\mathrm{mg} \mathrm{g}^{-1}\left(\mathrm{mg} \mathrm{L}^{-1}\right)^{-1 / n}\right) \\
\end{array}$ & $n$ & \\
\hline \multirow{3}{*}{$\mathrm{As}(\mathrm{III}) / \mathrm{HFO}$} & 50 & 2 & \multirow{3}{*}{0.00053} & 19.3 & \multirow{3}{*}{0.9619} & \multirow{3}{*}{0.0036} & & & \multirow{3}{*}{3.5} & \multirow{3}{*}{1.98} & \multirow{3}{*}{0.9735} \\
\hline & 75 & 2 & & 19.8 & & & & & & & \\
\hline & 100 & 2 & & 31.1 & & & & & & & \\
\hline \multirow{5}{*}{$\mathrm{As}(\mathrm{V}) / \mathrm{Fe}_{2} \mathrm{O}_{3}$} & 1 & 40 & \multirow{5}{*}{1.10} & 0.034 & \multirow{5}{*}{0.5248} & \multirow{5}{*}{0.0029} & \multirow{5}{*}{7.21} & \multirow{5}{*}{0.22} & & & \multirow{5}{*}{0.7968} \\
\hline & 2 & 40 & & 0.063 & & & & & & & \\
\hline & 4 & 40 & & 0.15 & & & & & & & \\
\hline & 8 & 40 & & 0.22 & & & & & & & \\
\hline & 10 & 40 & & 0.25 & & & & & & & \\
\hline \multirow{3}{*}{$\mathrm{Cd}(\mathrm{II}) / \mathrm{Fe}_{2} \mathrm{O}_{3}$} & 0.1 & 0.05 & \multirow{3}{*}{1.46} & 1.29 & \multirow{3}{*}{0.7575} & \multirow{3}{*}{1.72} & & & \multirow{3}{*}{34.4} & \multirow{3}{*}{0.98} & \multirow{3}{*}{0.7617} \\
\hline & 0.1 & 0.1 & & 0.77 & & & & & & & \\
\hline & 0.1 & 0.5 & & 0.19 & & & & & & & \\
\hline \multirow{4}{*}{$\begin{array}{l}\mathrm{Cr}(\mathrm{VI}) / \mathrm{Mg}- \\
\mathrm{Al}^{-\mathrm{CO}_{3}}\end{array}$} & 10 & 0.5 & & 7.33 & & & & & & & \\
\hline & 10 & 1 & דרי & 6.11 & 08275 & 020 & 000 & 720 & & & 0.727 \\
\hline & 10 & 1.5 & 0.127 & 5.28 & 0.8323 & 0.34 & 0.99 & 1.20 & & & $0.8 / 32$ \\
\hline & 10 & 2 & & 4.32 & & & & & & & \\
\hline
\end{tabular}




\section{Further results}

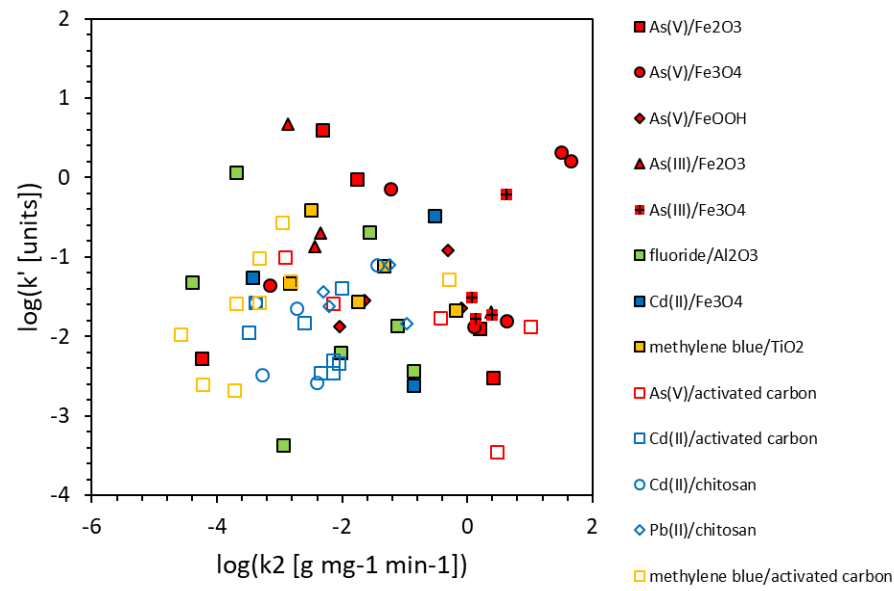

Figure 2: After normalising for $C_{0}$ and $C_{s}$, significant variation in $k^{\prime}$ remains between different literature sources. This is at least partially due to differences in sorbent morphology.

(a)

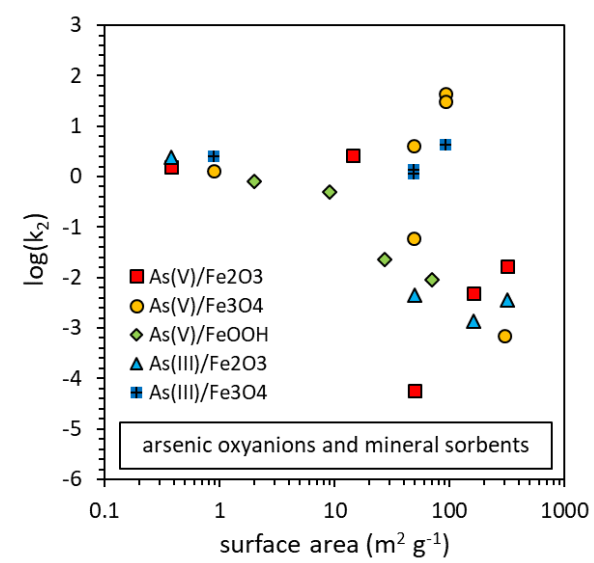

(c)

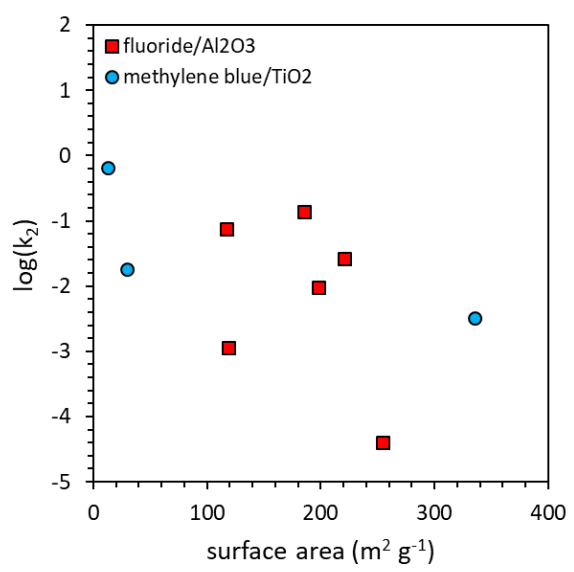

(b)

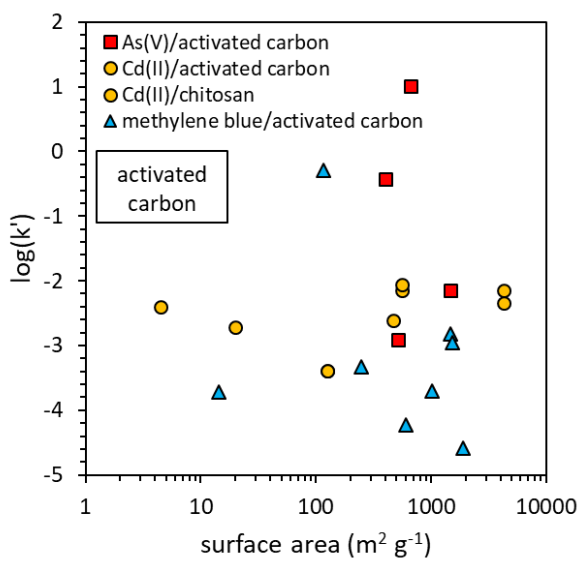

Figure 3: Influence of surface area on $\log \left(k_{2}\right)$. 

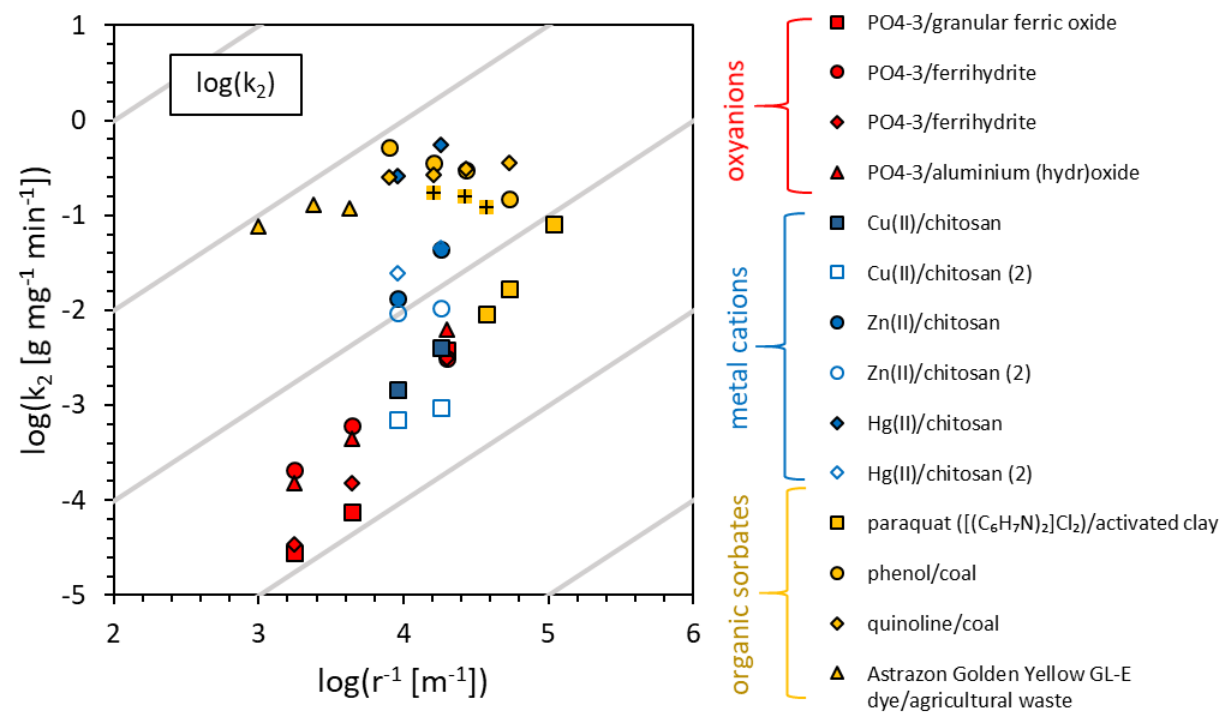

Figure 4: Influence of particle size on $\log \left(k_{2}\right)$. 


\section{Final data table}

Table 3: Initial sorbate concentration $\left(C_{0}\right)$, sorbent concentration $\left(C_{s}\right)$, surface area and particle size as well as the calculated values of PSO rate constant $k_{2}$, new rate constant $k^{\prime}$, and the initial rate (calculated via the PSO model), for adsorption kinetic experiments collected from the literature. In most cases, but not all, $q_{e}$ and $k_{2}$ were calculated in this work. In a few other cases these parameters have been pulled directly from the literature.

\begin{tabular}{|c|c|c|c|c|c|c|c|c|c|}
\hline System & $\begin{array}{c}\mathrm{C}_{0} \\
\left(\mathrm{mg} \mathrm{L}^{-1}\right)\end{array}$ & $\begin{array}{c}\mathrm{Cs} \\
\left(\mathrm{g} \mathrm{L}^{-1}\right)\end{array}$ & $\begin{array}{l}\text { Surface area } \\
\qquad\left(\mathrm{m}^{2} \mathrm{~g}^{-1}\right)\end{array}$ & $\begin{array}{l}\text { Particle size } \\
\quad(\mathrm{mm})\end{array}$ & $\begin{array}{c}\mathrm{q}_{\mathrm{e}} \\
\left(\mathrm{mg} \mathrm{g}^{-1}\right)\end{array}$ & $\begin{array}{c}\mathrm{k}_{2} \\
\left(\mathrm{~g} \mathrm{mg}^{-1}\right. \\
\left.\mathrm{min}^{-1}\right)\end{array}$ & $\begin{array}{c}k^{\prime} \\
\left(\mathrm{L} \mathrm{g}^{-1} \mathrm{~min}^{-1}\right)\end{array}$ & $\begin{array}{c}\text { Initial rate } \\
\left(\mathrm{mg} \mathrm{g}^{-1} \mathrm{~min}^{-1}\right)\end{array}$ & Reference \\
\hline \multicolumn{10}{|c|}{ Varying initial sorbate concentration, $\mathrm{C}_{0}$} \\
\hline \multirow{5}{*}{ As(V)/Fe2O3 } & 1 & 40 & 14.4 & 0.2 & 0.0341 & 2.58 & 0.003 & 0.003 & \multirow{5}{*}{1} \\
\hline & 2 & 40 & 14.4 & 0.2 & 0.0629 & 1.51 & 0.003 & 0.00597 & \\
\hline & 4 & 40 & 14.4 & 0.2 & 0.154 & 0.405 & 0.00241 & 0.0096 & \\
\hline & 8 & 40 & 14.4 & 0.2 & 0.222 & 0.532 & 0.00329 & 0.0262 & \\
\hline & 10 & 40 & 14.4 & 0.2 & 0.249 & 0.480 & 0.00297 & 0.030 & \\
\hline \multirow{5}{*}{$\mathrm{As}(\mathrm{V}) /$ laterite } & 1 & 2 & 18.05 & $0.23-0.65$ & 0.267 & 0.267 & 0.0136 & 0.019 & \multirow{5}{*}{2} \\
\hline & 2 & 2 & 18.05 & $0.23-0.65$ & 0.789 & 0.789 & 0.005 & 0.491 & \\
\hline & 4 & 2 & 18.05 & $0.23-0.65$ & 1 & 1 & 0.00317 & 1 & \\
\hline & 8 & 2 & 18.05 & $0.23-0.65$ & 1.05 & 1.05 & 0.00309 & 1.16 & \\
\hline & 10 & 2 & 18.05 & $0.23-0.65$ & 1.09 & 1.09 & 0.00309 & 1.3 & \\
\hline \multirow{3}{*}{$\mathrm{As}(\mathrm{III}) / \mathrm{HFO}$} & 50 & 2 & & $0.14-0.29$ & 19.3 & 0.000503 & 0.00376 & 0.187 & \multirow{3}{*}{3} \\
\hline & 75 & 2 & & $0.14-0.29$ & 19.8 & 0.000738 & 0.00384 & 0.289 & \\
\hline & 100 & 2 & & $0.14-0.29$ & 31.1 & 0.000335 & 0.00324 & 0.324 & \\
\hline \multirow[b]{2}{*}{ HPO4-2/iron hydroxide } & 2.8 & 7.5 & & $0.05-0.315$ & 0.35 & 0.722 & 0.0316 & 0.0884 & \multirow{2}{*}{4} \\
\hline & 14 & 7.5 & & $0.05-0.315$ & 2.03 & 0.0128 & 0.00374 & 0.0527 & \\
\hline
\end{tabular}




\begin{tabular}{|c|c|c|c|c|c|c|c|c|c|}
\hline System & $\begin{array}{c}\mathrm{C}_{0} \\
\left(\mathrm{mg} \mathrm{L}^{-1}\right)\end{array}$ & $\begin{array}{c}\mathrm{Cs} \\
\left(\mathrm{g} \mathrm{L}^{-1}\right)\end{array}$ & $\begin{array}{l}\text { Surface area } \\
\qquad\left(\mathrm{m}^{2} \mathrm{~g}^{-1}\right)\end{array}$ & $\begin{array}{l}\text { Particle size } \\
\qquad(\mathrm{mm})\end{array}$ & $\begin{array}{c}\mathrm{q}_{\mathrm{e}} \\
\left(\mathrm{mg} \mathrm{g}^{-1}\right)\end{array}$ & $\begin{array}{c}\mathrm{k}_{2} \\
\left(\mathrm{~g} \mathrm{mg}^{-1}\right. \\
\left.\mathrm{min}^{-1}\right) \\
\end{array}$ & $\begin{array}{c}k^{\prime} \\
\left(\mathrm{Lg}^{-1} \min ^{-1}\right)\end{array}$ & $\begin{array}{c}\text { Initial rate } \\
\left(\mathrm{mg} \mathrm{g}^{-1} \mathrm{~min}^{-1}\right)\end{array}$ & Reference \\
\hline & 53 & 7.5 & & $0.05-0.315$ & 3.73 & 0.0156 & 0.0041 & 0.217 & \\
\hline & 110 & 7.5 & & $0.05-0.315$ & 9.26 & 0.00551 & 0.0043 & 0.472 & \\
\hline \multirow{3}{*}{$\mathrm{Cu}(\mathrm{II}) / \mathrm{soil}$} & 20 & 10 & 287 & $<1$ & 0.84 & 0.177 & 0.00625 & 0.125 & \multirow{3}{*}{6} \\
\hline & 50 & 10 & 287 & $<1$ & 1.29 & 0.0636 & 0.00212 & 0.106 & \\
\hline & 100 & 10 & 287 & $<1$ & 1.94 & 0.0505 & 0.00189 & 0.19 & \\
\hline \multirow{2}{*}{ Zn(II)/soil } & 50 & 10 & 287 & $<1$ & 0.797 & 0.227 & 0.00288 & 0.144 & \multirow{2}{*}{6} \\
\hline & 100 & 10 & 287 & $<1$ & 0.995 & 0.223 & 0.00221 & 0.221 & \\
\hline \multirow{3}{*}{$\mathrm{Pb}(\mathrm{II}) /$ soil } & 20 & 10 & 287 & $<1$ & 0.831 & 0.146 & 0.00504 & 0.101 & \multirow{3}{*}{6} \\
\hline & 50 & 10 & 287 & $<1$ & 3.04 & 0.0123 & 0.00227 & 0.114 & \\
\hline & 100 & 10 & 287 & $<1$ & 3.35 & 0.0507 & 0.00569 & 0.569 & \\
\hline \multirow{5}{*}{ Rhodamine B/MgO-Fe-Co-Mn } & 10 & 0.1 & 59.33 & & 95.4 & 0.0259 & 23.6 & 236 & \multirow{5}{*}{9} \\
\hline & 30 & 0.1 & 59.33 & & 285 & 0.013 & 35.2 & 1060 & \\
\hline & 60 & 0.1 & 59.33 & & 568 & 0.0035 & 18.8 & 1130 & \\
\hline & 80 & 0.1 & 59.33 & & 752 & 0.002 & 14.1 & 1130 & \\
\hline & 120 & 0.1 & 59.33 & & 1120 & 0.0015 & 15.6 & 1880 & \\
\hline \multirow{4}{*}{$\mathrm{Hg}(\mathrm{II}) /$ raw activated sludge } & 50 & 2 & & $0.125-0.212$ & 20.7 & 0.0021 & 0.018 & 0.9 & \multirow{4}{*}{7} \\
\hline & 100 & 2 & & $0.125-0.212$ & 35.5 & 0.00126 & 0.016 & 1.59 & \\
\hline & 150 & 2 & & $0.125-0.212$ & 39.5 & 0.00287 & 0.0299 & 4.48 & \\
\hline & 200 & 2 & & $0.125-0.212$ & 46.9 & 0.00353 & 0.0389 & 7.76 & \\
\hline \multirow{2}{*}{$\mathrm{Cr}(\mathrm{VI}) /$ activated carbon } & 100 & 0.5 & 38.7 & $0.15-0.42$ & 6.41 & 0.00662 & 0.00272 & 0.272 & \multirow{2}{*}{5} \\
\hline & 200 & 0.5 & 38.7 & $0.15-0.42$ & 11.6 & 0.00371 & 0.00252 & 0.499 & \\
\hline
\end{tabular}




\begin{tabular}{|c|c|c|c|c|c|c|c|c|c|}
\hline System & $\begin{array}{c}\mathrm{C}_{0} \\
\left(\mathrm{mg} \mathrm{L}^{-1}\right)\end{array}$ & $\begin{array}{c}\mathrm{Cs} \\
\left(\mathrm{g} \mathrm{L}^{-1}\right)\end{array}$ & $\begin{array}{l}\text { Surface area } \\
\qquad\left(\mathrm{m}^{2} \mathrm{~g}^{-1}\right)\end{array}$ & $\begin{array}{l}\text { Particle size } \\
\quad(\mathrm{mm})\end{array}$ & $\begin{array}{c}\mathrm{qe}_{\mathrm{e}} \\
\left(\mathrm{mg} \mathrm{g}^{-1}\right)\end{array}$ & $\begin{array}{c}\mathrm{k}_{2} \\
\left(\mathrm{~g} \mathrm{mg}^{-1}\right. \\
\left.\mathrm{min}^{-1}\right)\end{array}$ & $\begin{array}{c}k^{\prime} \\
\left(\mathrm{L} \mathrm{g}^{-1} \mathrm{~min}^{-1}\right)\end{array}$ & $\begin{array}{c}\text { Initial rate } \\
\left(\mathrm{mg} \mathrm{g}^{-1} \mathrm{~min}^{-1}\right)\end{array}$ & Reference \\
\hline & 300 & 0.5 & 38.7 & $0.15-0.42$ & 16.5 & 0.00336 & 0.00303 & 0.915 & \\
\hline & 400 & 0.5 & 38.7 & $0.15-0.42$ & 21.2 & 0.00338 & 0.00382 & 1.52 & \\
\hline & 500 & 0.5 & 38.7 & $0.15-0.42$ & 25.1 & 0.0034 & 0.0043 & 2.14 & \\
\hline \multirow{5}{*}{ Rose Bengal dye/activated carbon } & 10 & 0.05 & & $0.073-0.15$ & 160 & 0.000706 & 1.8 & 18.1 & \multirow{5}{*}{8} \\
\hline & 20 & 0.05 & & $0.073-0.15$ & 312 & 0.000185 & 0.903 & 18 & \\
\hline & 30 & 0.05 & & $0.073-0.15$ & 451 & 0.000123 & 0.83 & 25 & \\
\hline & 40 & 0.05 & & $0.073-0.15$ & 584 & 0.0000839 & 0.715 & 28.6 & \\
\hline & 50 & 0.05 & & $0.073-0.15$ & 709 & 0.0000643 & 0.646 & 32.3 & \\
\hline \multicolumn{10}{|c|}{ Varying sorbent concentration, Cs } \\
\hline \multirow{4}{*}{$\mathrm{Cr}(\mathrm{VI}) / \mathrm{Fe} 2 \mathrm{O} 3$} & 50 & 1 & & & 49 & 0.000838 & 0.0402 & 2.01 & \multirow{4}{*}{10} \\
\hline & 50 & 1.5 & & & 39.4 & 0.000826 & 0.0257 & 1.28 & \\
\hline & 50 & 2 & & & 29.9 & 0.00121 & 0.0217 & 1.08 & \\
\hline & 50 & 3 & & & 19.6 & 0.00213 & 0.0164 & 0.818 & \\
\hline \multirow{4}{*}{$\mathrm{Cr}(\mathrm{VI}) / \mathrm{Mg}-\mathrm{Al}-\mathrm{CO} 3$} & 10 & 0.5 & 83.95 & $0.125-0.25$ & 6.35 & 0.0812 & 0.328 & 3.27 & \multirow{4}{*}{11} \\
\hline & 10 & 1 & 83.95 & $0.125-0.25$ & 5.86 & 0.0879 & 0.302 & 3.02 & \\
\hline & 10 & 1.5 & 83.95 & $0.125-0.25$ & 5.28 & 0.157 & 0.438 & 4.38 & \\
\hline & 10 & 2 & 83.95 & $0.125-0.25$ & 4.32 & 0.239 & 0.446 & 4.46 & \\
\hline \multirow{4}{*}{$\mathrm{Cr}(\mathrm{VI}) /$ chitin } & 100 & 0.5 & & $0.25-0.42$ & 36.7 & 0.00164 & 0.0221 & 2.21 & \multirow{4}{*}{12} \\
\hline & 100 & 0.75 & & $0.25-0.42$ & 25.4 & 0.00402 & 0.026 & 2.59 & \\
\hline & 100 & 1 & & $0.25-0.42$ & 29 & 0.00548 & 0.046 & 4.61 & \\
\hline & 100 & 1.5 & & $0.25-0.42$ & 8.14 & 0.0284 & 0.0188 & 1.88 & \\
\hline
\end{tabular}




\begin{tabular}{|c|c|c|c|c|c|c|c|c|c|}
\hline System & $\begin{array}{c}\mathrm{C}_{0} \\
\left(\mathrm{mg} \mathrm{L}^{-1}\right)\end{array}$ & $\begin{array}{c}\mathrm{Cs} \\
\left(\mathrm{g} \mathrm{L}^{-1}\right)\end{array}$ & $\begin{array}{l}\text { Surface area } \\
\qquad\left(\mathrm{m}^{2} \mathrm{~g}^{-1}\right)\end{array}$ & $\begin{array}{l}\text { Particle size } \\
\quad(\mathrm{mm})\end{array}$ & $\begin{array}{c}\mathrm{q}_{\mathrm{e}} \\
\left(\mathrm{mg} \mathrm{g}^{-1}\right)\end{array}$ & $\begin{array}{c}\mathrm{k}_{2} \\
\left(\mathrm{~g} \mathrm{mg}^{-1}\right. \\
\left.\mathrm{min}^{-1}\right)\end{array}$ & $\begin{array}{c}\mathrm{k}^{\prime} \\
\left(\mathrm{Lg}^{-1} \mathrm{~min}^{-1}\right)\end{array}$ & $\begin{array}{c}\text { Initial rate } \\
\left(\mathrm{mg} \mathrm{g}^{-1} \mathrm{~min}^{-1}\right)\end{array}$ & Reference \\
\hline & 100 & 2 & & $0.25-0.42$ & 7.98 & 0.013 & 0.00826 & 0.828 & \\
\hline & 100 & 2.5 & & $0.25-0.42$ & 5.53 & 0.0205 & 0.00627 & 0.627 & \\
\hline \multirow{2}{*}{$\begin{array}{l}\text { PO4-3/peat/amorphous iron(III) } \\
\text { hydroxide }\end{array}$} & 25 & 0.2 & 43.8 & & 4.72 & 0.001 & 0.000891 & 0.0223 & \multirow{2}{*}{13} \\
\hline & 25 & 1 & 43.8 & & 2.02 & 0.037 & 0.00604 & 0.151 & \\
\hline \multirow{5}{*}{$\mathrm{Cr}(\mathrm{VI}) /$ guava seeds } & 75 & 5 & & $0.3-0.8$ & 10 & 0.0101 & 0.0136 & 1.01 & \multirow{5}{*}{14} \\
\hline & 75 & 7.5 & & $0.3-0.8$ & 7.63 & 0.0136 & 0.0105 & 0.792 & \\
\hline & 75 & 10 & & $0.3-0.8$ & 6.63 & 0.0168 & 0.00988 & 0.738 & \\
\hline & 75 & 12.5 & & $0.3-0.8$ & 5.79 & 0.0169 & 0.00753 & 0.567 & \\
\hline & 75 & 15 & & $0.3-0.8$ & 4.88 & 0.0266 & 0.00844 & 0.633 & \\
\hline \multirow{3}{*}{$\mathrm{Cd}(\mathrm{II}) / \mathrm{Fe} 2 \mathrm{O} 3$} & 0.1 & 0.05 & 31.7 & & 1.29 & 0.0986 & 1.63 & 0.164 & \multirow{3}{*}{15} \\
\hline & 0.1 & 0.1 & 31.7 & & 0.765 & 0.362 & 2.12 & 0.212 & \\
\hline & 0.1 & 0.5 & 31.7 & & 0.189 & 3.9 & 1.4 & 0.139 & \\
\hline \multirow{3}{*}{$\mathrm{Cu}(\mathrm{II}) / \mathrm{Fe} 2 \mathrm{O} 3$} & 0.1 & 0.05 & 31.7 & & 0.852 & 0.0181 & 0.129 & 0.0131 & \multirow{3}{*}{15} \\
\hline & 0.1 & 0.1 & 31.7 & & 0.435 & 0.252 & 0.47 & 0.0477 & \\
\hline & 0.1 & 0.5 & 31.7 & & 0.187 & 0.656 & 0.225 & 0.0229 & \\
\hline \multirow{3}{*}{$\mathrm{Zn}(\mathrm{II}) / \mathrm{Fe} 2 \mathrm{O}$} & 0.1 & 0.05 & 31.7 & & 1.61 & 0.0336 & 0.894 & 0.0871 & \multirow{3}{*}{15} \\
\hline & 0.1 & 0.1 & 31.7 & & 0.983 & 0.216 & 2.13 & 0.209 & \\
\hline & 0.1 & 0.5 & 31.7 & & 0.197 & 7.47 & 2.97 & 0.29 & \\
\hline \multirow{3}{*}{$\mathrm{Hg}(\mathrm{II}) /$ Lessonia nigrescens } & 50 & 0.4 & & $0.125-0.25$ & 97.4 & 0.00034 & 0.0645 & 3.23 & \multirow{3}{*}{16} \\
\hline & 50 & 0.2 & & $0.125-0.25$ & 143 & 0.000171 & 0.0695 & 3.5 & \\
\hline & 50 & 0.1 & & $0.125-0.25$ & 190 & 0.000073 & 0.0526 & 2.64 & \\
\hline
\end{tabular}




\begin{tabular}{|c|c|c|c|c|c|c|c|c|c|}
\hline System & $\begin{array}{c}\mathrm{C}_{0} \\
\left(\mathrm{mg} \mathrm{L}^{-1}\right)\end{array}$ & $\begin{array}{c}\mathrm{Cs} \\
\left(\mathrm{g} \mathrm{L}^{-1}\right)\end{array}$ & $\begin{array}{l}\text { Surface area } \\
\qquad\left(\mathrm{m}^{2} \mathrm{~g}^{-1}\right)\end{array}$ & $\begin{array}{l}\text { Particle size } \\
\quad(\mathrm{mm})\end{array}$ & $\begin{array}{c}\mathrm{qe}_{\mathrm{e}} \\
\left(\mathrm{mg} \mathrm{g}^{-1}\right)\end{array}$ & $\begin{array}{c}\mathrm{k}_{2} \\
\left(\mathrm{~g} \mathrm{mg}^{-1}\right. \\
\left.\mathrm{min}^{-1}\right)\end{array}$ & $\begin{array}{c}\mathrm{k}^{\prime} \\
\left(\mathrm{Lg}^{-1} \mathrm{~min}^{-1}\right)\end{array}$ & $\begin{array}{c}\text { Initial rate } \\
\left(\mathrm{mg} \mathrm{g}^{-1} \mathrm{~min}^{-1}\right)\end{array}$ & Reference \\
\hline \multirow{3}{*}{$\mathrm{Hg}(I I) / L e s s o n i a$ trabeculata } & 50 & 0.4 & & $0.125-0.25$ & 90.5 & 0.00039 & 0.0639 & 3.19 & \multirow{3}{*}{16} \\
\hline & 50 & 0.2 & & $0.125-0.25$ & 140 & 0.000148 & 0.0579 & 2.9 & \\
\hline & 50 & 0.1 & & $0.125-0.25$ & 200 & 0.000089 & 0.0713 & 3.56 & \\
\hline \multirow{5}{*}{ Eriochrome Black-T dye/TiO2 } & 25 & 0.2 & & & 101 & 0.0012 & 0.489 & 12.2 & \multirow{5}{*}{17} \\
\hline & 25 & 0.4 & & & 58.8 & 0.00335 & 0.463 & 11.6 & \\
\hline & 25 & 0.6 & & & 37.4 & 0.0038 & 0.212 & 5.32 & \\
\hline & 25 & 0.8 & & & 30 & 0.00484 & 0.174 & 4.36 & \\
\hline & 25 & 1 & & & 24.7 & 0.00613 & 0.15 & 3.74 & \\
\hline \multirow{5}{*}{ methylene blue/rafia fibres } & 11 & 2 & 1.08 & & 5.91 & 0.000198 & 0.000629 & 0.00692 & \multirow{5}{*}{18} \\
\hline & 11 & 2.5 & 1.08 & & 4.55 & 0.000491 & 0.000922 & 0.0102 & \\
\hline & 11 & 3 & 1.08 & & 3.66 & 0.000808 & 0.000985 & 0.0108 & \\
\hline & 11 & 3.5 & 1.08 & & 3.21 & 0.00114 & 0.00107 & 0.0117 & \\
\hline & 11 & 4 & 1.08 & & 2.67 & 0.00188 & 0.00122 & 0.0134 & \\
\hline \multicolumn{10}{|c|}{ Varying surface area } \\
\hline \multirow{6}{*}{$\mathrm{As}(\mathrm{V}) / \mathrm{Fe} 2 \mathrm{O} 3$} & 35.21 & 1 & 20 & & 2.43 & 0.00295 & 0.000493 & 0.0174 & \multirow{6}{*}{80} \\
\hline & 35.21 & 1 & 29 & & 2.02 & 0.00245 & 0.000284 & 0.01 & \\
\hline & 35.21 & 1 & 14 & & 2.1 & 0.0032 & 0.000402 & 0.0141 & \\
\hline & 35.21 & 1 & 24 & & 2.99 & 0.0027 & 0.000685 & 0.0241 & \\
\hline & 35.21 & 1 & 15 & & 0.911 & 0.00454 & 0.000107 & 0.00377 & \\
\hline & 35.21 & 1 & 109 & & 75.8 & 0.000141 & 0.023 & 0.81 & \\
\hline \\
\hline
\end{tabular}




\begin{tabular}{|c|c|c|c|c|c|c|c|c|c|}
\hline System & $\begin{array}{c}\mathrm{C}_{0} \\
\left(\mathrm{mg} \mathrm{L}^{-1}\right)\end{array}$ & $\begin{array}{c}\mathrm{Cs} \\
\left(\mathrm{g} \mathrm{L}^{-1}\right)\end{array}$ & $\begin{array}{l}\text { Surface area } \\
\qquad\left(\mathrm{m}^{2} \mathrm{~g}^{-1}\right)\end{array}$ & $\begin{array}{l}\text { Particle size } \\
\qquad(\mathrm{mm})\end{array}$ & $\begin{array}{c}\mathrm{q}_{\mathrm{e}} \\
\left(\mathrm{mg} \mathrm{g}^{-1}\right)\end{array}$ & $\begin{array}{c}\mathrm{k}_{2} \\
\left(\mathrm{~g} \mathrm{mg}^{-1}\right. \\
\left.\mathrm{min}^{-1}\right) \\
\end{array}$ & $\begin{array}{c}k^{\prime} \\
\left(\mathrm{L} \mathrm{g}^{-1} \mathrm{~min}^{-1}\right)\end{array}$ & $\begin{array}{c}\text { Initial rate } \\
\left(\mathrm{mg} \mathrm{g}^{-1} \mathrm{~min}^{-1}\right)\end{array}$ & Reference \\
\hline \multirow{3}{*}{ PO4-3/granular ferric oxide } & 25 & 2 & 244 & 1.13 & 11.3 & 0.000028 & 0.000143 & 0.00358 & \multirow{3}{*}{19} \\
\hline & 25 & 2 & 244 & 0.45 & 11.8 & 0.000075 & 0.000418 & 0.0104 & \\
\hline & 25 & 2 & 244 & 0.1 & 12.1 & 0.0038 & 0.0223 & 0.556 & \\
\hline \multirow{3}{*}{ PO4-3/ferrihydrite } & 25 & 2 & 179 & 1.13 & 11.8 & 0.00021 & 0.00117 & 0.0292 & \multirow{3}{*}{19} \\
\hline & 25 & 2 & 179 & 0.45 & 11.7 & 0.00062 & 0.00339 & 0.0849 & \\
\hline & 25 & 2 & 179 & 0.1 & 11.6 & 0.0031 & 0.0167 & 0.417 & \\
\hline \multirow{3}{*}{ PO4-3/ferrihydrite } & 25 & 2 & 119 & 1.13 & 12.4 & 0.000034 & 0.000209 & 0.00523 & \multirow{3}{*}{19} \\
\hline & 25 & 2 & 119 & 0.45 & 12.6 & 0.00015 & 0.000953 & 0.0238 & \\
\hline & 25 & 2 & 119 & 0.1 & 12.6 & 0.0031 & 0.0197 & 0.492 & \\
\hline \multirow{3}{*}{ PO4-3/aluminium (hydr)oxide } & 25 & 11 & 235 & 1.13 & 11.8 & 0.00015 & 0.000835 & 0.0209 & \multirow{3}{*}{19} \\
\hline & 25 & 12 & 235 & 0.45 & 11.9 & 0.00044 & 0.00249 & 0.0623 & \\
\hline & 25 & 13 & 235 & 0.1 & 11.3 & 0.0063 & 0.0322 & 0.804 & \\
\hline \multirow{3}{*}{$\begin{array}{c}\text { paraquat }\left(\left[\left(\mathrm{C}_{6} \mathrm{H}_{7} \mathrm{~N}\right)_{2}\right] \mathrm{Cl}_{2}\right) / \text { activated } \\
\text { clay }\end{array}$} & 30 & 0.25 & 266.91 & 0.053 & 57.8 & 0.0092 & 1.02 & 30.7 & \multirow{3}{*}{21} \\
\hline & 30 & 0.25 & 266.71 & 0.037 & 55.6 & 0.0166 & 1.71 & 51.3 & \\
\hline & 30 & 0.25 & 229.42 & 0.0185 & 45.5 & 0.082 & 5.65 & 170 & \\
\hline \multirow{4}{*}{ phenol/coal } & 50 & 40 & & 0.037 & 1.16 & 0.15 & 0.00404 & 0.202 & \multirow{4}{*}{22} \\
\hline & 50 & 40 & & 0.074 & 0.36 & 0.303 & 0.000785 & 0.0393 & \\
\hline & 50 & 40 & & 0.125 & 0.18 & 0.353 & 0.000229 & 0.0114 & \\
\hline & 50 & 40 & & 0.25 & 0.11 & 0.52 & 0.000126 & 0.00629 & \\
\hline \multirow{2}{*}{ quinoline/coal } & 50 & 40 & & 0.037 & 1.24 & 0.353 & 0.0108 & 0.543 & \multirow[b]{2}{*}{81} \\
\hline & 50 & 40 & & 0.074 & 0.76 & 0.308 & 0.00356 & 0.178 & \\
\hline
\end{tabular}




\begin{tabular}{|c|c|c|c|c|c|c|c|c|c|}
\hline System & $\begin{array}{c}\mathrm{C}_{0} \\
\left(\mathrm{mg} \mathrm{L}^{-1}\right)\end{array}$ & $\begin{array}{c}\mathrm{Cs} \\
\left(\mathrm{g} \mathrm{L}^{-1}\right)\end{array}$ & $\begin{array}{l}\text { Surface area } \\
\left(\mathrm{m}^{2} \mathrm{~g}^{-1}\right)\end{array}$ & $\begin{array}{l}\text { Particle size } \\
\text { (mm) }\end{array}$ & $\begin{array}{c}\mathrm{q}_{\mathrm{e}} \\
\left(\mathrm{mg} \mathrm{g}^{-1}\right)\end{array}$ & $\begin{array}{c}\mathrm{k}_{2} \\
\left(\mathrm{~g} \mathrm{mg}^{-1}\right. \\
\left.\mathrm{min}^{-1}\right) \\
\end{array}$ & $\begin{array}{c}\mathrm{k}^{\prime} \\
\left(\mathrm{Lg}^{-1} \mathrm{~min}^{-1}\right)\end{array}$ & $\begin{array}{c}\text { Initial rate } \\
\left(\mathrm{mg} \mathrm{g}^{-1} \mathrm{~min}^{-1}\right)\end{array}$ & Reference \\
\hline & 50 & 40 & & 0.125 & 0.42 & 0.27 & 0.000952 & 0.0476 & \\
\hline \multirow{2}{*}{$\mathrm{Cu}(\mathrm{II}) /$ chitosan } & 20 & $0.125-0.5$ & & 0.11 & 16.3 & 0.00407 & 0.054 & 1.08 & \multirow{2}{*}{20} \\
\hline & 20 & $0.125-0.5$ & & 0.22 & 16.1 & 0.00148 & 0.0191 & 0.384 & \\
\hline \multirow{2}{*}{$\mathrm{Cu}(\mathrm{II}) /$ chitosan (2) } & 50 & $0.125-0.5$ & & 0.11 & 36.9 & 0.000958 & 0.0261 & 1.3 & \multirow{2}{*}{20} \\
\hline & 50 & $0.125-0.5$ & & 0.22 & 28.3 & 0.000707 & 0.0113 & 0.566 & \\
\hline \multirow{2}{*}{$\mathrm{Zn}(\mathrm{II}) /$ chitosan } & 20 & $0.125-0.5$ & & 0.11 & 3.75 & 0.0436 & 0.0307 & 0.613 & \multirow{2}{*}{20} \\
\hline & 20 & $0.125-0.5$ & & 0.22 & 4.13 & 0.0134 & 0.0114 & 0.229 & \\
\hline \multirow{2}{*}{$\mathrm{Zn}(\mathrm{II}) /$ chitosan (2) } & 50 & $0.125-0.5$ & & 0.11 & 8.98 & 0.0105 & 0.0169 & 0.847 & \multirow{2}{*}{20} \\
\hline & 50 & $0.125-0.5$ & & 0.22 & 8.57 & 0.00939 & 0.0138 & 0.69 & \\
\hline \multirow{2}{*}{$\mathrm{Hg}(\mathrm{II}) /$ chitosan } & 20 & $0.125-0.5$ & & 0.11 & 2.5 & 0.546 & 0.683 & 3.41 & \multirow{2}{*}{20} \\
\hline & 20 & $0.125-0.5$ & & 0.22 & 2.5 & 0.263 & 0.329 & 1.64 & \\
\hline \multirow{2}{*}{$\mathrm{Hg}(I I) /$ chitosan (2) } & 50 & $0.125-0.5$ & & 0.11 & 10.1 & 0.0457 & 0.232 & 4.66 & \multirow{2}{*}{20} \\
\hline & 50 & $0.125-0.5$ & & 0.22 & 10.1 & 0.0248 & 0.127 & 2.53 & \\
\hline \multirow{3}{*}{ Omega Chrome Red ME dye/fly ash } & 10 & & 5.77 & 0.053 & 0.496 & 0.121 & 0.00298 & 0.0298 & \multirow{3}{*}{23} \\
\hline & 10 & & 5.77 & 0.075 & 0.406 & 0.156 & 0.00257 & 0.0257 & \\
\hline & 10 & & 5.77 & 0.125 & 0.35 & 0.173 & 0.00212 & 0.0212 & \\
\hline \multicolumn{10}{|c|}{ Extra data for literature cross-comparison } \\
\hline $\mathrm{As}(\mathrm{V}) / \mathrm{Fe} 2 \mathrm{O} 3$ & 1.5 & 4 & 56 & 0.0001 & 7.13 & 0.116 & 3.94 & 5.9 & 82 \\
\hline $\mathrm{As}(\mathrm{V}) / \mathrm{Fe} 2 \mathrm{O} 3$ & 0.2 & 0.01 & 50 & $6.25 \mathrm{E}-08$ & 4.31 & 0.0000567 & 0.00527 & 0.00105 & 26 \\
\hline $\mathrm{As}(\mathrm{V}) / \mathrm{Fe} 2 \mathrm{O} 3$ & 1.5 & 0.1 & 0.38 & 0.000125 & 0.109 & 1.58 & 0.0126 & 0.0188 & 27 \\
\hline $\mathrm{As}(\mathrm{V}) / \mathrm{Fe} 2 \mathrm{O} 3$ & 0.01 & 0.005 & 162 & $2.5 \mathrm{E}-09$ & 8.87 & 0.004 & 33.1 & 0.315 & 28 \\
\hline
\end{tabular}




\begin{tabular}{|c|c|c|c|c|c|c|c|c|c|}
\hline System & $\begin{array}{c}\mathrm{C}_{0} \\
\left(\mathrm{mg} \mathrm{L}^{-1}\right)\end{array}$ & $\begin{array}{c}\mathrm{Cs} \\
\left(\mathrm{g} \mathrm{L}^{-1}\right)\end{array}$ & $\begin{array}{l}\text { Surface area } \\
\qquad\left(\mathrm{m}^{2} \mathrm{~g}^{-1}\right)\end{array}$ & $\begin{array}{l}\text { Particle size } \\
\text { (mm) }\end{array}$ & $\begin{array}{c}\mathrm{q}_{\mathrm{e}} \\
\left(\mathrm{mg} \mathrm{g}^{-1}\right)\end{array}$ & $\begin{array}{c}\mathrm{k}_{2} \\
\left(\mathrm{~g} \mathrm{mg}^{-1}\right. \\
\left.\mathrm{min}^{-1}\right)\end{array}$ & $\begin{array}{c}\mathrm{k}^{\prime} \\
\left(\mathrm{Lg}^{-1} \mathrm{~min}^{-1}\right)\end{array}$ & $\begin{array}{c}\text { Initial rate } \\
\left(\mathrm{mg} \mathrm{g}^{-1} \mathrm{~min}^{-1}\right)\end{array}$ & Reference \\
\hline & 0.01 & 0.007 & 162 & $2.5 \mathrm{E}-09$ & 8.01 & 0.006 & 40.5 & 0.385 & \\
\hline & 0.01 & 0.01 & 162 & $2.5 \mathrm{E}-09$ & 7.12 & 0.019 & 101 & 0.963 & \\
\hline & 0.01 & 0.02 & 162 & $2.5 \mathrm{E}-09$ & 4.78 & 0.033 & 79.4 & 0.754 & \\
\hline $\mathrm{As}(\mathrm{V}) / \mathrm{Fe} 2 \mathrm{O} 3$ & 10 & 0.4 & 317 & 0.000000002 & 23.7 & 0.017 & 0.955 & 9.55 & 29 \\
\hline \multirow{4}{*}{ As(V)/ferrihydrite } & 2000.36 & 2.5 & 202 & & 176 & 1.29 & 20 & 40000 & \multirow{4}{*}{83} \\
\hline & 40.01 & 2.5 & 202 & & 124 & 0.000859 & 0.328 & 13.2 & \\
\hline & 2000.36 & 2.5 & 202 & & 19.7 & 0.458 & 0.0888 & 178 & \\
\hline & 40.01 & 2.5 & 202 & & 19.8 & 0.989 & 9.72 & 388 & \\
\hline As(V)/ferrihydrite & 50 & 1 & 120 & & 31.5 & 0.00066 & 0.0131 & 0.655 & 84 \\
\hline As(V)/Fe3O4 & 1.5 & 0.1 & 0.89 & 0.00005 & 0.125 & 1.29 & 0.0133 & 0.0202 & 27 \\
\hline \multirow[b]{2}{*}{$\mathrm{As}(\mathrm{V}) / \mathrm{Fe} 3 \mathrm{O} 4$} & 0.04 & 1 & 92 & 0.00000015 & 0.0364 & 44.6 & 1.64 & 0.0591 & \multirow{2}{*}{30} \\
\hline & 0.07 & 1 & 92 & 0.00000015 & 0.0663 & 31 & 2.07 & 0.136 & \\
\hline As(V)/Fe3O4 & 1 & 0.2 & 94.07 & 0.00000025 & 4.3 & 2.75 & 50.9 & 50.8 & 31 \\
\hline $\mathrm{As}(\mathrm{V}) / \mathrm{Fe} 3 \mathrm{O} 4 / \mathrm{\gamma}-\mathrm{Fe} 2 \mathrm{O} 3$ & 1 & 0.4 & 49 & 0.000000015 & 0.0619 & 4.15 & 0.0159 & 0.0159 & 32 \\
\hline $\mathrm{As}(\mathrm{V}) / \mathrm{Fe} 3 \mathrm{O} 4 / \mathrm{\gamma}-\mathrm{Fe} 2 \mathrm{O} 3$ & 2 & 0.4 & 49 & 0.000000015 & 4.97 & 0.059 & 0.729 & 1.46 & 32 \\
\hline $\mathrm{As}(\mathrm{V}) / \mathrm{Fe} 3 \mathrm{O} 4-\mathrm{HBC}$ & 0.1 & 0.2 & 0.03 & & 0.474 & 0.0162 & 0.0365 & 0.00364 & 33 \\
\hline $\mathrm{As}(\mathrm{V}) / \mathrm{Fe} 3 \mathrm{O} 4$ & 1 & 0.1 & 300 & $1.25 \mathrm{E}-08$ & 7.89 & 0.000704 & 0.0438 & 0.0438 & 85 \\
\hline $\mathrm{As}(\mathrm{V}) / \mathrm{FeOOH}$ & 8.99 & 1.98 & 27 & 0.00000075 & 3.34 & 0.0228 & 0.0282 & 0.254 & 34 \\
\hline $\mathrm{As}(\mathrm{V}) / \mathrm{FeOOH}$ & 1.5 & 0.1 & 2.01 & 0.000125 & 0.205 & 0.797 & 0.0224 & 0.0335 & 27 \\
\hline $\mathrm{As}(\mathrm{V}) / \beta-\mathrm{FeOOH}$ & 3.36 & 0.27 & 9 & 0.000000145 & 0.911 & 0.488 & 0.121 & 0.405 & 35 \\
\hline $\mathrm{As}(\mathrm{V}) / \mathrm{FeOOH}$ & 5 & 1.8 & 69.62 & 0.000000145 & 2.73 & 0.00496 & 0.00739 & 0.037 & 36 \\
\hline
\end{tabular}




\begin{tabular}{|c|c|c|c|c|c|c|c|c|c|}
\hline System & $\begin{array}{c}\mathrm{C}_{0} \\
\left(\mathrm{mg} \mathrm{L}^{-1}\right)\end{array}$ & $\begin{array}{c}\mathrm{Cs} \\
\left(\mathrm{g} \mathrm{L}^{-1}\right)\end{array}$ & $\begin{array}{l}\text { Surface area } \\
\qquad\left(\mathrm{m}^{2} \mathrm{~g}^{-1}\right)\end{array}$ & $\begin{array}{l}\text { Particle size } \\
\qquad(\mathrm{mm})\end{array}$ & $\begin{array}{c}\mathrm{q}_{\mathrm{e}} \\
\left(\mathrm{mg} \mathrm{g}^{-1}\right)\end{array}$ & $\begin{array}{c}\mathrm{k}_{2} \\
\left(\mathrm{~g} \mathrm{mg}^{-1}\right. \\
\left.\mathrm{min}^{-1}\right) \\
\end{array}$ & $\begin{array}{c}k^{\prime} \\
\left(\mathrm{Lg}^{-1} \mathrm{~min}^{-1}\right)\end{array}$ & $\begin{array}{c}\text { Initial rate } \\
\left(\mathrm{mg} \mathrm{g}^{-1} \mathrm{~min}^{-1}\right)\end{array}$ & Reference \\
\hline $\mathrm{As}(\mathrm{V}) / \mathrm{FeOOH}$ & 5 & 1.8 & 69.62 & 0.000035 & 2.73 & 0.009 & 0.0134 & 0.0671 & 36 \\
\hline $\mathrm{As}(\mathrm{V}) / \mathrm{FeOOH}$ & 74.92 & 2.5 & 103 & & 12.6 & 0.00984 & 0.0208 & 1.56 & 37 \\
\hline $\mathrm{As}(\mathrm{III}) / \mathrm{Fe} 2 \mathrm{O} 3$ & 0.2 & 0.01 & 50 & 0.00000006 & 3.02 & 0.00443 & 0.202 & 0.0404 & 26 \\
\hline $\mathrm{As}(\mathrm{III}) / \mathrm{Fe} 2 \mathrm{O} 3$ & 1.5 & 0.1 & 0.38 & 0.000125 & 0.112 & 2.4 & 0.0201 & 0.0301 & 27 \\
\hline \multirow{4}{*}{ As(III)/Fe2O3 } & 0.12 & 0.01 & 162 & $2.5 \mathrm{E}-09$ & 8.92 & 0.002 & 1.38 & 0.159 & \multirow{4}{*}{28} \\
\hline & 0.12 & 0.02 & 162 & $2.5 \mathrm{E}-09$ & 5.46 & 0.006 & 1.56 & 0.179 & \\
\hline & 0.12 & 0.04 & 162 & $2.5 \mathrm{E}-09$ & 2.86 & 0.027 & 1.92 & 0.221 & \\
\hline & 0.12 & 0.06 & 162 & $2.5 \mathrm{E}-09$ & 1.92 & 0.086 & 2.76 & 0.317 & \\
\hline $\mathrm{As}(\mathrm{III}) / \mathrm{Fe} 2 \mathrm{O}$ & 10 & 0.4 & 317 & 0.000000002 & 19.5 & 0.0036 & 0.137 & 1.37 & 29 \\
\hline \multirow{4}{*}{ As(III)/ferrihydrite } & 2000.36 & 2.5 & 202 & & 306 & 0.0059 & 0.277 & 552 & \multirow{4}{*}{83} \\
\hline & 40.01 & 2.5 & 202 & & 378 & 0.00279 & 9.98 & 399 & \\
\hline & 2000.36 & 2.5 & 202 & & 19.7 & 0.422 & 0.082 & 164 & \\
\hline & 40.01 & 2.5 & 202 & & 20 & 2.3 & 22.9 & 920 & \\
\hline As(III)/ferrihydrite & 50 & 1 & 120 & & 46.8 & 0.000913 & 0.0399 & 2 & \multirow[t]{2}{*}{84} \\
\hline As(III)/ferrihydrite & 50 & 1 & 120 & & 48.1 & 0.00114 & 0.0529 & 2.64 & \\
\hline As(III)/Fe3O4 & 1.5 & 0.1 & 0.89 & 0.00005 & 0.106 & 2.49 & 0.0186 & 0.028 & 27 \\
\hline As(III)/Fe3O4 & 0.16 & 1 & 92 & 0.00000015 & 0.155 & 4.22 & 0.619 & 0.101 & 30 \\
\hline \multirow{2}{*}{$\mathrm{As}(\mathrm{III}) / \mathrm{Fe} 3 \mathrm{O} 4 / \mathrm{Y}-\mathrm{Fe} 2 \mathrm{O} 3$} & 1 & 0.4 & 49 & 0.000000015 & 0.161 & 1.17 & 0.0304 & 0.0303 & \multirow{2}{*}{32} \\
\hline & 2 & 0.4 & 49 & 0.000000015 & 0.154 & 1.39 & 0.0165 & 0.033 & \\
\hline $\mathrm{As}(\mathrm{III}) / \mathrm{FeOOH}$ & 74.92 & 2.5 & 103 & & 17.2 & 0.0413 & 0.164 & 12.2 & 37 \\
\hline $\mathrm{As}(\mathrm{III}) / \mathrm{FeOOH}$ & 1.5 & 0.1 & 2.01 & 0.000125 & 0.212 & 1.12 & 0.0334 & 0.0503 & 27 \\
\hline
\end{tabular}




\begin{tabular}{|c|c|c|c|c|c|c|c|c|c|}
\hline System & $\begin{array}{c}\mathrm{C}_{0} \\
\left(\mathrm{mg} \mathrm{L}^{-1}\right)\end{array}$ & $\begin{array}{c}\mathrm{Cs} \\
\left(\mathrm{g} \mathrm{L}^{-1}\right)\end{array}$ & $\begin{array}{l}\text { Surface area } \\
\qquad\left(\mathrm{m}^{2} \mathrm{~g}^{-1}\right)\end{array}$ & $\begin{array}{l}\text { Particle size } \\
\qquad(\mathrm{mm})\end{array}$ & $\begin{array}{c}\mathrm{qe}_{\mathrm{e}} \\
\left(\mathrm{mg} \mathrm{g}^{-1}\right)\end{array}$ & $\begin{array}{c}\mathrm{k}_{2} \\
\left(\mathrm{~g} \mathrm{mg}^{-1}\right. \\
\left.\mathrm{min}^{-1}\right)\end{array}$ & $\begin{array}{c}k^{\prime} \\
\left(\operatorname{Lg}^{-1} \min ^{-1}\right)\end{array}$ & $\begin{array}{c}\text { Initial rate } \\
\left(\mathrm{mg} \mathrm{g}^{-1} \mathrm{~min}^{-1}\right)\end{array}$ & Reference \\
\hline $\mathrm{Cd}(\mathrm{II}) / \mathrm{Fe} 3 \mathrm{O} 4$ & 50 & 5 & 47.87 & 0.0000625 & 0.938 & 0.139 & 0.00245 & 0.122 & 86 \\
\hline \multirow{4}{*}{$\mathrm{Cd}(\mathrm{II}) / \mathrm{Fe} 3 \mathrm{O} 4$} & 200 & 1 & & 0.000000138 & 174 & 0.000365 & 0.0554 & 11.1 & \multirow{4}{*}{87} \\
\hline & 200 & 1 & & 0.000000138 & 124 & 0.000559 & 0.0433 & 8.6 & \\
\hline & 200 & 1 & & 0.000000138 & 133 & 0.000216 & 0.0192 & 3.82 & \\
\hline & 200 & 1 & & 0.000000138 & 118 & 0.000469 & 0.0324 & 6.53 & \\
\hline $\mathrm{Cd}(\mathrm{II}) / \mathrm{Fe} 3 \mathrm{O} 4$ & 100 & 5 & & 0.0000002 & 10.4 & 0.303 & 0.328 & 32.8 & 88 \\
\hline $\mathrm{Cd}(\mathrm{II}) /$ activated carbon & 50 & 1 & 471.67 & 0.000005 & 17.3 & 0.00248 & 0.0148 & 0.742 & 43 \\
\hline $\mathrm{Cd}(\mathrm{II}) /$ activated carbon & 495.61 & 2.5 & & 0.0000185 & 131 & 0.000323 & 0.0111 & 5.54 & 44 \\
\hline $\mathrm{Cd}(\mathrm{II}) /$ activated carbon & 60 & 0.4 & 560 & 0.000425 & 5.41 & 0.00709 & 0.00346 & 0.208 & 45 \\
\hline $\mathrm{Cd}(\mathrm{II}) /$ activated carbon & 500 & 20 & 4273 & 0.000213 & 18.7 & 0.00716 & 0.00499 & 2.5 & 46 \\
\hline $\mathrm{Cd}(\mathrm{II}) /$ activated carbon & 100 & 0.05 & & 0.00005 & 20.4 & 0.0099 & 0.041 & 4.12 & 47 \\
\hline $\mathrm{Cu}(I I) /$ activated carbon & 60 & 0.4 & 560 & 0.000425 & 5.64 & 0.00872 & 0.00462 & 0.277 & 45 \\
\hline $\mathrm{Pb}(I I) /$ activated carbon & 500 & 20 & 4273 & 0.000213 & 19.6 & 0.00452 & 0.00349 & 1.74 & 46 \\
\hline $\mathrm{Cd}(\mathrm{II}) /$ chitosan & 100 & 1 & 125.24 & 0.000125 & 81.3 & 0.000405 & 0.0268 & 2.68 & 60 \\
\hline $\mathrm{Cd}(\mathrm{II}) /$ chitosan & 100 & 5 & & 0.00005 & 25 & 0.000525 & 0.00328 & 0.328 & 61 \\
\hline $\mathrm{Cd}(\mathrm{II}) /$ chitosan & 100 & 0 & 4.45 & 0.00005 & 8.08 & 0.00398 & 0.00259 & 0.26 & 62 \\
\hline $\mathrm{Cd}(\mathrm{II}) /$ chitosan & 50 & 4 & 20.06 & 0.000005 & 24.5 & 0.00189 & 0.0227 & 1.13 & 63 \\
\hline $\mathrm{Cd}(\mathrm{II}) /$ chitosan & 50 & 1.72 & & 0.0000315 & 10.5 & 0.0363 & 0.0805 & 4 & 64 \\
\hline $\mathrm{Pb}(\mathrm{II}) /$ chitosan & 100 & 5 & & 0.00005 & 19.6 & 0.00618 & 0.0237 & 2.37 & 61 \\
\hline $\mathrm{Pb}(\mathrm{II}) /$ chitosan & 50 & 1.72 & & 0.0000315 & 18.9 & 0.00504 & 0.0359 & 1.8 & 64 \\
\hline $\mathrm{Pb}(\mathrm{II}) / \mathrm{Fe} 3 \mathrm{O} 4$ & 100 & 5 & & 0.0000002 & 11.9 & 0.0564 & 0.0801 & 7.99 & 88 \\
\hline
\end{tabular}




\begin{tabular}{|c|c|c|c|c|c|c|c|c|c|}
\hline System & $\begin{array}{c}\mathrm{C}_{0} \\
\left(\mathrm{mg} \mathrm{L}^{-1}\right)\end{array}$ & $\begin{array}{c}C s \\
\left(\mathrm{~g} \mathrm{~L}^{-1}\right)\end{array}$ & $\begin{array}{c}\text { Surface area } \\
\left(\mathrm{m}^{2} \mathrm{~g}^{-1}\right)\end{array}$ & $\begin{array}{l}\text { Particle size } \\
\quad(\mathrm{mm})\end{array}$ & $\begin{array}{c}\mathrm{q}_{\mathrm{e}} \\
\left(\mathrm{mg} \mathrm{g}^{-1}\right)\end{array}$ & $\begin{array}{c}\mathrm{k}_{2} \\
\left(\mathrm{~g} \mathrm{mg}^{-1}\right. \\
\left.\mathrm{min}^{-1}\right)\end{array}$ & $\begin{array}{c}\mathrm{k}^{\prime} \\
\left(\mathrm{Lg}^{-1} \mathrm{~min}^{-1}\right)\end{array}$ & $\begin{array}{c}\text { Initial rate } \\
\left(\mathrm{mg} \mathrm{g}^{-1} \mathrm{~min}^{-1}\right)\end{array}$ & Reference \\
\hline $\mathrm{Cu}(\mathrm{II}) / \mathrm{Fe} 3 \mathrm{O} 4$ & 50 & 5 & 47.87 & 0.0000625 & 2.6 & 0.108 & 0.0146 & 0.73 & 86 \\
\hline methylene blue/activated carbon & 4.48 & 4 & 116 & 0.000325 & 0.682 & 0.508 & 0.0528 & 0.236 & 49 \\
\hline methylene blue/activated carbon & 200 & 1 & & 0.000106 & 203 & 0.000468 & 0.0968 & 19.3 & 50 \\
\hline methylene blue/activated carbon & 750 & 10 & 1483 & 0.00025 & 157 & 0.00151 & 0.0492 & 37.2 & 51 \\
\hline methylene blue/activated carbon & 250 & 1 & 1531 & 0.000045 & 250 & 0.00109 & 0.273 & 68.1 & 52 \\
\hline methylene blue/activated carbon & 500 & 1 & 1894 & 0.000075 & 455 & 0.000026 & 0.0107 & 5.38 & 53 \\
\hline methylene blue/activated carbon & 1000 & 0.5 & 600 & 0.00025 & 205 & 0.0000593 & 0.00249 & 2.49 & 54 \\
\hline methylene blue/activated carbon & 600 & 1.333 & 1029 & 0.000106 & 280 & 0.000201 & 0.0262 & 15.8 & 55 \\
\hline methylene blue/activated carbon & 200 & 1.8 & 14.27 & 0.0005 & 47.2 & 0.00019 & 0.00212 & 0.423 & 56 \\
\hline methylene blue/activated carbon & 500 & 1.6 & 248 & 0.000158 & 169 & 0.00047 & 0.027 & 13.4 & 58 \\
\hline methylene blue/TiO2 & 12.5 & 0.5 & 13 & 0.0000017 & 0.647 & 0.642 & 0.0215 & 0.269 & 65 \\
\hline methylene blue/TiO2 & 100 & 2 & 29.6 & 0.00000005 & 12.4 & 0.0179 & 0.0274 & 2.75 & 66 \\
\hline methylene blue/TiO2 & 200 & 0.8 & & 0.0000003 & 80.3 & 0.00145 & 0.0467 & 9.35 & 67 \\
\hline methylene blue/TiO2 & 20 & 0.2 & 335 & 0.0000005 & 49 & 0.00321 & 0.386 & 7.71 & 68 \\
\hline methylene blue/TiO2 & 10 & 2 & & 0.000005 & 4.06 & 0.0462 & 0.0762 & 0.762 & 69 \\
\hline fluoride/Al2O3 & 10 & 1 & 221 & 0.0000001 & 8.8 & 0.0268 & 0.207 & 2.08 & 73 \\
\hline fluoride/Al2O3 & 10 & 6.667 & 118.6 & 0.001 & 1.93 & 0.00115 & 0.000426 & 0.00428 & 74 \\
\hline fluoride/Al2O3 & 5 & 1 & & 0.0000315 & 169 & 0.0002 & 1.15 & 5.71 & 75 \\
\hline fluoride/Al2O3 & 304 & 0.5 & 254.1 & 0.00000045 & 600 & 0.0000404 & 0.0479 & 14.5 & 76 \\
\hline fluoride/Al2O3 & 10 & 10 & 185.6 & 0.00005 & 0.522 & 0.137 & 0.00372 & 0.0373 & 77 \\
\hline fluoride/Al2O3 & 5 & 4 & 117.4 & 0.000125 & 0.944 & 0.0762 & 0.0136 & 0.0679 & 78 \\
\hline
\end{tabular}




\begin{tabular}{|c|c|c|c|c|c|c|c|c|c|}
\hline System & $\begin{array}{c}\mathrm{C}_{0} \\
\left(\mathrm{mg} \mathrm{L}^{-1}\right)\end{array}$ & $\begin{array}{c}\mathrm{Cs} \\
\left(\mathrm{g} \mathrm{L}^{-1}\right)\end{array}$ & $\begin{array}{l}\text { Surface area } \\
\left(\mathrm{m}^{2} \mathrm{~g}^{-1}\right)\end{array}$ & $\begin{array}{l}\text { Particle size } \\
\text { (mm) }\end{array}$ & $\begin{array}{c}\mathrm{q}_{\mathrm{e}} \\
\left(\mathrm{mg} \mathrm{g}^{-1}\right)\end{array}$ & $\begin{array}{c}\mathrm{k}_{2} \\
\left(\mathrm{~g} \mathrm{mg}^{-1}\right. \\
\left.\mathrm{min}^{-1}\right)\end{array}$ & $\begin{array}{c}k^{\prime} \\
\left(\mathrm{L} \mathrm{g}^{-1} \mathrm{~min}^{-1}\right)\end{array}$ & $\begin{array}{c}\text { Initial rate } \\
\left(\mathrm{mg} \mathrm{g}^{-1} \mathrm{~min}^{-1}\right)\end{array}$ & Reference \\
\hline fluoride/AI2O3 & 5 & 2.2 & 198 & 0.00005 & 1.81 & 0.00949 & 0.00623 & 0.0311 & 79 \\
\hline $\mathrm{As}(\mathrm{V}) / \mathrm{Fe} 2 \mathrm{O} 3$ & 0.1 & 0.005 & 162 & $2.5 \mathrm{E}-09$ & 8.77 & 0.00487 & 3.95 & 0.375 & 28 \\
\hline $\mathrm{As}(\mathrm{III}) / \mathrm{Fe} 2 \mathrm{O} 3$ & 0.1 & 0.005 & 162 & $2.5 \mathrm{E}-09$ & 18 & 0.00138 & 4.71 & 0.447 & 28 \\
\hline As(V)/activated carbon & 4.5 & 1 & & 0.001 & 0.0231 & 2.99 & 0.000354 & 0.0016 & 38 \\
\hline As(V)/activated carbon & 10 & 1 & 1470 & 0.000012 & 6.05 & 0.00707 & 0.0258 & 0.259 & 39 \\
\hline $\mathrm{As}(\mathrm{V}) /$ activated carbon & 2 & 1 & 405 & 0.0005 & 0.303 & 0.376 & 0.0172 & 0.0345 & 40 \\
\hline $\mathrm{As}(\mathrm{V}) /$ activated carbon & 0.1 & 0.03 & 520 & 0.00018 & 2.87 & 0.00122 & 0.101 & 0.01 & 41 \\
\hline As $(\mathrm{V}) /$ activated carbon & 0.15 & 5 & 660 & 0.00025 & 0.014 & 10.2 & 0.0133 & 0.002 & 42 \\
\hline $\mathrm{Pb}(\mathrm{II}) / \mathrm{Al} 2 \mathrm{O} 3$ & 414.4 & 13.3 & 100 & & 0.000591 & 93.9 & $7.92 \mathrm{E}-08$ & 0.0000328 & 89 \\
\hline $\mathrm{Pb}(\mathrm{II}) / \mathrm{Al} 2 \mathrm{O} 3$ & 20 & 5 & 243 & 0.0000005 & 4.27 & 0.0109 & 0.00992 & 0.199 & 90 \\
\hline methylene blue/TiO2 & 10 & 0.5 & 51 & 0.00001 & 21.1 & 0.0333 & 1.49 & 14.8 & 71 \\
\hline
\end{tabular}




\section{References}

(1) Singh, D. B.; Prasad, G.; Rupainwar, D. C. Adsorption Technique for the Treatment of As(V)-Rich Effluents. Colloids Surfaces A Physicochem. Eng. Asp. 1996, 111 (1-2), 49-56. https://doi.org/10.1016/0927-7757(95)03468-4.

(2) Maiti, A.; Basu, J. K.; De, S. Desorption Kinetics and Leaching Study of Arsenic from Arsenite/Arsenate-Loaded Natural Laterite. Int. J. Environ. Technol. Manag. 2010, 12 (2/3/4), 294. https://doi.org/10.1504/ijetm.2010.031534.

(3) Manna, B. R.; Dey, S.; Debnath, S.; Ghosh, U. C. Removal of Arsenic from Groundwater Using Crystalline Hydrous Ferric Oxide (CHFO). Water Qual. Res. J. Canada 2003, 38 (1), 193-210. https://doi.org/10.2166/wqrj.2003.013.

(4) Mezenner, N. Y.; Bensmaili, A. Kinetics and Thermodynamic Study of Phosphate Adsorption on Iron Hydroxide-Eggshell Waste. Chem. Eng. J. 2009. https://doi.org/10.1016/j.cej.2008.06.024.

(5) Aworanti, A.; Agarry, S. E. Kinetics, Isothermal and Thermodynamic Modelling Studies of Hexavalent Chromium Ions Adsorption from Simulated Wastewater onto Parkia Biglobosa Sawdust Derived Acid-Steam Activated. Appl. J. Environ. Eng. Sci. 2017, 3 (1), 58-76.

(6) Lim, S. F.; Lee, A. Y. W. Kinetic Study on Removal of Heavy Metal Ions from Aqueous Solution by Using Soil. Environ. Sci. Pollut. Res. 2015. https://doi.org/10.1007/s11356-015-4203-6.

(7) Natarajan, R.; Manivasagan, R. Biosorptive Removal of Heavy Metal onto Raw Activated Sludge: Parametric, Equilibrium, and Kinetic Studies. J. Environ. Eng. (United States) 2016. https://doi.org/10.1061/(ASCE)EE.1943-7870.0000961.

(8) Nandhakumar, V. Adsorption of Rose Bengal Dye from Aqueous Solution onto Zinc Chloride Activated Carbon. SOJ Mater. Sci. Eng. 2015, 3 (2), 1-9. https://doi.org/10.15226/sojmse.2015.00126.

(9) Rahdar, S.; Rahdar, A.; Zafar, M. N.; Shafqat, S. S.; Ahmadi, S. Synthesis and Characterization of MgO Supported Fe-Co-Mn Nanoparticles with Exceptionally High Adsorption Capacity for Rhodamine B Dye. J. Mater. Res. Technol. 2019, 8 (5), 3800-3810. https://doi.org/10.1016/j.jmrt.2019.06.041.

(10) Debnath, A.; Bera, A.; Chattopadhyay, K. K.; Saha, B. Facile Additive-Free Synthesis of Hematite Nanoparticles for Enhanced Adsorption of Hexavalent Chromium from Aqueous Media: Kinetic, Isotherm, and Thermodynamic Study. Inorg. Nano-Metal Chem. 2017, 47 (12), 1605-1613. https://doi.org/10.1080/24701556.2017.1357581.

(11) Lazaridis, N. K.; Pandi, T. A.; Matis, K. A. Chromium(VI) Removal from Aqueous Solutions by MgAl-CO3 Hydrotalcite: Sorption-Desorption Kinetic and Equilibrium Studies. Ind. Eng. Chem. Res. 2004, 43 (9), 2209-2215. https://doi.org/10.1021/ie030735n.

(12) Sağ, Y.; Aktay, Y. Mass Transfer and Equilibrium Studies for the Sorption of Chromium lons onto Chitin. Process Biochem. 2000, 36 (1-2), 157-173. https://doi.org/10.1016/S00329592(00)00200-4.

(13) Robalds, A.; Dreijalte, L.; Bikovens, O.; Klavins, M. A Novel Peat-Based Biosorbent for the Removal of Phosphate from Synthetic and Real Wastewater and Possible Utilization of Spent Sorbent in Land Application. Desalin. Water Treat. 2016, 57 (28), 13285-13294. https://doi.org/10.1080/19443994.2015.1061450. 
(14) Abdelwahab, O.; El Sikaily, A.; Khaled, A.; El Nemr, A. Mass-Transfer Processes of Chromium(VI) Adsorption onto Guava Seeds. Chem. Ecol. 2007, 23 (1), 73-85. https://doi.org/10.1080/02757540601083922.

(15) Shipley, H. J.; Engates, K. E.; Grover, V. A. Removal of Pb(II), $\mathrm{Cd}(\mathrm{II}), \mathrm{Cu}(\mathrm{II})$, and $\mathrm{Zn}$ (II) by Hematite Nanoparticles: Effect of Sorbent Concentration, PH, Temperature, and Exhaustion. Environ. Sci. Pollut. Res. 2013, 20 (3), 1727-1736. https://doi.org/10.1007/s11356-012-0984-z.

(16) Reategui, M.; Maldonado, H.; Ly, M.; Guibal, E. Mercury(II) Biosorption Using Lessonia Sp. Kelp. Appl. Biochem. Biotechnol. 2010. https://doi.org/10.1007/s12010-010-8912-5.

(17) Priyadarshini, B.; Rath, P. P.; Behera, S. S.; Panda, S. R.; Sahoo, T. R.; Parhi, P. K. Kinetics, Thermodynamics and Isotherm Studies on Adsorption of Eriochrome Black-T from Aqueous Solution Using Rutile TiO2. IOP Conf. Ser. Mater. Sci. Eng. 2018, 310 (1). https://doi.org/10.1088/1757-899X/310/1/012051.

(18) Staroń, P.; Chwastowski, J.; Banach, M. Sorption Behavior of Methylene Blue from Aqueous Solution by Raphia Fibers. Int. J. Environ. Sci. Technol. 2019, 16 (12), 8449-8460. https://doi.org/10.1007/s13762-019-02446-9.

(19) Suresh Kumar, P.; Korving, L.; Keesman, K. J.; van Loosdrecht, M. C. M.; Witkamp, G. J. Effect of Pore Size Distribution and Particle Size of Porous Metal Oxides on Phosphate Adsorption Capacity and Kinetics. Chem. Eng. J. 2019, 358 (September 2018), 160-169. https://doi.org/10.1016/j.cej.2018.09.202.

(20) Benavente, M. Adsorption of Metallic lons onto Chitosan: Equilibrium and Kinetic Studies, KTH Royal Institute of Technology, 2008.

(21) Tsai, W. T.; Lai, C. W.; Hsien, K. J. Effect of Particle Size of Activated Clay on the Adsorption of Paraquat from Aqueous Solution. J. Colloid Interface Sci. 2003, 263 (1), 29-34. https://doi.org/10.1016/S0021-9797(03)00213-3.

(22) Sun, X.; Ma, L.; Ye, G.; Wu, L.; Li, J.; Xu, H.; Huang, G. Phenol Adsorption Kinetics and Isotherms on Coal: Effect of Particle Size. Energy Sources, Part A Recover. Util. Environ. Eff. 2019, 00 (00), 1-14. https://doi.org/10.1080/15567036.2019.1628130.

(23) Gupta, G. S.; Prasad, G.; Panday, K. K.; Singh, V. N. Removal of Chrome Dye from Aqueous Solutions by Fly Ash. Water. Air. Soil Pollut. 1988, 37 (1-2), 13-24. https://doi.org/10.1007/BF00226476.

(24) Pimol, P.; Khanidtha, M.; Prasert, P. Influence of Particle Size and Salinity on Adsorption of Basic Dyes by Agricultural Waste: Dried Seagrape (Caulerpa Lentillifera). J. Environ. Sci. 2008, 20 (6), 760-768. https://doi.org/10.1016/S1001-0742(08)62124-5.

(25) Arai, Y.; Sparks, D. L.; Davis, J. A. Effects of Dissolved Carbonate on Arsenate Adsorption and Surface Speciation at the Hematite-Water Interface. Environ. Sci. Technol. 2004, 38 (3), 817824. https://doi.org/10.1021/es034800w.

(26) Dickson, D.; Liu, G.; Cai, Y. Adsorption Kinetics and Isotherms of Arsenite and Arsenate on Hematite Nanoparticles and Aggregates. J. Environ. Manage. 2017, 186, 261-267. https://doi.org/10.1016/j.jenvman.2016.07.068.

(27) Giménez, J.; Martínez, M.; de Pablo, J.; Rovira, M.; Duro, L. Arsenic Sorption onto Natural Hematite, Magnetite, and Goethite. J. Hazard. Mater. 2007, 141 (3), 575-580. https://doi.org/10.1016/j.jhazmat.2006.07.020.

(28) Tang, W.; Li, Q.; Gao, S.; Shang, J. K. Arsenic (III,V) Removal from Aqueous Solution by Ultrafine 
a-Fe2O3 Nanoparticles Synthesized from Solvent Thermal Method. J. Hazard. Mater. 2011, 192 (1), 131-138. https://doi.org/10.1016/j.jhazmat.2011.04.111.

(29) Cheng, W.; Zhang, W.; Hu, L.; Ding, W.; Wu, F.; Li, J. Etching Synthesis of Iron Oxide Nanoparticles for Adsorption of Arsenic from Water. RSC Adv. 2016, 6 (19), 15900-15910. https://doi.org/10.1039/c5ra26143k.

(30) Monárrez-Cordero, B. E.; Amézaga-Madrid, P.; Leyva-Porras, C. C.; Pizá-Ruiz, P.; Miki-Yoshida, M. Study of the Adsorption of Arsenic (III and V) by Magnetite Nanoparticles Synthetized via AACVD. Mater. Res. 2016, 19, 103-112. https://doi.org/10.1590/1980-5373-MR-2015-0667.

(31) Luo, H.; Cheng, F.; Hu, W.; Wang, J.; Xiang, S.; Fidalgo de Cortalezzi, M. 2D-Fe3O4 Nanosheets for Effective Arsenic Removal. J. Contemp. Water Res. Educ. 2017, 160 (1), 132-143. https://doi.org/10.1111/j.1936-704x.2017.03245.x.

(32) Chowdhury, S. R.; Yanful, E. K. Arsenic and Chromium Removal by Mixed MagnetiteMaghemite Nanoparticles and the Effect of Phosphate on Removal. J. Environ. Manage. 2010, 91 (11), 2238-2247. https://doi.org/10.1016/j.jenvman.2010.06.003.

(33) Baig, S. A.; Sheng, T.; Sun, C.; Xue, X.; Tan, L.; Xu, X. Arsenic Removal from Aqueous Solutions Using Fe3O4-HBC Composite: Effect of Calcination on Adsorbents Performance. PLoS One 2014, 9 (6). https://doi.org/10.1371/journal.pone.0100704.

(34) Zhang, J.; Stanforth, R. Slow Adsorption Reaction between Arsenic Species and Goethite ( $\alpha-$ FeOOH): Diffusion or Heterogeneous Surface Reaction Control. 2005, No. 11, 2895-2901. https://doi.org/10.1021/la047636e.

(35) Wei, Y.; Wei, S.; Liu, C.; Chen, T.; Tang, Y.; Ma, J.; Yin, K.; Luo, S. Efficient Removal of Arsenic from Groundwater Using Iron Oxide Nanoneedle Array-Decorated Biochar Fibers with High Fe Utilization and Fast Adsorption Kinetics. Water Res. 2019, 167, 115107. https://doi.org/10.1016/j.watres.2019.115107.

(36) Simsek, E. B.; Beker, U. Kinetic Performance of Aluminum and Iron Oxides in the Removal of Arsenate from Aqueous Environment. J. Clean Energy Technol. 2014, 2 (3), 206-209. https://doi.org/10.7763/jocet.2014.v2.124.

(37) Grafe, M.; Eick, M. J.; Grossl, P. R. Adsorption of Arsenate (V) and Arsenite (III) on Goethite in the Presence and Absence of Dissolved Organic Carbon. Soil Sci. Soc. Am. J. 2010, 65 (6), 1680. https://doi.org/10.2136/sssaj2001.1680.

(38) Bakkal Gula, C.; Bilgin Simsek, E.; Duranoglu, D.; Beker, U. An Experimental Design Approach for Modeling As(V) Adsorption from Aqueous Solution by Activated Carbon. Water Sci. Technol. 2015. https://doi.org/10.2166/wst.2014.491.

(39) Matović, L. L.; Vukelić, N. S.; Jovanović, U. D.; Kumrić, K. R.; Krstić, J. B.; Babić, B. M.; Đukić, A. B. Mechanochemically Improved Surface Properties of Activated Carbon Cloth for the Removal of $\mathrm{As}(\mathrm{V})$ from Aqueous Solutions. Arab. J. Chem. 2019. https://doi.org/10.1016/j.arabjc.2016.07.004.

(40) Mondal, S.; Aikat, K.; Halder, G. Biosorptive Uptake of Arsenic(V) by Steam Activated Carbon from Mung Bean Husk: Equilibrium, Kinetics, Thermodynamics and Modeling. Appl. Water Sci. 2017. https://doi.org/10.1007/s13201-017-0596-3.

(41) Chuang, C. L.; Fan, M.; Xu, M.; Brown, R. C.; Sung, S.; Saha, B.; Huang, C. P. Adsorption of Arsenic(V) by Activated Carbon Prepared from Oat Hulls. Chemosphere 2005. https://doi.org/10.1016/j.chemosphere.2005.03.012. 
(42) Yang, L.; Wu, S.; Chen, J. P. Modification of Activated Carbon by Polyaniline for Enhanced Adsorption of Aqueous Arsenate. Ind. Eng. Chem. Res. 2007. https://doi.org/10.1021/ie0611352.

(43) Naeem, M. A.; Imran, M.; Amjad, M.; Abbas, G.; Tahir, M.; Murtaza, B.; Zakir, A.; Shahid, M.; Bulgariu, L.; Ahmad, I. Batch and Column Scale Removal of Cadmium from Water Using Raw and Acid Activated Wheat Straw Biochar. Water (Switzerland) 2019. https://doi.org/10.3390/w11071438.

(44) Özer, A.; Tanyildizi, M. S.; Tümen, F. Study of Cadmium Adsorption from Aqueous Solution on Activated Carbon from Sugar Beet Pulp. Environ. Technol. 1998, 19 (11), 1119-1125. https://doi.org/10.1080/09593331908616770.

(45) Liu, X.; Xu, X.; Dong, X.; Park, J. Competitive Adsorption of Heavy Metal lons from Aqueous Solutions onto Activated Carbon and Agricultural Waste Materials. Polish J. Environ. Stud. 2020, 29 (1), 749-761. https://doi.org/10.15244/pjoes/104455.

(46) Asuquo, E.; Martin, A.; Nzerem, P.; Siperstein, F.; Fan, X. Adsorption of $\mathrm{Cd}(\mathrm{II})$ and $\mathrm{Pb}$ (II) lons from Aqueous Solutions Using Mesoporous Activated Carbon Adsorbent: Equilibrium, Kinetics and Characterisation Studies. J. Environ. Chem. Eng. 2017. https://doi.org/10.1016/j.jece.2016.12.043.

(47) Batool, F.; Akbar, J.; Iqbal, S.; Noreen, S.; Bukhari, S. N. A. Study of Isothermal, Kinetic, and Thermodynamic Parameters for Adsorption of Cadmium: An Overview of Linear and Nonlinear Approach and Error Analysis. Bioinorg. Chem. Appl. 2018, 2018. https://doi.org/10.1155/2018/3463724.

(48) Wan Ibrahim, W. M. H.; Mohamad Amini, M. H.; Sulaiman, N. S.; Kadir, W. R. A. Powdered Activated Carbon Prepared from Leucaena Leucocephala Biomass for Cadmium Removal in Water Purification Process. Arab J. Basic Appl. Sci. 2019, 26 (1), 30-40. https://doi.org/10.1080/25765299.2018.1533203.

(49) Jia, P.; Tan, H.; Liu, K.; Gao, W. Removal of Methylene Blue from Aqueous Solution by Bone Char. Appl. Sci. 2018, 8 (10). https://doi.org/10.3390/app8101903.

(50) Geçgel, Ü.; Özcan, G.; Gürpnar, G. Ç. Removal of Methylene Blue from Aqueous Solution by Activated Carbon Prepared from Pea Shells (Pisum Sativum). J. Chem. 2013. https://doi.org/10.1155/2013/614083.

(51) Dural, M. U.; Cavas, L.; Papageorgiou, S. K.; Katsaros, F. K. Methylene Blue Adsorption on Activated Carbon Prepared from Posidonia Oceanica (L.) Dead Leaves: Kinetics and Equilibrium Studies. Chem. Eng. J. 2011. https://doi.org/10.1016/j.cej.2010.12.038.

(52) Gao, J. J.; Qin, Y. B.; Zhou, T.; Cao, D. D.; Xu, P.; Hochstetter, D.; Wang, Y. F. Adsorption of Methylene Blue onto Activated Carbon Produced from Tea (Camellia Sinensis L.) Seed Shells: Kinetics, Equilibrium, and Thermodynamics Studies. J. Zhejiang Univ. Sci. B 2013. https://doi.org/10.1631/jzus.B12a0225.

(53) Bello, O. S.; Adeogun, I. A.; Ajaelu, J. C.; Fehintola, E. O. Adsorption of Methylene Blue onto Activated Carbon Derived from Periwinkle Shells: Kinetics and Equilibrium Studies. Chem. Ecol. 2008. https://doi.org/10.1080/02757540802238341.

(54) Mahmoudi, K.; Hamdi, N.; Srasra, E. Study of Adsorption of Methylene Blue onto Activated Carbon from Lignite. Surf. Eng. Appl. Electrochem. 2015, 51 (5), 427-433. https://doi.org/10.3103/S1068375515050105.

(55) Li, D.; Yan, J.; Liu, Z.; Liu, Z. Adsorption Kinetic Studies for Removal of Methylene Blue Using 
Activated Carbon Prepared from Sugar Beet Pulp. Int. J. Environ. Sci. Technol. 2016. https://doi.org/10.1007/s13762-016-1012-5.

(56) Liu, L.; Lin, Y.; Liu, Y.; Zhu, H.; He, Q. Removal of Methylene Blue from Aqueous Solutions by Sewage Sludge Based Granular Activated Carbon: Adsorption Equilibrium, Kinetics, and Thermodynamics. J. Chem. Eng. Data 2013, 58 (8), 2248-2253. https://doi.org/10.1021/je4003543.

(57) Luo, L.; Wu, X.; Li, Z.; Zhou, Y.; Chen, T.; Fan, M.; Zhao, W. Synthesis of Activated Carbon from Biowaste of Fir Bark for Methylene Blue Removal. R. Soc. Open Sci. 2019. https://doi.org/10.1098/rsos.190523.

(58) Gherbia, A.; Chergui, A.; Yeddou, A. R.; Selatnia Ammar, S.; Boubekeur, N. Removal of Methylene Blue Using Activated Carbon Prepared from Date Stones Activated with $\mathrm{NaOH}$. Glob. Nest J. 2019, 21 (3), 374-380. https://doi.org/10.30955/gnj.002913.

(59) Bamgbose, J. T.; Adewuyi, S.; Bamgbose, O.; Adetoye, A. A. Adsorption Kinetics of Cadmium and Lead by Chitosan. African J. Biotechnol. 2010, 9 (17), 2560-2565. https://doi.org/10.5897/AJB2010.000-3071.

(60) Madala, S.; Nadavala, S. K.; Vudagandla, S.; Boddu, V. M.; Abburi, K. Equilibrium, Kinetics and Thermodynamics of Cadmium (II) Biosorption on to Composite Chitosan Biosorbent. Arabian Journal of Chemistry. 2017, pp S1883-S1893. https://doi.org/10.1016/j.arabjc.2013.07.017.

(61) Park, S.; Gomez-Flores, A.; Chung, Y. S.; Kim, H. Removal of Cadmium and Lead from Aqueous Solution by Hydroxyapatite/Chitosan Hybrid Fibrous Sorbent: Kinetics and Equilibrium Studies. J. Chem. 2015, 2015, 396290. https://doi.org/10.1155/2015/396290.

(62) Kelesoglu, S. Comparative Adsorption Studies of Heavy Metal lons on Chitin and Chitosan Biopolymers, Izmir Institute of Technology, 2007.

(63) Pandey, S.; Tiwari, S. Facile Approach to Synthesize Chitosan Based Composite Characterization and Cadmium(II) Ion Adsorption Studies. Carbohydr. Polym. 2015, 134, 646656. https://doi.org/10.1016/j.carbpol.2015.08.027.

(64) Unagolla, J. M.; Adikary, S. U. Adsorption of Cadmium and Lead Heavy Metals by Chitosan Biopolymer: A Study on Equilibrium Isotherms and Kinetics. MERCon 2015 - Moratuwa Eng. Res. Conf. 2015, 234-239. https://doi.org/10.1109/MERCon.2015.7112351.

(65) Matos, J.; Ocares-Riquelme, J.; Poon, P. S.; Montaña, R.; García, X.; Campos, K.; HernándezGarrido, J. C.; Titirici, M. M. C-Doped Anatase TiO2: Adsorption Kinetics and Photocatalytic Degradation of Methylene Blue and Phenol, and Correlations with DFT Estimations. J. Colloid Interface Sci. 2019. https://doi.org/10.1016/j.jcis.2019.03.074.

(66) Makama, A. B.; Salmiaton, A.; Saion, E. B.; Choong, T. S. Y.; Abdullah, N. Synthesis of CdS Sensitized TiO2 Photocatalysts: Methylene Blue Adsorption and Enhanced Photocatalytic Activities. Int. J. Photoenergy 2016. https://doi.org/10.1155/2016/2947510.

(67) Mohammadi, A.; Aliakbarzadeh Karimi, A. Methylene Blue Removal Using Surface-Modified TiO2 Nanoparticles: A Comparative Study on Adsorption and Photocatalytic Degradation. J. Water Environ. Nanotechnol. 2017, 2 (2), 118-128. https://doi.org/10.22090/jwent.2017.02.007.

(68) Kurajica, S.; Minga, I.; Blazic, R.; Muzina, K.; Tominac, P. Adsorption and Degradation Kinetics of Methylene Blue on As-Prepared and Calcined Titanate Nanotubes. Athens J. Sci. 2018. https://doi.org/10.30958/ajs.5-1-1. 
(69) Geng, Y.; Zhang, J.; Zhou, J.; Lei, J. Study on Adsorption of Methylene Blue by a Novel Composite Material of TiO2 and Alum Sludge. RSC Adv. 2018. https://doi.org/10.1039/c8ra05946b.

(70) Hu, A.; Liang, R.; Zhang, X.; Kurdi, S.; Luong, D.; Huang, H.; Peng, P.; Marzbanrad, E.; Oakes, K. D.; Zhou, Y.; et al. Enhanced Photocatalytic Degradation of Dyes by TiO2 Nanobelts with Hierarchical Structures. J. Photochem. Photobiol. A Chem. 2013. https://doi.org/10.1016/j.jphotochem.2013.01.015.

(71) Zulmajdi, S. L. N.; Zamri, N. I. I.; Yasin, H. M.; Kusrini, E.; Hobley, J.; Usman, A. Comparative Study on the Adsorption, Kinetics, and Thermodynamics of the Photocatalytic Degradation of Six Different Synthetic Dyes on TiO2 Nanoparticles. React. Kinet. Mech. Catal. 2019. https://doi.org/10.1007/s11144-019-01701-x.

(72) Thomas, J.; Harsha, T. K.; Anitha, P. K.; Thomas, N. Ultrafast Dye Removal Using Capped TiO2 Nanocrystallites. In AIP Conference Proceedings; 2019. https://doi.org/10.1063/1.5130359.

(73) Chinnakoti, P.; Chunduri, A. L. A.; Vankayala, R. K.; Patnaik, S.; Kamisetti, V. Enhanced Fluoride Adsorption by Nano Crystalline $\gamma$-Alumina: Adsorption Kinetics, Isotherm Modeling and Thermodynamic Studies. Appl. Water Sci. 2017. https://doi.org/10.1007/s13201-016-0437-9.

(74) Camacho, L. M.; Torres, A.; Saha, D.; Deng, S. Adsorption Equilibrium and Kinetics of Fluoride on Sol-Gel-Derived Activated Alumina Adsorbents. J. Colloid Interface Sci. 2010. https://doi.org/10.1016/j.jcis.2010.05.066.

(75) Ahamad, K. U.; Singh, R.; Baruah, I.; Choudhury, H.; Sharma, M. R. Equilibrium and Kinetics Modeling of Fluoride Adsorption onto Activated Alumina, Alum and Brick Powder. Groundw. Sustain. Dev. 2018. https://doi.org/10.1016/j.gsd.2018.06.005.

(76) Lanas, S. G.; Valiente, M.; Aneggi, E.; Trovarelli, A.; Tolazzi, M.; Melchior, A. Efficient Fluoride Adsorption by Mesoporous Hierarchical Alumina Microspheres. RSC Adv. 2016. https://doi.org/10.1039/c5ra27371d.

(77) Dhawane, S. H.; Khan, A. A.; Singh, K.; Tripathi, A.; Hasda, R.; Halder, G. Insight into Optimization, Isotherm, Kinetics, and Thermodynamics of Fluoride Adsorption onto Activated Alumina. Environ. Prog. Sustain. Energy 2018. https://doi.org/10.1002/ep.12814.

(78) Duan, Y.; Wang, C.; Li, X.; Xu, W. Fluoride Adsorption Properties of Three Modified Forms of Activated Alumina in Drinking Water. J. Water Health 2014. https://doi.org/10.2166/wh.2014.016.

(79) Mouelhi, M.; Giraudet, S.; Amrane, A.; Hamrouni, B. Competitive Adsorption of Fluoride and Natural Organic Matter onto Activated Alumina. Environ. Technol. (United Kingdom) 2016. https://doi.org/10.1080/09593330.2016.1149521.

(80) Di, E.; Goo, H.; Liu, Y.; Cheng, Z. Arsenate Retention Mechanisms on Hematite with Different Morphologies Evaluated Using AFM, TEM Measurements and Vibrational Spectroscopy ScienceDirect Arsenate Retention Mechanisms on Hematite with Different Morphologies Evaluated Using AFM , TEM Measure. Geochim. Cosmochim. Acta 2018, 237 (July), 155-170. https://doi.org/10.1016/j.gca.2018.06.027.

(81) Xu, H.; Sun, X.; Yu, Y.; Liu, G.; Ma, L.; Huang, G. Removal of Quinoline Using Various Particle Sizes Anthracite: Adsorption Kinetics and Adsorption Isotherms. Physicochem. Probl. Miner. Process. 2019, 55 (1), 196-207. https://doi.org/10.5277/ppmp18121.

(82) Arai, Y.; Sparks, D. L.; Davis, J. A. Effects of Dissolved Carbonate on Arsenate Adsorption and Surface Speciation at the Hematite-Water Interface. Environ. Sci. Technol. 2004, 38 (3), 817824. https://doi.org/10.1021/es034800w. 
(83) Raven, K. P.; Jain, A.; Loeppert, R. H. Arsenite and Arsenate Adsorption on Ferrihydrite : Kinetics , Equilibrium, and Adsorption Envelopes. 1998, 32 (3), 344-349. https://doi.org/10.1021/es970421p.

(84) Qi, P.; Pichler, T. Competitive Adsorption of $\mathrm{As}(\mathrm{III}), \mathrm{As}(\mathrm{V}), \mathrm{Sb}(\mathrm{III})$ and $\mathrm{Sb}(\mathrm{V})$ onto Ferrihydrite in Multi-Component Systems: Implications for Mobility and Distribution. J. Hazard. Mater. 2017, 330, 142-148. https://doi.org/10.1016/j.jhazmat.2017.02.016.

(85) Roy, P. K.; Choudhury, M. R.; Ali, M. A. As (III) and As (V) Adsorption on Magnetite Nanoparticles: Adsorption Isotherms, Effect of PH and Phosphate, and Adsorption Kinetics. Int. J. Chem. Environ. Eng. 2013, 4 (1).

(86) Jain, M.; Yadav, M.; Kohout, T.; Lahtinen, M.; Garg, V. K.; Sillanpää, M. Development of Iron Oxide/Activated Carbon Nanoparticle Composite for the Removal of $\mathrm{Cr}(\mathrm{VI}), \mathrm{Cu}(\mathrm{II})$ and $\mathrm{Cd}(\mathrm{II})$ Ions from Aqueous Solution. Water Resour. Ind. 2018, 20 (June), 54-74. https://doi.org/10.1016/j.wri.2018.10.001.

(87) Liu, F.; Zhou, K.; Chen, Q.; Wang, A.; Chen, W. Comparative Study on the Synthesis of Magnetic Ferrite Adsorbent for the Removal of Cd(II) from Wastewater. Adsorpt. Sci. Technol. 2018, 36 (7-8), 1456-1469. https://doi.org/10.1177/0263617418779729.

(88) Hosseinzadeh, M.; Ali Seyyed Ebrahimi, S.; Raygan, S.; Morteza Masoudpanah, S. Removal of Cadmium and Lead Ions from Aqueous Solution by Nanocrystalline Magnetite Through Mechanochemical Activation. J. Ultrafine Grained Nanostructured Mater. 2016. https://doi.org/10.7508/jufgnsm.2016.02.03.

(89) Strawn, D. G.; Scheidegger, A. M.; Sparks, D. L. Kinetics and Mechanisms of Pb(II) Sorption and Desorption at the Aluminum Oxide - Water Interface. Environ. Sci. Technol. 1998. https://doi.org/10.1021/es980152i.

(90) Bhat, A.; Megeri, G. B.; Thomas, C.; Bhargava, H.; Jeevitha, C.; Chandrashekar, S.; Madhu, G. M. Adsorption and Optimization Studies of Lead from Aqueous Solution Using $\gamma$-Alumina. J. Environ. Chem. Eng. 2015. https://doi.org/10.1016/j.jece.2014.11.014. 
A revised pseudo-second order kinetic model for adsorptio... (1.34 MiB) view on ChemRxiv • download file 